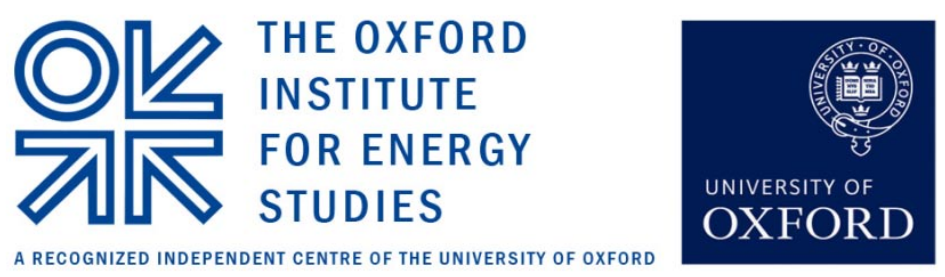

\title{
Gas storage in Great Britain
}

\section{Chris Le Fevre}

\author{
NG 72 \\ January 2013
}


The contents of this paper are the author's sole responsibility. They do not necessarily represent the views of the Oxford Institute for Energy Studies, of any of the Institute's members, and/or of the author's other affiliations.

Copyright (C) 2013

Oxford Institute for Energy Studies

(Registered Charity, No. 286084)

This publication may be reproduced in part for educational or non-profit purposes without special permission from the copyright holder, provided acknowledgment of the source is made. No use of this publication may be made for resale or for any other commercial purpose whatsoever without prior permission in writing from the Oxford Institute for Energy Studies.

ISBN 978-1-907555-65-7 


\section{Acknowledgements}

I would like to record my thanks for the help I have been given by many organisations and individuals in writing this paper. I received much valuable input from individual storage operators and project promoters, National Grid and the SBGI Gas Storage Operator's Group - particular mention should be made of Ben Farrington, George Grant, Roddy Monroe and Peter Parsons. I am also most grateful to colleagues at the Oxford Institute of Energy Studies, particularly Howard Rogers and Jonathan Stern for their support and encouragement and John Elkins for editing the final document. 


\section{Preface}

During the last decade any discussion of Great Britain's natural gas security of supply has touched on the issue of the adequacy, or otherwise, of underground storage capacity. Simplistic comparisons with neighbouring continental European national gas markets are questionable due to the differing pace of market liberalisation, changing demand and supply patterns and the availability of other forms of flexibility. The 'right' level of storage has been an elusive quantity, still less the appropriate means by which it can be brought into existence.

In this working paper Chris Le Fevre provides a thorough and comprehensive review of gas storage in Great Britain starting with an explanation of the practicalities of storage, the evolution of the UK storage sector and the attendant debate on security of supply. The paper examines the role of storage and other sources of flexibility in recent winter periods and the factors which will determine future flexibility needs. The suite of potential storage projects is described together with a realistic assessment of the barriers and challenges to their successful implementation. In addressing these issues Chris considers the UK's situation in the context of increasing infrastructure linkages to the European continent and to the world LNG market.

The outstanding feature of this paper is the successful integration of regulatory framework development with the evolving physical and commercial/economic dimensions. Given the recent increased emphasis on gas in Great Britain's energy mix and the ongoing work of government departments and regulators on how best to avoid supply security events, this paper represents a timely summary of all relevant aspects of gas storage which will be of use to a range of constituencies.

Howard Rogers 


\section{Contents}

Acknowledgements ................................................................................................................................ iii

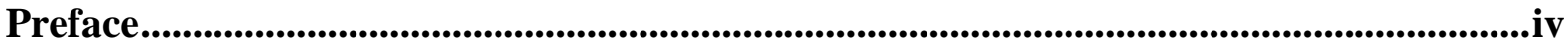

1. Introduction .............................................................................................................................1

2. The role of gas storage …........................................................................................2

2.1. Technical and commercial fundamentals.....................................................................2

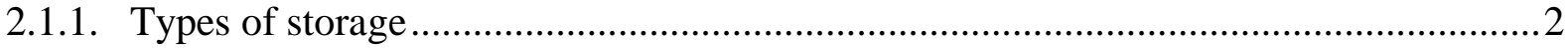

2.1.2. Development costs and project timescales ………………………………………….

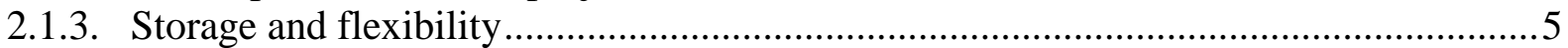

2.1.4. How much storage is required?...........................................................................

2.1.5. Storage in liberalised markets ..................................................................................

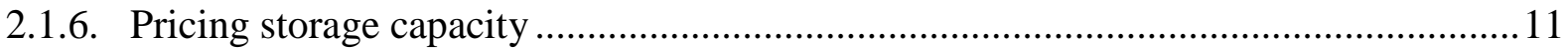

2.1.7. Economic evaluation of storage projects ...................................................................13

2.1.8. Development of storage projects .............................................................................. 14

2.2. Regulation of storage in Europe ......................................................................................15

2.3. Gas storage and security of supply....................................................................................17

2.3.1. Defining security of supply ......................................................................................17

2.4. Summary and conclusions on the role of gas storage .......................................................21

3. Storage in the GB gas market.............................................................................................21

3.1. A brief history - Evolution of the GB gas market and the role of storage .................21

3.2. The regulation of gas storage in GB...............................................................................22

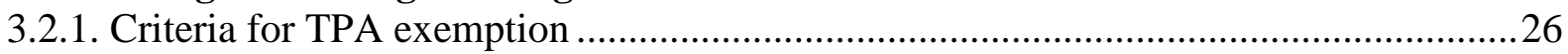

3.3. Security of supply in the UK.............................................................................................2

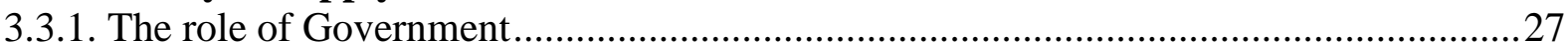

3.3.2. The role of the regulator....................................................................................30

3.3.2.1. Licence obligations ................................................................................................... 30

3.3.2.2. Project Discovery ............................................................................................. 31

3.3.2.3 The Significant Code Review and "Further Interventions" ...........................................31

3.3.3. The role of the industry ...............................................................................................33

3.3.3.1. The role and view of the transporter .....................................................................33

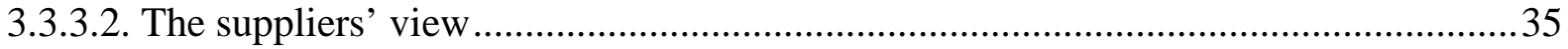

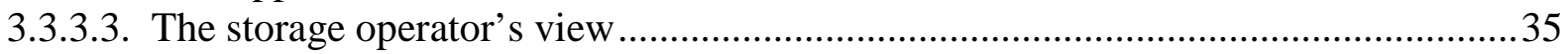

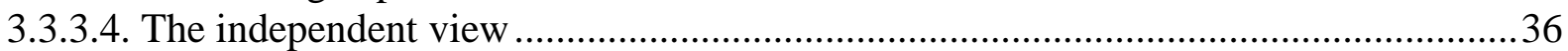

3.4 Summary and conclusions on storage in the GB gas market............................................37

4. How storage operates today in the GB gas market...............................................................37

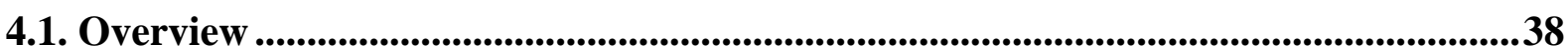

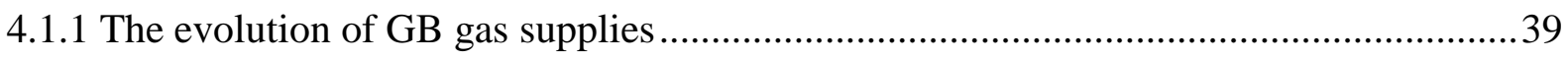

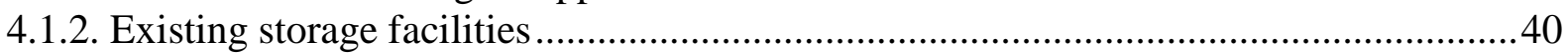

4.1.3. Recent winters in detail......................................................................................... 41

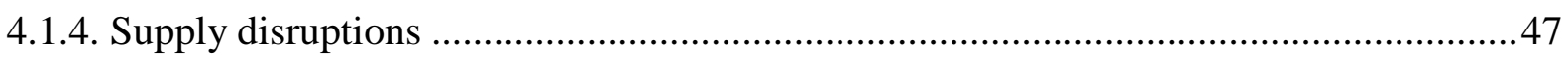

4.2. GB storage value and profitability ..................................................................................49

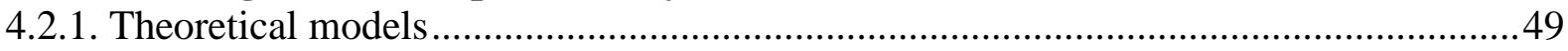

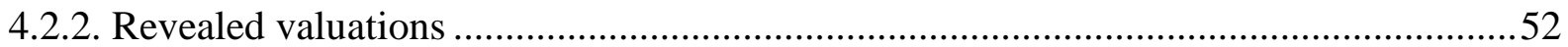


4.3. Summary and conclusions on how storage operates today in the GB gas market ...54

5. The future outlook for storage. .54

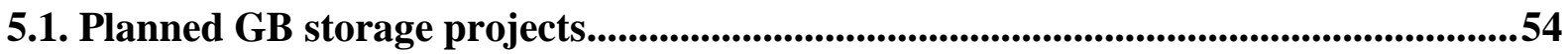

5.2. Barriers to storage project implementation ..................................................................59

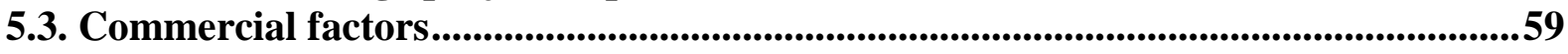

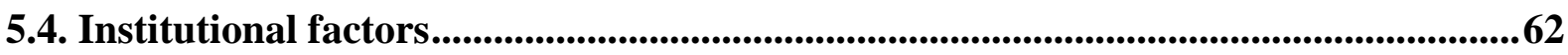

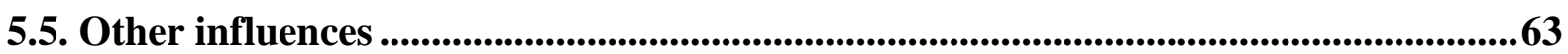

5.6. Summary and conclusions on the future outlook for storage ..................................63

6. Future requirements for storage ....................................................................................................63

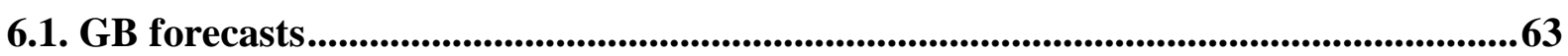

6.2. GB storage and the NW European context .......................................................................69

6.3. Summary and conclusions on the future requirements for storage in GB................75

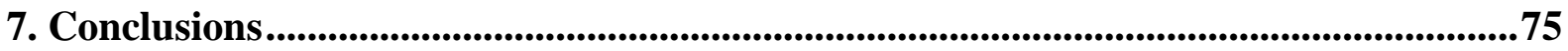

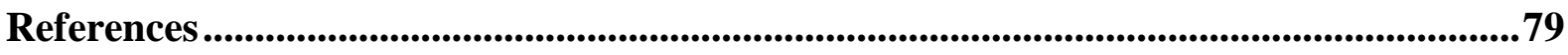

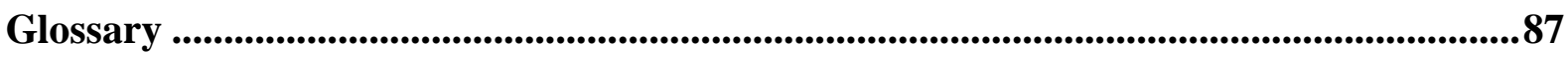

\section{Figures}

Figure 1: Notional Load Duration Curve for GB.................................................................

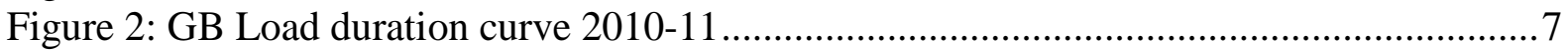

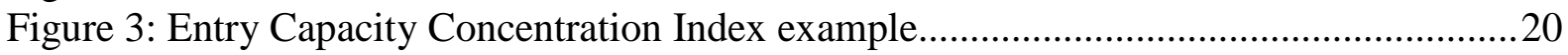

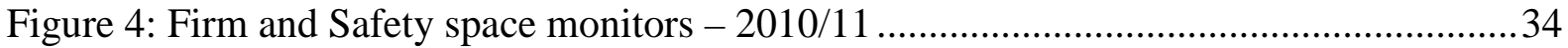

Figure 5: Map of key GB gas infrastructure showing terminals and storage facilities.............38

Figure 6: UK Gas sources and destinations January 2000-June 2012 ...................................40

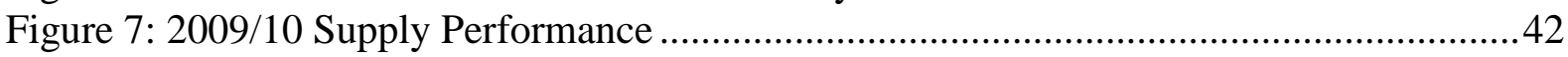

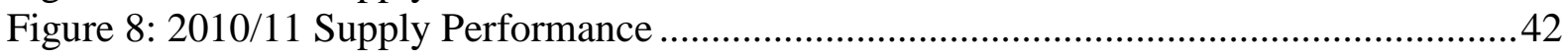

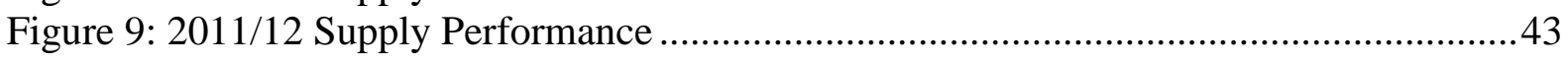

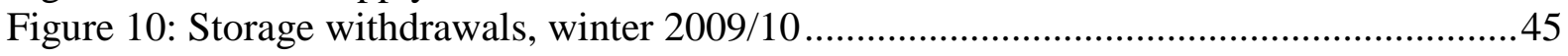

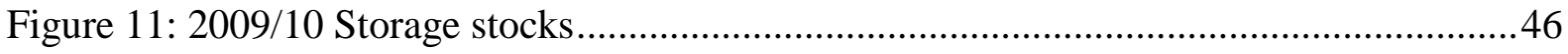

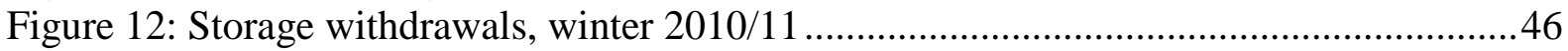

Figure 13: Storage withdrawals, winter 2011/12 ............................................................... 47

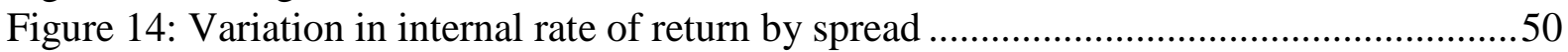

Figure 15: Main Halite basins and planned storage projects (in 2008) .................................55

Figure 16: Evolution of planned storage projects 2007-2010 ...............................................58

Figure 17: Summer-winter price spreads and storage profitability break-even......................59

Figure 18: GB total gas demand forecast (Slow Progression scenario).................................64

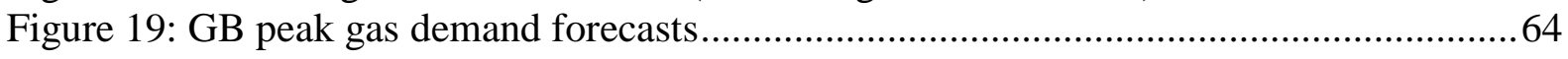

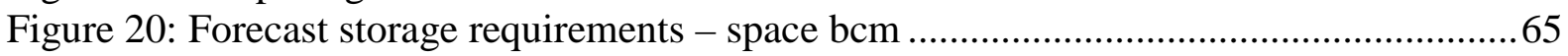

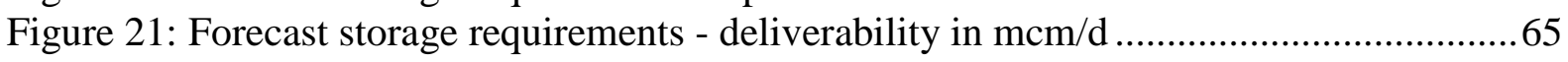

Figure 22: NG Peak demand and supply forecast for the Slow Progression scenario.............66

Figure 23: Potential maximum day to day variation in daily national demand.......................67

Figure 24: Storage profiles (degree of fullness in \%) for NBP and PSV (Italy) ..................... 72

Figure 25: Number of separate sources of gas supply for EU countries by year of FID.........74 


\section{Tables}

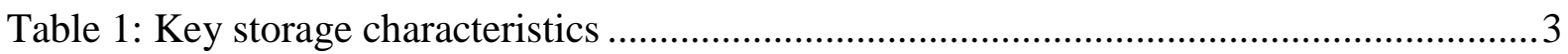

Table 2: Typical capital and operating costs for storage facilities...........................................

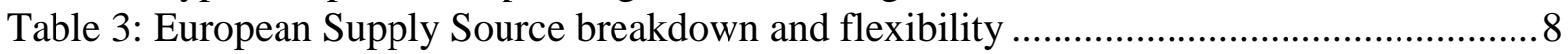

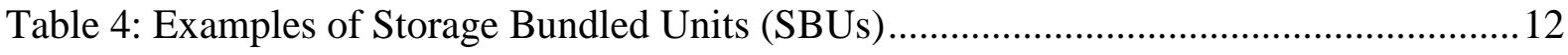

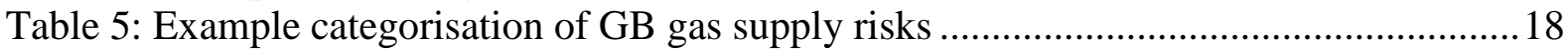

Table 6: Average annual probability of at least one outage....................................................32

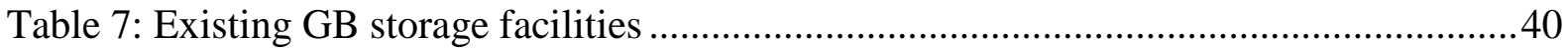

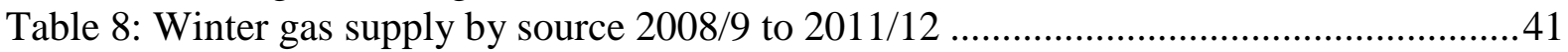

Table 9: GB Supply sources on days of very high demand................................................4

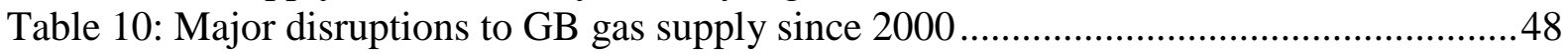

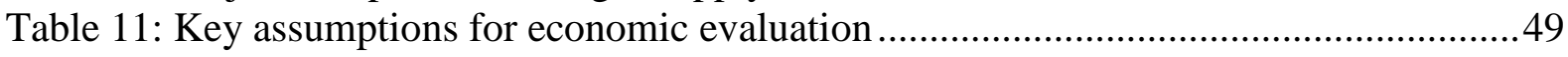

Table 12: Economic evaluation of storage - NPV at 5\% discount rate in $£ \mathrm{~m}$........................50

Table 13: Transactions involving storage facilities in Great Britain .....................................52

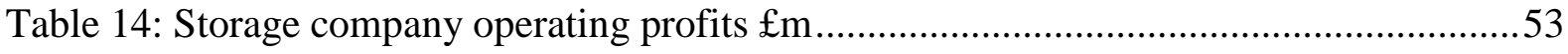

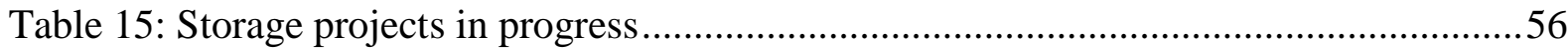

Table 16: Storage projects not yet in progress but with planning permission .........................57

Table 17: Storage projects not yet in progress without planning permission ...........................58

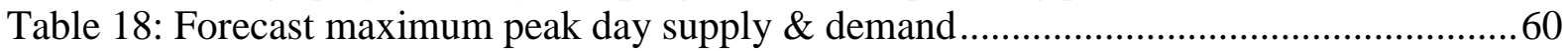

Table 19: Key storage indicators for main European gas countries ......................................69

Table 20: Storage Capacity at European Hubs as at September 2012 .....................................70

Table 21: Degree of fullness of storage at European Hubs ................................................ 71

Table 22: Maximum potential deliverability to GB gas market by source as at May 2012

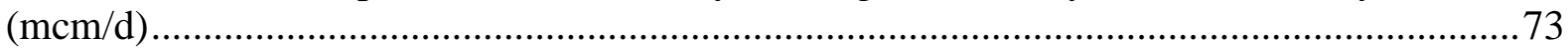

Table 23: Planned storage investments in selected European countries ................................ 74 


\section{Introduction}

Gas storage plays a crucial role in balancing supply and demand in most gas consuming countries. However, Great Britain ${ }^{1}$ has a relatively low level of gas storage as a proportion of total demand compared with other gas consuming countries in Europe - primarily but not exclusively due its historical reliance on flexible UKCS gas supplies.

Great Britain became a net gas importer in 2004 and this, coupled with growing peak demand forecasts and concerns over the reliability of supplies, led to an increase in the value of existing storage capacity which in turn led to a number of new storage projects being proposed by both suppliers and independent project promoters.

A number of the supplier led storage projects have progressed (though at a much slower pace than forecast) whilst independent projects have either stalled or only moved forward when being underwritten by suppliers. In 2005 National Grid listed ten separate storage projects that were planned to come on stream by 2010 with a combined working capacity (WC) of over 6 BCM. By the end of 2010 only one project had come on stream (WC=0.35 BCM), a further three were under construction (0.7 BCM) whilst a total of 15 projects with a combined working capacity estimated at 17 BCM had either achieved planning permission or were under consideration but had not proceeded any further.

As indigenous production continues to fall and gas demand becomes increasingly volatile as a result of the growth in intermittent renewable power generation, demands for greater supply flexibility are likely to increase. Security of supply concerns are also growing, as demonstrated by the Gas Security of Supply Significant Code Review (SCR) initiated by Ofgem and the request by DECC for Ofgem to investigate the case for "further interventions" to ensure secure gas supplies into the future. The recently-published Energy Bill indicates that gas-fired power will still have a major role to play and that the issue of gas storage is still very relevant.

This paper seeks to answer two key questions.

- Why have so few storage projects been developed in recent years?

- Is there a case for more storage and if so how can it be achieved?

To address these, the paper is structured as follows:

Chapter 2 provides a brief technical, commercial and regulatory overview of gas storage including an examination of security of supply considerations and the role of storage. This is intended as an introduction to the fundamentals of storage for readers less familiar with the subject.

Chapter 3 reviews gas storage in GB, how the sector has evolved in terms of regulation and operation in the context of the changing nature of GB gas supplies and the security of supply

\footnotetext{
${ }^{1}$ This report uses Great Britain when referring to issues that relate solely (or predominantly) to England,Scotland and Wales and the UK for matters concerning GB and N Ireland. Thus for example National Grid is the GB TSO whilst national energy statistics relate to the UK. Notwithstanding this there may be some occasional errors or inconsistencies in usage for which the author apologises.
} 
debate and how these factors have impacted on the economic fundamentals for gas storage in a liberalised market.

Chapter 4 examines in detail how GB storage has operated during recent winters, which have been characterised by a range of demand and supply events.

Chapter 5 examines the outlook for GB gas storage taking account of planned and possible projects and existing barriers to implementation.

Chapter 6 contains an assessment of the future requirements for gas storage based on forecasts for GB gas demand and supply and taking account of developments in the wider NW Europe gas sector.

Chapter 7 draws together the conclusions from the individual chapters.

\section{The role of gas storage}

\subsection{Technical and commercial fundamentals}

\subsubsection{Types of storage}

There are two key characteristics of gas storage - how much can be injected, stored and then delivered (referred to as working capacity and typically expressed in Gwh or million cubic metres - mcm) and the rate of injection and withdrawal usually expressing in Gwh or million cubic metres per hour/per day ${ }^{2}$. Most gas storage facilities are underground in either salt caverns, depleted gas fields or aquifers. Whilst storage facilities can be located above ground, with the exception of LNG storage facilities ${ }^{3}$, these are primarily low pressure facilities with little strategic significance (e.g. gas holders) ${ }^{4}$.

In order to provide the required level of deliverability any storage facility requires an element of so called cushion gas. This is the volume of gas required to be kept in a facility in order to maintain operating pressure and can represent a significant element of total capital cost, because it is not recovered until the store ceases operations. The amount of cushion gas a particular facility will require depends on the pressure of the facility relative to the transmission system and the method of operation. Typical configurations would range between:

- Lower pressure facilities (e.g. min 20 bar, max 70 bar) with low cushion gas and low working volumes

- Higher pressure facilities (e.g. min 100 bar, max 200 bar)

- Compression on entry/exit giving a high injection rate and medium withdrawal rate

- Compression on entry giving a lower injection rate and high withdrawal rate generally the preferred option

- In a depleted field storage the cushion gas is often provided by using the existing "native" gas

\footnotetext{
${ }^{2}$ Where possible this report uses the volumetric measure of million cubic metres $(\mathrm{mcm})$. Where data is provided in energy terms it has been converted to volumes as $1 \mathrm{mcm}=10.83 \mathrm{GwH}$

${ }^{3}$ LNG storage in this context and unless specified otherwise refers to peak shaving facilities and not storage tanks at LNG regasification terminals

${ }^{4}$ Some networks include high pressure above ground storage systems which are essentially arrays of pipes often referred to as methane bullets. See http://www.hse.gov.uk/comah/sragmgb/crit33.htm for more details
} 
The sub-surface depth of the facility is also an important consideration - particularly for salt cavern storage. In general potential operating pressure - and therefore working capacity increases with depth. However temperature and overburden pressure also increase and in the case of salt caverns this can lead to greater rates on convergence ${ }^{5}-$ this is the reduction in cavern volume caused by creep in the salt formation. As a result the optimum depth for salt cavity facilities is typically in the range 1,000 to 1,500 metres $^{6}$.

The key characteristics of the alternative types of storage together with their advantages and disadvantages are summarised in Table 1which includes an illustrative deliverability based on a working capacity of $500 \mathrm{mcm}$. An increasingly important characteristic is the cycle or turnover rate of a storage facility. This is defined as the number of times in a year that the facility could be filled and emptied ${ }^{7}$.

Table 1: Key storage characteristics

\begin{tabular}{|c|c|c|c|c|}
\hline Factor & Salt cavity & Depleted field & Aquifer & $\mathrm{LNG}^{8}$ \\
\hline Main Usage & Multi cycle & $\begin{array}{l}\text { Limited multi } \\
\text { cycle } \\
\text { Seasonal } \\
\text { Strategic }\end{array}$ & $\begin{array}{l}\text { Seasonal } \\
\text { Strategic }\end{array}$ & $\begin{array}{l}\text { Peak shaving } \\
\text { System support }\end{array}$ \\
\hline Advantages & $\begin{array}{l}\text { High injection and } \\
\text { withdrawal rates } \\
\text { Low cushion gas } \\
\text { Phased } \\
\text { development }\end{array}$ & $\begin{array}{l}\text { Existing and } \\
\text { understood } \\
\text { Relatively low } \\
\text { cost } \\
\text { Large capacity }\end{array}$ & Large capacity & $\begin{array}{l}\text { Very high rates } \\
\text { of deliverability }\end{array}$ \\
\hline Disadvantages & $\begin{array}{l}\text { Small volume in } \\
\text { individual cavern } \\
\text { Brine disposal } \\
\text { Subject to } \\
\text { convergence } \\
\text { Higher operating } \\
\text { cost }\end{array}$ & $\begin{array}{l}\text { High Cushion } \\
\text { gas requirement } \\
\text { Slow injection } \\
\text { and withdrawal } \\
\text { rates }\end{array}$ & $\begin{array}{l}\text { High cost } \\
\text { Extended } \\
\text { development } \\
\text { time } \\
\text { Potential } \\
\text { environmental } \\
\text { objections }\end{array}$ & $\begin{array}{l}\text { High cost } \\
\text { Low capacity } \\
\text { Greater safety } \\
\text { exposure }\end{array}$ \\
\hline $\begin{array}{l}\text { Working } \\
\text { capacity mcm }\end{array}$ & 500 & 500 & 500 & 32 \\
\hline $\begin{array}{l}\text { Deliverability } \\
\mathrm{mcm} / \mathrm{d}\end{array}$ & 23.8 & 7.2 & 5.4 & 5.0 \\
\hline $\begin{array}{l}\text { Cushion gas } \\
\text { requirements }\end{array}$ & $\begin{array}{l}20 \% \text { of total } \\
\text { capacity }\end{array}$ & $\begin{array}{l}45 \% \text { of total } \\
\text { capacity }\end{array}$ & $\begin{array}{l}55 \% \text { of total } \\
\text { capacity }\end{array}$ & $\begin{array}{l}\text { "Heel" of } \\
\text { around } 5 \text { to } 10 \%\end{array}$ \\
\hline Cycle rates & 6.9 & 2.1 & 1.6 & $\mathrm{n} / \mathrm{a}$ \\
\hline
\end{tabular}

Source: Author's calculations based on industry sources

\footnotetext{
${ }^{5}$ See Glossary.

${ }^{6}$ HSE 2008, p 23

${ }^{7}$ This is a theoretical measure used to demonstrate the relative flexibility of a storage facility. Cycle rates have been calculated as follows: (365-14)/(days to fill working volume + days to empty working volume) where 14 represents the number of days the facility is unavailable for routine maintenance. The cycle rates in the table are calculated on the assumption that injection rates are $70 \%$ of withdrawal with the exception of LNG which has a much slower injection rate

${ }^{8}$ An LNG working capacity of $500 \mathrm{mcm}$ would not be feasible so a typical capacity is shown
} 
In summary most storage options are now confined to either depleted fields or salt caverns though some aquifer storage may be built where geological and political considerations allow. LNG terminals also provide a form of storage though this is linked to the level of imported LNG - the impact of LNG facilities is considered further in Chapter 3.

The types of usage terms in Table 1 can be explained as follows:

- Multi cycle or flexible storage - gas would be injected and delivered several times within the year. Typical cycle or turnover rates for these facilities can range significantly with some having the potential for up to 15 cycles per annum.

- Seasonal - gas would be injected in the summer and withdrawn in the winter. Rates may differ between the two seasons.

- Strategic - this is normally referred to as gas that is stored for use only in case of an emergency which would be a clearly defined set of circumstances. ${ }^{9}$

- Peak shaving - high deliverability storage that is used to meet very high demands for short periods of time - usually an LNG facility.

- System support- storage facilities located at key points on the network to provide short term back up in the event of a pipeline or compressor failure. These facilities are often located towards the end of networks or close to large areas of demand. In addition to LNG storage this support can also be provided by above ground high pressure units (methane bullets) and propane air injection.

Storage facilities can also be categorised as short term, medium term and long term. These refer to the number of days the facility would be able to deliver at design rates; the ascending order being LNG peak shaving plant, salt cavity and depleted fields respectively. In some countries aquifer storage is used instead of or as well as depleted fields although this is not the case in the UK.

It is important to recognise that whilst storage may be built with the usage objectives described above, in practice all types of storage could be used for common purposes within reasonable physical limits. For example seasonal storage may significantly vary delivery rates from one day to the next and may inject at different rates to take advantage of price movements.

\subsubsection{Development costs and project timescales}

Storage facilities are capital intensive and this is reflected in the high proportion of total spend accounted for by capital costs. The main capital cost elements are:

- $\quad$ Land/depleted field acquisition

- $\quad$ Cavern construction (leaching and brine disposal) for salt cavern

- $\quad$ Wells and above ground treatment facilities

\footnotetext{
${ }^{9}$ See Ramboll 2008 p 12 for a detailed definition
} 
- Compressors

- $\quad$ Connecting pipelines

- $\quad$ Cushion gas.

Other capital costs can include sub-surface analysis (e.g. seismic data), control systems and planning and environmental approvals.

Operating costs are often only a very small fraction of capital costs - typically 1-3\% excluding fuel costs - and primarily comprise personnel and maintenance costs. Fuel costs required for running compressors can account for between $0.5 \%$ and $3 \%$ of stored gas volume depending on the depth and location of the facilities. Whilst not a cost item it should be noted that salt cavern capacities will normally reduce over time as a result of convergence - typical rates are below $1 \%$ per annum ${ }^{10}$.

Both capital and operating costs can be significantly higher if the facilities are located offshore. Typical costs are shown in Table 2, the capital cost excludes cushion gas.

Table 2: Typical capital and operating costs for storage facilities

\begin{tabular}{|l|l|l|l|l|}
\hline Description & \multicolumn{2}{|l|}{ Capital cost } & Capital Cost/ & $\begin{array}{l}\text { Operating Cost/ } \\
\text { cm of WC }(€)\end{array}$ \\
\cline { 2 - 5 } & $\begin{array}{l}\text { Cushion } \\
\text { Gas }\end{array}$ & Facilties* & cm of WC $(€)$ & \\
\hline Salt cavity & $20 \%$ & $80 \%$ & $0.8-1.2$ & $0.01-0.08$ \\
\hline Depleted field & $35 \%$ & $65 \%$ & $0.4-0.7$ & $0.01-0.025$ \\
\hline
\end{tabular}

* Include above and below ground costs plus exploration but excludes connection costs

Source: Ramboll and industry sources

\subsubsection{Storage and flexibility}

Volume flexibility is a critical component in gas markets. Demand can vary due to a number of factors. Ambient temperature is probably the most important - particularly where heating load is a major part of demand - but levels of economic activity, electricity demand and diurnal and seasonal factors can also drive swings in demand. The growing share of intermittent renewable generation (particularly wind) is leading to an increasing requirement for gas volume flexibility as discussed below.

Whilst price changes may affect demand from some large users that are able to switch fuels or, in the case of electricity generation, may be displaced by other, cheaper generators, most gas users are captive in the short to medium term. Demand for gas from these captive users is relatively price inelastic and they place a high premium on having a reliable uninterrupted supply. Furthermore the gas system "fails dangerous" so keeping the system pressurised with gas is also a vital safety objective.

${ }^{10}$ HSE 2008, p23 
System operators have a range of tools available to them to provide volume flexibility. These can be categorised as:

1. Those that increase supply flexibility, such as variations in supply from producers (referred to as beach swing in GB) and LNG terminals

2. Those providing a buffer stock - principally gas storage but also from line pack provided by utilising the gas under pressure in a pipeline system

3. Those requiring some form of demand side response (DSR) either through fuel switching in response to higher gas prices or shipper/transporter initiated interruption.

It is generally accepted that gas storage is one of the most effective means of providing flexibility through increasing supply to meet higher demand both in the form of short terms peaks or over a longer period of time - ie seasonally. However, gas storage can also provide other functions:

- Balancing needs and system optimisation - Transmission systems may use storage located in key points to facilitate balancing and/or reduce the need for pipeline capacity. This enables the system to work more effectively by increasing the transmission load factor.

- Storage placed at key interconnections can support market developments such as wheeling, parking and loaning. ${ }^{11}$

- Security of supply/strategic storage - to ensure supplies of gas are maintained to consumers in the event of a major supply disruption.

- Commercial requirements - such as managing take-or-pay contracts and the make-up or carry-forward provisions in these contracts, optimising gas deliveries from production and providing back-up to supply from multiple fields - particularly when force majeure provisions are unlikely to provide sufficient protection.

- Exploiting trading opportunities - separate from the direct physical requirements for storage, traders have been able to exploit a range of opportunities for extracting value by trading around a storage asset.

The role for storage versus other sources of flexibility can best be demonstrated by a load duration curve (LDC). An LDC is formed by rearranging daily gas supply data from the highest demand day to the lowest demand day in any given year. A notional example is shown in Figure 1.

\footnotetext{
${ }^{11}$ Wheeling allows shippers to move gas from one system to another, parking and loaning are short term services to cover mismatches between shippers' supply and demand portfolios.
} 
Figure 1: Notional Load Duration Curve for GB

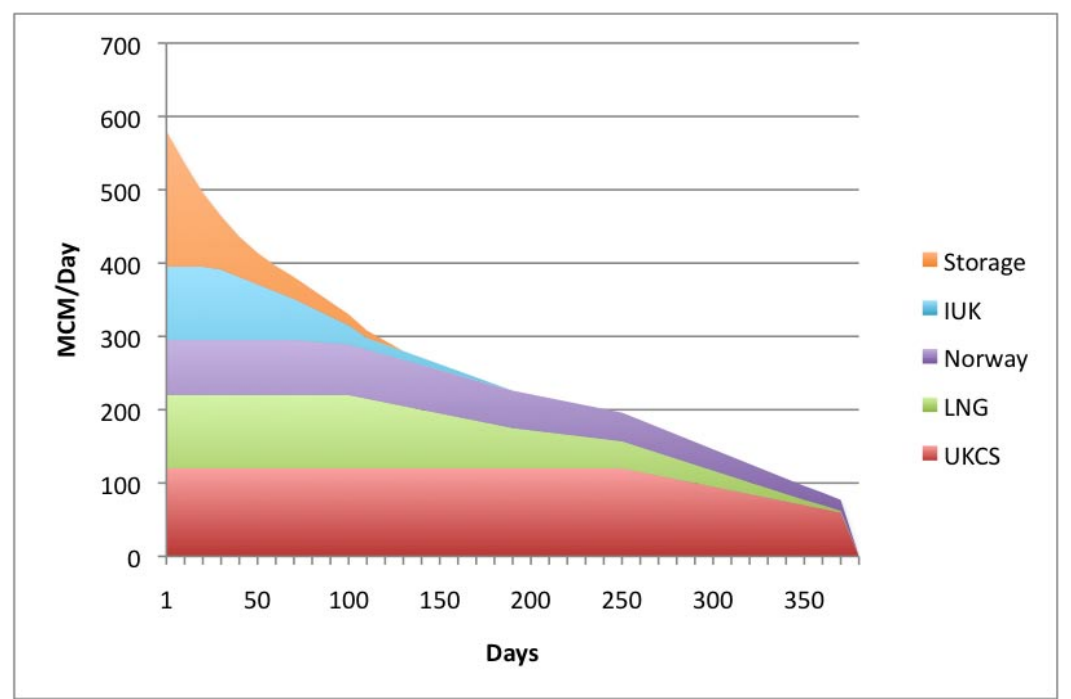

Source: Author's schematic

The LDC in Figure 1 is based on a theoretical situation in GB where the alternative sources of supply are incrementally brought on stream in response to higher demand. In effect the LDC represents a merit order with UKCS production providing base load supplies and more costly sources such as gas via the Interconnector and from storage only being utilised at high levels of demand.

The LDC in Figure 2, which is derived from data from the 2010-11 gas year, shows that in practise, however, the various alternative tools for meeting peak demands are not always used, or available, in a systematic way.

Figure 2: GB Load duration curve 2010-11

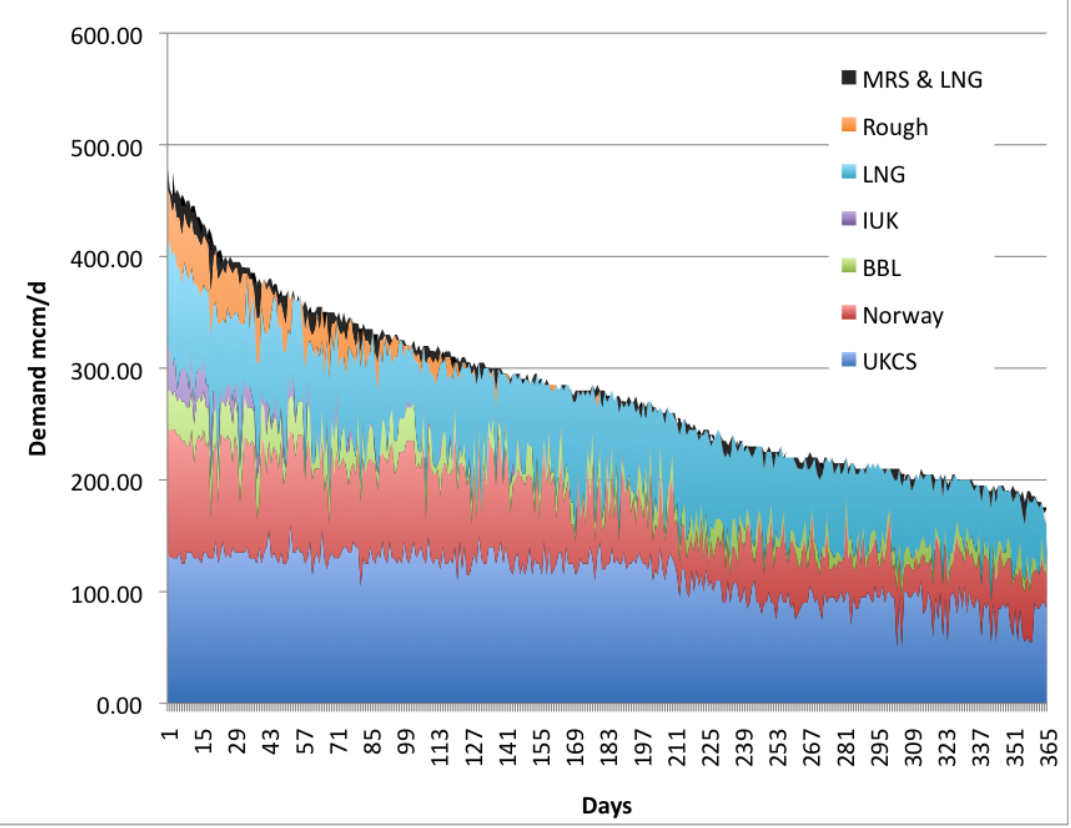

Source: National Grid Data and author's estimates 
In Figure 2 "baseload" supply is provided by UKCS and pipeline imports from Norway (Langeled) and the Netherlands (BBL) though even these vary significantly. Mid range storage (MRS) provides gas on some days throughout the year whilst supplies from Norway were disrupted by facility problems on days of very high demand.

Furthermore the means of providing a flexible response to peaks in demand on a specific system will vary depending on factors such as levels of indigenous gas production (if any), the level and availability of gas storage, the source and nature (i.e. whether they are via pipeline or LNG terminals) of imports and the components of demand with particular regard to the extent there is interruptible demand. This is illustrated in Table 3 which gives examples of how the EU gas system as a whole met demand from different sources - all percentages are approximate ${ }^{12}$.

Whilst storage might appear to play a relatively minor role in total terms, its true importance was during periods of particularly high demand. During the coldest $6 \%$ of the winter storage was, with national production, the joint highest source of supply. Storage also made a much greater contribution to flexibility as withdrawals varied much more closely with demand than the other sources and was actually injecting gas on low demand days. The importance of storage is further emphasised by the column showing variability of supply during the extreme cold weather in Europe in January and February 2012 when supplies from Russia were disrupted ${ }^{13}$.

Table 3: European Supply Source breakdown and flexibility

\begin{tabular}{|l|l|l|}
\hline Source & $\begin{array}{l}\text { Winter } \\
2010-11 \%\end{array}$ & $\begin{array}{l}\text { Variability Jan-Feb } \\
2012 \%{ }^{14}\end{array}$ \\
\hline National production & $28 \%$ & $10.7 \%$ \\
\hline Russian Imports & $22 \%$ & $17.2 \%$ \\
\hline Norwegian imports & $16 \%$ & $4.4 \%$ \\
\hline LNG imports & $15 \%$ & $40.5 \%$ \\
\hline Storage & $12 \%$ & $159.1 \%$ \\
\hline N African imports & $7 \%$ & $23 \%$ \\
\hline
\end{tabular}

Source: ENTSOG,2011b p28 and ENTSOG 2012a, p23

\footnotetext{
${ }^{12}$ ENTSOG, 2011b, p 28

13 ENTSOG, 2012a, p23

${ }^{14}$ Variability is defined as the percentage increase between January 2012 average flows and peak flows during the cold spell in February 2012
} 


\subsubsection{How much storage is required?}

Because there are so many alternative sources of supply and supply flexibility there is no generally accepted approach to specifying a required amount of storage for a given system particularly in a liberalised market. In general terms storage requirements will be higher when the following conditions apply:

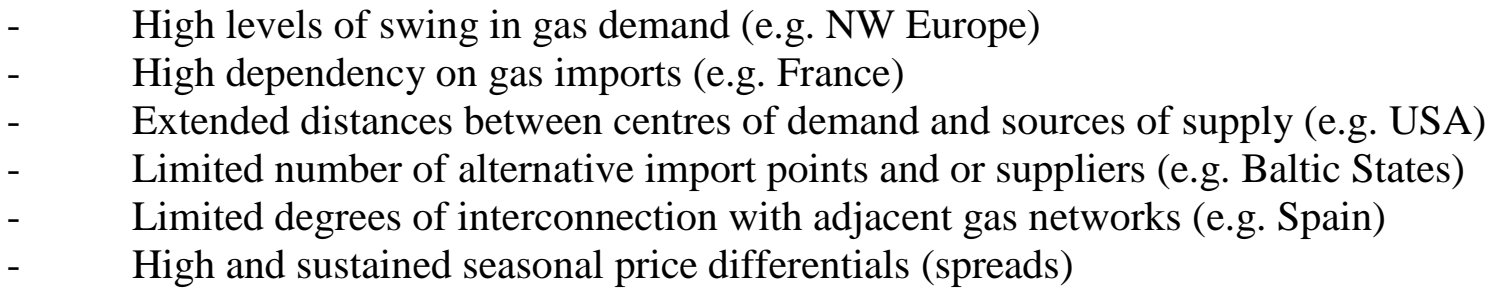

Given the above conditions comparative analysis is often used to assess whether the level of storage available in a particular system is appropriate. Typical measures include:

- $\quad$ Working capacity as a percentage of overall demand

- Working capacity as a percentage of domestic demand

- Working capacity as a percentage of imported gas

- $\quad$ Daily deliverability as a percentage of average winter demand

- $\quad$ Daily deliverability as a percentage of peak winter demand

- $\quad$ The overall number of storage cycles in the system

- $\quad$ Concentration measures such as the $\mathrm{HHI}^{15}$ indicating the degree of diversity of supply sources.

Further refinements to the above measures may include comparing the ratio of working capacity to measures of relative dependence on gas versus other fuels or the proximity of fast cycle storage to centres of demand. Comparative measures for GB and other European countries are shown in Table 19.

It is also important to recognise that measures and flexibility requirements can change significantly through time. An increase in base load gas fired power generation may reduce seasonal demand variation whilst an increase in the proportion of intermittent renewable generation may lead to greater day to day swings in gas demand. An increase in import reliance may lead to real or perceived increases in exposure to supply disruption and this can be an important factor leading to more storage being required.

\subsubsection{Storage in liberalised markets}

The requirement for gas storage was traditionally determined as part of the overall system design process typically undertaken by an integrated gas monopoly. Flexibility requirements, including storage, were determined on the basis of optimising the physical system together with the gas supply and sales contracts. The cost of building and operating storage facilities was often embedded within the overall system costs and was not priced separately. There was often a tendency to over build or "gold plate" assets in line with a desire to reduce supply disruption risks to very low levels.

\footnotetext{
${ }^{15} \mathrm{HHI}$ is the Herfindahl Hirschman Index which is normally used as an indicator of market concentration. It has also been used to assess the degree of supply security and diversity - see OECD NEA, 2010, P 75.
} 
As gas markets are opened up and the roles of transporter and shipper/supplier become unbundled there is typically a move towards using the price mechanism as the primary instrument for balancing supply and demand. System users are incentivised to balance their inputs with offtakes and can be penalised if they are significantly out of balance - for example through being required to buy or sell gas at the highest or lowest price prevailing on the day. The market is therefore setting the price or charge for being out of balance. ${ }^{16}$

Shippers and other players will also develop gas trading activities to manage the interface between a portfolio of gas supply contracts and the demands of their customers and to generate additional returns from arbitrage opportunities. The trading unit will be required to manage the shipper's imbalances - often through trades made at hubs - and a market for flexibility services develops that is priced independently from, but inevitably linked to, the price of gas.

Market liberalisation presents both challenges and opportunities for storage. A major challenge is that the unbundling of activities, one of the key features of liberalisation, can expose physical storage assets as stand-alone entities having to compete with other sources of flexibility. In these circumstances the market value of storage may be revealed to be below the underlying asset value - particularly if there has been over investment and/or individual system users opt for lower levels of flexibility than was purchased in aggregate hitherto.

The discovery of the market value of storage is enhanced by the tendency for shippers to settle imbalances through trading at liquid hubs rather than using physical means. The shipper/supplier - and some categories of gas users - will often be the most able to make informed decisions on the commercial trade-off between the costs of flexibility and the financial penalties of imbalance or supply disruption. A shipper may decide to under book storage or another source of flexibility because it expects to cover any imbalances through trading and considers the financial exposure arising from an unbalanced portfolio is much less than the costs of, say, booking storage. Two concerns arise from this tendency. Firstly, if all shippers tend to rely on trading to meet imbalances the system will be less able to deal with low probability high impact events such as prolonged periods of severe weather or a major supply disruption because storage capacity will not have been booked and filled in sufficient quantity. Secondly, it would appear that suppliers are in the best position to make informed trade-offs having the best access to all of the information revealing the value of flexibility. Independent storage investors will only be partially aware of these values and so will be making investment decisions in a more uncertain environment.

Concerns over these issues have led to requirements for the system operator to play a role in taking an overview of the likelihood and impact of extreme events and, in some cases, formulating measures to deal with them.

The biggest opportunity for profit for storage investments created by liberalisation arises from being able to utilise storage assets to enhance value through trading and optimisation. In the USA unbundled storage also provides additional services such as parking, balancing and loaning. Examples of how trading and optimisation values can be derived include:

${ }^{16}$ For a detailed description of how gas systems are balanced in Europe see Nera/TPA, 2005 p 11 
- Storing gas in the summer when prices are low and withdrawing during the winter when prices are high - thereby exploiting the so called seasonal spread.

- Exploiting the difference between spot and future prices during periods of high price volatility - e.g. if spot prices move significantly above futures prices traders can sell gas from storage and lock in future volumes at a lower price - this is referred to as exploiting the flex spread.

Experience from the USA, which liberalised its wholesale gas market in 1993, suggests that operation of storage facilities becomes much more market orientated after liberalisation with the following characteristics ${ }^{17}$ :

- An increase in high deliverability facilities

- An increase in average cycling rates

- Greater emphasis on inventory management with a trend towards overall lower inventories

- Tariffs linked to market prices.

The requirement for more frequent cycling and higher deliverability rates suggests that salt cavern facilities would deliver higher returns over other forms of storage. Needless to say it is necessary to have gas prices based on deep and liquid trading hubs with a degree of price volatility in order to derive maximum value from storage in a liberalised market.

For gas suppliers, owning storage facilities not only provides a range of trading opportunities but also gives them a hedge against price spikes in the wholesale market. This arises from the fact that during such spikes they may suffer from negative margins in their retailing activities but gain strongly positive margins in their storage business. However, incumbent suppliers with large market shares and a near monopoly of storage facilities may be subject to particular scrutiny from regulators and this is discussed below.

Liberalised markets can also encourage the development and operation of independent storage facilities. Independent storage project promoters have developed a number of alternative business models. These include:

- Selling their projects in their entirety to other players at varying stages of development

- Pre-selling capacity in the form of long term capacity contracts with one or more users to underwrite the investment (i.e. develop it as a tolling facility) or

- Developing the facility on a speculative basis with a view to selling and trading capacity as a merchant facility.

- Combining merchant and tolling aspects within the same facility.

\subsubsection{Pricing storage capacity}

When storage is separated from being embedded within a transportation system it is necessary to define a price for providing the service. Whilst storage actually comprises three separate activities - injection, storing and delivering - the service is often combined into a product known as a storage bundled unit (SBU) containing a pre-determined mix of the three elements typically designed to provide a single unit of delivery. Combining the three

${ }^{17}$ See IEA (2002), p63 
elements allows storage operators to ensure that all of their capacities are utilised and it is not left with, say, unused injection capacity that it cannot sell because all of its storage space has been committed.

The definitions of SBUs will vary according to the features of an individual facility. Some examples are shown in Table 4.

Table 4: Examples of Storage Bundled Units (SBUs)

\begin{tabular}{|l|l|l|l|}
\hline Storage facility & $\begin{array}{l}\text { Injection capacity in } \\
\text { SBU }\end{array}$ & $\begin{array}{l}\text { Storage capacity in } \\
\text { SBU }\end{array}$ & $\begin{array}{l}\text { Delivery capacity in } \\
\text { SBU }\end{array}$ \\
\hline Rough (GB) & $0.35 \mathrm{kWh} / \mathrm{d}$ & $67 \mathrm{kWh}$ & $1 \mathrm{kWh} / \mathrm{d}$ \\
\hline Hornsea (GB) & $0.11 \mathrm{kWh} / \mathrm{d}$ & $18 \mathrm{kWh}$ & $1 \mathrm{kWh} / \mathrm{d}$ \\
\hline Kalle (Germany) $^{20}$ & $1 \mathrm{~m} 3 / \mathrm{hour}$ & $1,250 \mathrm{~m} 3$ & $3 \mathrm{~m} 3 / \mathrm{hour}$ \\
\hline Epe H-cal (Germany) & $3 \mathrm{MWh} / \mathrm{d}$ & $7.5 \mathrm{GWh}$ & $10 \mathrm{MWh} / \mathrm{d}$ \\
\hline
\end{tabular}

Source: Company websites (see footnotes)

The difference in configuration of SBUs between Rough (a depleted field) and Hornsea (salt cavity) is evident with the latter involving smaller injection and storage volumes to deliver an equivalent amount of energy. Kalle, which is an aquifer storage close to the Dutch border has similar injection:withdrawal ratios as Rough as does Epe, though the latter is a salt cavern facility.

It has been pointed out by Ramboll that SBUs can act as a barrier to entry for new suppliers whose portfolio may have very different characteristics from an incumbent and so there may be a case for storage products to be sold as separate components or, as in the case of Denmark, to develop multiple SBU configurations ${ }^{22}$.

Pricing of SBUs will depend on the degree of liberalisation in the market and the extent to which prices are regulated. In a fully liberalised market storage providers are essentially price takers $^{23}$ and prices can be determined by auctions or linked to traded prices. For example the Rough SBU is priced on the published prices for Q1 of the next calendar year minus the summer price in the present year (both in pence per therm) multiplied by 2.27 (one Rough SBU provides space equivalent to 2.27 therms). In less liberalised markets, where storage access is provided to third parties, prices are either in the form of published tariffs in the case of regulated TPA ${ }^{24}$ or subject to negotiation if negotiated TPA rules apply. In this latter case the main commercial conditions plus the price of any standardised services must be published. Some capacity may also be auctioned in these markets.

\footnotetext{
${ }^{18}$ http://www.centrica-sl.co.uk/index.asp?pageid=49

19 http://www.sse.com/WhatWeDo/GasStorage/HornseaServices/

${ }^{20}$ http://www.rwe.com/web/cms/en/535520/rwe-gasspeicher/products-and-services/products-and-fees/products/

21 E.On storage in Germany offers five different configurations of SBU depending on the facility - details are at https://www.eon-gas-storage.de/cps/rde/xchg/SID-56F6EFFE-D41257CE/eon-gas-storage/hs.xsl/2614.htm

${ }_{22}$ Energienet.dk offers both seasonal and high flexibility SBUs under annual contracts as well as a longer term SBU. See http://gaslager.energinet.dk/EN/Produkter-og-tariffer/Sider/Standardpakker.aspx for more details ${ }^{23}$ See Felix et al, 2010

${ }^{24}$ An example of published tariffs for E.On's German storage facilities can be downloaded from https://www.eon-gas-storage.de/cps/rde/xchg/SID-A9A54E51-124901E2/eon-gas-storage/hs.xsl/2452.htm
} 
Analysis by Kubler (2012) of comparative storage tariffs in various continental European markets shows that that price of SBUs is generally above (in some cases well above) the prevailing spreads on the TTF hub. This suggests both that European gas storage is still to feel the full effect of liberalisation and that some erosion of value may occur when (if?) it does.

\subsubsection{Economic evaluation of storage projects}

This section looks at the economic evaluation of storage projects in liberalised markets. In regulated regimes economic evaluation of storage will depend on the particular aspects of that regime and as described above may be part of a bundled consideration of the value of the transportation facilities.

The evaluation of storage projects in a liberalised market typically examines two key elements of value:

- The intrinsic value of being able to store gas across seasons that is cheaper to buy in the summer and of higher value in the winter - referred to as the seasonal spread. Whilst intrinsic value is effectively captured on an annual basis it can be optimised within year for example by altering injection profiles from day to day in order to take advantage of changing spot gas prices

- The extrinsic value from being able to exploit the arbitrage between spot and future prices through injecting and withdrawing gas in multiple cycles in a year and further optimisation through trading around a physical position. This element will be higher the greater the number of cycles that the asset is able to deliver - so salt cavern storage will, other things being equal, have a higher extrinsic value than a depleted field facility.

The intrinsic value is primarily driven by the seasonal spread whilst the extrinsic value element is primarily driven by price volatility. Whilst intrinsic valuations are relatively straightforward conceptually the task is complicated by uncertainty over the level of spreads going forwards - particularly in thinly traded markets where forward curves are unreliable (or non-existent) beyond the next two or three years. A long term forecast of future prices that indicates the spread between each summer and winter is therefore required. Forecasting seasonal prices is far from straightforward, particularly when there are competing sources of flexibility, and most approaches use a range of fixed spreads to determine profitability.

Because capturing extrinsic value involves a dynamic process of constant re-optimisation in the light of changing spot and forward prices valuing this element is much more complex. A number of approaches have been proposed and there is both an extensive literature ${ }^{25}$ and a number of models developed by consultants ${ }^{26}$. The usual method involves developing a statistical model of price movements over time that captures different levels of daily volatility and underlying absolute price levels to generate a series of daily price forecasts for the entire evaluation period. A Monte Carlo method is then used to simulate a range of outcomes based on these price iterations and the actions of a gas trader based on every possible combination of gas volumes remaining in store or under contract for every day of the year. The model calculates the revenue derived from each possible trading position (i.e. every combination of

\footnotetext{
${ }^{25}$ See for example Kaminski et al, 2008 and Felix et al 2010

${ }^{26}$ For example Poyry's Maelstrom model described at http://www.poyry.co.uk/sites/www.poyry.co.uk/files/184.pdf
} 
gas volumes remaining in store for each day of the year) to generate an average value derived from these assets.

There has been some criticism of the efficacy of extrinsic valuation models. Felix et al ${ }^{27}$ have pointed out that in illiquid markets the actions of a storage capacity owner could influence prices and thereby capture less value than if it was a completely liquid market where the facility was a price taker. There is also anecdotal evidence from gas traders that simulation models tend to generate a distribution of value in excess of historic actuals and in discussions with storage project promoters there was general agreement that extrinsic valuations needed to be treated with caution.

Whilst intrinsic and extrinsic value measures, which are primarily related to the revenue generating capability of storage, are the most critical drivers, there are other elements of value that range widely and therefore may have an important impact. These include:

- Capital and operating cost - for example offshore facilities will generally be more expensive than those located onshore. Depth and operating pressure can also have an impact.

- Cushion gas requirements - these can range quite widely, particularly in depleted fields.

- Market served - a location in a more liquid market is likely to enhance value. Some facilities such as those on the Dutch-German border are able to serve both markets giving additional upside.

- Connection costs and local access conditions - are storage users able to move gas from and to the network without constraint. Some users may only be able to access network entry capacity on an interruptible basis and find that this capacity is not available when they most need it.

- Potential for expansion - salt cavern facilities often comprise a series of cavities that can be added to relatively cheaply if warranted by the market conditions.

- Development timescales - extended periods to obtain planning permission, seek network connections and commission facilities can all have a major impact on cost and project payback.

\subsubsection{Development of storage projects}

In traditional gas markets the development of storage projects was generally the exclusive preserve of incumbent integrated gas monopolies. As markets have unbundled a wide range of companies have entered the development space.

Storage developers will generally fall into the following categories.

- $\quad$ Upstream producers seeking to maintain or enhance the value of their sales portfolios through providing additional swing. Examples include Dutch gas producer NAM which owns and operates two depleted field facilities at Langelo and Grijpskirk ${ }^{28}$ and the Gazprom facility at Haidach in Austria. ${ }^{29}$

\footnotetext{
${ }^{27}$ Felix et al 2010, page 9 onwards

${ }^{28}$ Details of upstream storage in the Netherlands can be found at http://www-static.shell.com/static/namen/downloads/pdf/brochure underground gas storage.pdf

${ }^{29}$ See Gazprom export’s website http://www.gazpromexport.ru/en/haidah/
} 
- Gas supply companies with a range of customers seeking to balance their supply/demand portfolios through the use of storage. In GB examples include SSE and Centrica. Note that in the case of Centrica the company is required to maintain its storage business as a legally, financially and physically separate from all other Centrica businesses as a separate undertaking ${ }^{30}$.

- Property owners with land that is appropriate for development as gas storage facilities. Examples from GB include British Salt and chemical company Ineos and from Germany, IVG, whose assets include the Etzel site comprising 52 existing gas and oil storage caverns with the rights to build a further $90^{31}$.

- Independent project promoters that have identified and acquired suitable sites and put together a project with a view to either developing it or selling it on to another company to complete. Examples from GB include Warwick Energy that sold its Caythorpe project to Centrica in $2008^{32}$ and Halite that is promoting the Preesall facility in Lancashire ${ }^{33}$.

To a greater or lesser degree all project developers will have choice regarding how they capture value from their project. As described above, they may elect to capture all elements of value by developing their project as a merchant facility - in other words building the project on a speculative basis and buying and selling gas. Alternatively they may decide to operate the facility on a tolling basis - i.e. selling some or all of the capacity on a long term contract for a fixed fee. Financing a merchant facility has proved to be very difficult and most lenders will want to see long term contracts in place. The developer will therefore have to sacrifice some or all of the potential upside in order to attract long term capacity holders. Developing a merchant storage project is only really feasible for a major producer or supplier. How this issue has evolved in GB is discussed further below.

\subsection{Regulation of storage in Europe}

Given that storage normally plays a crucial role in physical gas supply, non-discriminatory open access to gas storage is an important principle in ensuring an effective competitive market. Regulators have typically required storage facilities to be unbundled and operated as stand-alone facilities providing third party access (TPA). In practice, however, the regulation of storage has not always kept pace with other aspects of transportation infrastructure. In Europe, storage users (particularly new entrants) have complained about lack of transparency over availability and discrimination in the application of access rules and capacity allocation methods.

The 2003 European Gas Directive (European Commission, 2003) gave rise to the Guidelines for Good Practice for Storage System Operators (GGPSSO) which were published in 2005 by the European Regulators Group for Electricity and Gas and updated in 2011 (ERGEG, 2011). The guidelines included the following requirements for storage system operators (SSOs):

- They should offer regulated or negotiated third party access (rTPA and nTPA respectively) services on a non-discriminatory and transparent basis using standard storage contracts or a storage code, developed by the SSOs in proper consultation with users with appropriate regulatory involvement. Exemption from TPA is, however, possible - see below.

\footnotetext{
${ }^{30}$ Centrica website http://www.centrica-sl.co.uk/index.asp?pageid=16

${ }^{31}$ IVG website http://www.ivg.de/en/investment/caverns/

32 Centrica press release 22/09/08 http://www.centrica.com/index.asp?pageid=1041\&newsid=1644

${ }^{33}$ Halite website http://www.halite-energy.co.uk/
} 
- They should establish rules on the use of capacity (capacity allocation management) and dealing with congestion aimed at facilitating competitive and efficient use of the storage facility and to discourage capacity hoarding.

- Products offered should include a menu of services that would be both bundled and unbundled, of short or long term duration and firm or interruptible.

- Tariffs and tariff methodologies should be published if the access regime is rTPA as should the main commercial terms and tariffs for standard services if the regime is nTPA.

- Where Public Service Obligations (PSO) were present these should be clearly defined and not used to hamper access or market development.

- Operational information, including details on accessing the facility, available capacity and levels of usage, should be published.

- SSOs should co-operate with TSOs to ensure efficient and secure operation of storage and transportation networks.

In 2006 ERGEG published a monitoring report on the GGPSSO (ERGEG, 2006) which included an overview of the legal and regulatory frameworks covering access regimes and an assessment of compliance with the Guidelines. This report noted that whilst both nTPA and rTPA regimes were evident there was unsatisfactory compliance with the Guidelines in a number of key areas. These included:

- Limited access to storage facilities with a number of large facilities having very few users:

- A lack of transparency with regard to access conditions that could strengthen dominant positions and hamper market development:

- Disregard for confidentiality provisions with information flows between storage operators and affiliates disadvantaging other market participants:

- A lack of effective and non discriminatory congestion management procedures allowing capacity hoarding and creating barriers to entry.

In light of these finding ERGEG recommended to the European Commission that binding legislation, broadly based on the Guidelines, should be introduced. This was reflected in the Directive issued as part of the Third Legislative Package for the Liberalisation of the Energy Market enacted in August 2009 ${ }^{34}$. The Directive (European Commission, 2009) requires SSOs, along with LNG terminal system operators, to be specifically designated ${ }^{35}$ and operate along the same lines as Transmission System Operators ${ }^{36}$ (TSOs). This means, inter alia, they must provide non-discriminatory access to their facilities and provide users with the information they need for efficient access to the system.

One aspect of the Second Gas Directive that remains is the process whereby regulators are able to grant exemption to TPA to new storage facilities subject to meeting certain criteria. This process is discussed in more detail in Chapter 3.2.

\footnotetext{
${ }^{34}$ The legislation comprised three Regulations - establishing ACER (the Agency for Cooperation of Regulators); Conditions for access to the network for cross border exchanges in gas and ditto for electricity and two Directives covering common rules for the internal market in gas and electricity. See European Commission, 2009

${ }^{35}$ European Commission, 2009, Article 12, p211/108

${ }^{36}$ European Commission, 2009, Article 13, p 211/109
} 
The introduction of the Third Package has led to a significant change in the visibility of storage both in commercial terms for access and in information provision. For example the Gas Storage Europe (GSE - the organisation representing the European SSOs) website now publishes daily information on aggregate injection, withdrawal and capacity utilisation for storage facilities grouped by all the main European hubs ${ }^{37}$ and many SSO websites contain extensive information on contract terms, tariffs and technical issues. EFET (The European Federation of Energy Traders) has argued that the ultimate goal should be to establish a competitive market in storage with minimal regulatory oversight and that regulated TPA should not act as a disincentive to new investment (EFET, 2009).

There are however still some concerns that in certain markets ownership and concentration issues act as barriers to entry to new storage providers. Across Europe there is a wide range of ownership models and concentration levels. According to Ramboll (2008) in 2008 the most concentrated levels were in Italy, the Netherlands and France - (approximate HHI's of 0.9, 0.8 and 0.7 respectively). The UK had an HHI of 0.6 and in Germany, where ownership of facilities is widely distributed, it was 0.5. More recently EFET (2011) has pointed out the challenges facing new entrants to the Italian gas market where, despite changes in regime, the approach to storage still creates problems. Specific concerns include:

- Despite a virtual storage decree access rules are still discriminatory in that allocation of storage is pre-defined and on the basis of market served. This creates a strong incentive to vertical integration and restricts access to storage by trading intermediaries

- Security of supply arrangements are largely based on administrative measures that include strategic storage that inhibit the development of market based solutions

Overall it would appear that regulation of storage - particularly regarding capacity allocation and congestion management - is an important contributor to the development of a fully liberalised market. As markets liberalise storage operating regimes will need to change and regulators must pay particular attention to creating the necessary degree of flexibility whilst safeguarding against obstructive behaviour. On the other hand failure to ensure that storage regulation keeps pace with other developments can act as a significant brake on progress to ensuring that storage flexibility provision is 'in synch' with market requirements.

\subsection{Gas storage and security of supply}

Gas storage is often referred to as having a crucial role in ensuring adequate security of supply. This factor has gained increasing prominence in GB as the level of dependence of imported gas supplies increases. This raises the question of whether gas storage investments can be justified on security grounds and if so what level of investment might be appropriate.

\subsubsection{Defining security of supply}

As Winzer (2011) points out there are a wide range of definitions of energy security of supply. These definitions can be restricted to consider the availability or otherwise of the energy commodity relative to demand or extended to include severity measures such as scope, size, frequency and timescale and associated impacts such as price effects or wider economic or environmental damage (Stern 2002).

\footnotetext{
${ }^{37}$ GSE website https://transparency.gie.eu.com/
} 
Winzer notes that a common feature is the exposure to risks - these can be categorised into four main sources:

- $\quad$ Technical risk such as infrastructure failure, gas quality issues, under investment in facilities;

- $\quad$ Commercial risks - contractual disputes, diversion to higher priced markets;

- Human - ranging from sudden changes in demand to major geo-political interventions;

- $\quad$ Natural - such as extreme weather events or intermittency in wind powered renewable generation.

Looking at the gas supply chain these risks can be identified at each stage - i.e. source of supply, transit, reception and distribution facilities and market/technical operation. In GB the scope of the risks has extended as the gas supply chain has lengthened. An example of how these risks might categorised in the case of the UK is shown in Table 5.

Table 5: Example categorisation of GB gas supply risks

\begin{tabular}{|c|c|c|c|c|}
\hline & Source & Transit & Facility & Operational \\
\hline Technical risk & $\begin{array}{l}\text { Underinvestment } \\
\text { in UKCS or key } \\
\text { supply countries }\end{array}$ & Damage to IUK & $\begin{array}{l}\text { LNG terminal or } \\
\text { storage failure }\end{array}$ & $\begin{array}{l}\text { Data problems } \\
\text { between } \\
\text { shippers and } \\
\text { TSO }\end{array}$ \\
\hline $\begin{array}{l}\text { Commercial } \\
\text { risks }\end{array}$ & $\begin{array}{l}\text { LNG diverts to } \\
\text { Asia Pacific }\end{array}$ & $\begin{array}{l}\text { Contractual } \\
\text { disputes }\end{array}$ & $\begin{array}{l}\text { Quality issues } \\
\text { restrict volumes }\end{array}$ & $\begin{array}{lr}\text { LNG supplies } \\
\text { diverted to more } \\
\text { liquid } \\
\text { (TTF) }\end{array}$ \\
\hline Human & $\begin{array}{l}\text { Russia/EU } \\
\text { standoff, } \\
\text { Norwegian } \\
\text { strikes }\end{array}$ & $\begin{array}{lr}\text { PSOs restrict } \\
\text { access } \\
\text { continental } \\
\text { storage }\end{array}$ & $\begin{array}{l}\text { Uncertain policy } \\
\text { framework leads } \\
\text { to } \\
\text { underinvestment }\end{array}$ & $\begin{array}{l}\text { Renewables } \\
\text { subsidies lead to } \\
\text { unbalanced } \\
\text { portfolio }\end{array}$ \\
\hline Natural & $\begin{array}{ll}\text { Cold weather in } \\
\text { Japan leads to } \\
\text { diversion } & \text { of } \\
\text { LNG supplies } & \end{array}$ & $\begin{array}{l}\text { Major global } \\
\text { disaster impacts } \\
\text { on supplies }\end{array}$ & Flood damage & $\begin{array}{l}\text { Renewables } \\
\text { intermittency }\end{array}$ \\
\hline
\end{tabular}

Source: Author

Table 5 presents an approach towards the categorisation of the nature of the risk of disruption to gas security of supply. The next step would be to consider the level of impact (e.g. size and duration) and the wider consequences of such a disruption. The unique characteristics of gas also need to be taken into account. Unlike electricity gas supply networks would not be subject to a sudden loss of supply as the system will hold sufficient linepack ${ }^{38}$ to enable supplies to be maintained albeit for a limited period. However gas networks do not fail safe it is generally essential to ensure there is sufficient gas in the system. If the supply fails there is the danger that air can enter the network and create a potentially explosive air/gas mixture or lead to incomplete combustion and the risk of carbon monoxide poisoning.

If the gas supply fails it is therefore necessary to purge the system in order to displace a gas/air mixture. This can be both time consuming and labour intensive - and therefore very

\footnotetext{
${ }^{38}$ Linepack is the amount of gas stored under pressure within the networks that can be utilised for supply before reducing pressures below required levels for operation - it is therefore available instantly though for only a limited duration.
} 
expensive - if a large number of consumers are affected. For example in September 1998 a catastrophic failure in the Esso gas treatment plant in Longford, Australia led to the complete cessation of supplies to the city of Melbourne and surrounding areas for 19 days affecting over 1.4 million households and 89,000 businesses $^{39}$. Two people were killed in the initial blast and the total commercial and industry cost was assessed at AU\$1.3 billion.

The comparison between the responses of gas and electricity to supply shocks could be measured as differences of resilience. Analysis by Chaudry et al (2009) points out that whilst gas supply shocks can last for weeks-months - compared to electricity shocks which last for hours-days - there have been no major global supply disruptions for the past twenty years. Furthermore the disruptions that have occurred tend to be regional in nature and usually lasting for several days (e.g. Russia/Ukraine disputes) to some weeks as in the case of Longford. They also note that the disruptions to gas supply caused by the 2005 hurricanes in the USA lasted for up to four months.

If risks to security of supply can be identified the next step is to examine ways in which the risk can be removed, mitigated or managed. In the gas supply context there are a number of ways in which this is done. Examples include:

- Upstream: Portfolio of supply sources, spare terminal and pipeline capacity, standby/peak shaving contracts

- Midstream: seasonal or strategic storage, spare network capacity, capacity management procedures

- Downstream: alternative fuel sources such as standby generators, interruptible contracts, load shedding procedures.

All of these approaches have a price attached to them. Silve and Noel (2010) have developed a security of supply cost curve that enables security of supply projects to be ranked in terms of cost per unit of peak gas supply that is insured by the project. The projects can then be stacked in cost order until the desired level of security of supply has been reached. Associated with this approach is assessing value of lost load to different classes of consumers that could then enable a trade-off between a specific level of security and the cost of introducing it.

There are however a number of difficulties with these approaches. First, as Winzer notes there are also subjective elements relating to supply security that mean there will be different perspectives depending on the group involved. Domestic consumers will have different views from those of public servants or private utility companies. The extent to which a market is liberalised and interconnected will also have a major impact and it should be noted that the timescales for introducing many of the security insurance projects can be extended. Given the notorious difficulty of forecasting future peak demand it is quite possible that investments would become stranded before they were completed. This issue is returned to below in the context of UK security of supply.

A final point to note in this section is the role of the EU in determining energy supply security policies and measures. The European Commission published a Directive in $2004{ }^{40}$ which set out

\footnotetext{
${ }^{39}$ Details can be found on the Australian Government Attorney General's website http://www.emknowledge.gov.au/resource/?id=383 .

${ }^{40}$ European Commission, 2004, summary
} 
security of supply standards to be adopted by member states which later formed a Regulation enacted in December, $2010^{41}$. The regulation contains the following provisions:

- $\quad$ Supplies must be secured to protected customers - i.e. all households and possibly small and medium-sized enterprises and essential social services -under severe conditions such as a seven day temperature peak or infrastructure disruption under normal winter conditions.

- All countries must meet an infrastructure standard whereby they ensure they can meet peak demand in the event of a disruption of the single largest infrastructure element by December 2014, the so called N-1 test.

- All cross border interconnections between EU countries have to be capable of reverse flows by December 2013.

- The competent national authority must undertake a full assessment of the risks affecting the security of gas supply and the measures required to remove or mitigate the risk identified and develop an emergency plan to deal with supply disruptions.

- Confirmation of the establishment of the Gas Coordination Group (already formed) to coordinate security of gas supply measures. This group was active during the 2009 Russia/Ukraine supply crisis.

Much of the subsequent work on assessing and coordinating overall security of supply has been done by ENTSOG ${ }^{42}$ (The European Network of TSOs for gas) as part of their Ten Year Development Plan activities. ENTSOG has suggested developing an Entry Capacity Concentration Index (ENCC) using the HHI approach but calculated on the shares of entry capacity of various sources. An example of this is shown in Figure 3.

Figure 3: Entry Capacity Concentration Index example

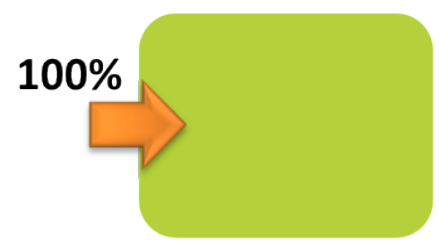

Country A: $\mathrm{ENCC}=100^{2}=10,000$

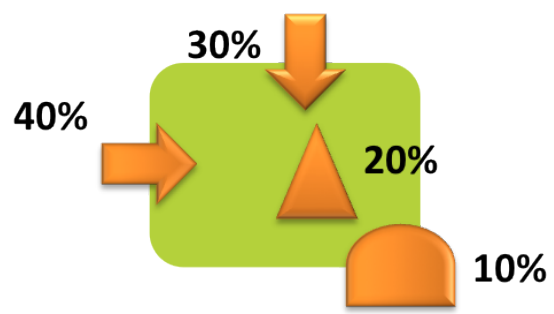

Source: ENTSOG 2012b

Country B: $\mathrm{ENCC}=40^{2}+30^{2}+20^{2}+10^{2}=3,000$

In Figure 3 country A is solely reliant on a single source of gas so has the highest possible ENCC of 10,000 . Country B has $20 \%$ indigenous production capacity, $10 \%$ storage capacity

\footnotetext{
${ }^{41}$ European Commission, 2010 , summary

${ }^{42}$ See ENTSOG 2012b, Slide 19
} 
and separate import capacities of $40 \%$ and $30 \%$ respectively - this yields a much lower (i.e, more diverse) ENCC of 3,000.

The Directive included a recognition that states may use storage facilities to help achieve security of supply standards (Article 4) but there was no obligation to do so. The Directive also included details of specific national provisions which were already in place. These included:

- $\quad$ public service obligations (PSO) that contained specific standards with regard to security of supply that may or may not require storage to be booked;

- $\quad$ strategic storage requirements - separate from PSOs these were specific requirements to hold storage for emergency purposes.

\subsection{Summary and conclusions on the role of gas storage}

Storage facilities play a key role in providing flexibility in gas markets though the amount of storage in any given system will vary widely according to a wide range of supply and demand factors. Liberalisation of gas markets will generally have a profound impact on the role, pricing and value of storage and there are both opportunities and risks for owners of storage capacity in such markets. The regulation of storage is likely to be an important element in the development of a fully liberalised gas market - particularly with regard to capacity allocation and congestion management. Security of supply is growing in importance and, as discussed below, this is likely to be an even bigger issue as import dependency in Europe increases. The contribution of storage will be a key component in meeting these concerns though diversification of supply sources is also seen to be necessary.

Having established the key fundamentals for gas storage in broad terms the following chapter examines the role played by storage in the GB gas market.

\section{Storage in the GB gas market}

\subsection{A brief history - Evolution of the GB gas market and the role of storage}

The natural gas industry in Great Britain was overwhelmingly reliant on UKCS supplies until the early 2000s. In addition UKCS fields in the Southern North Sea, given their close proximity to the main centres of demand, were the most important provider of flexibility with an average swing of 150 to $160 \%$ up to 1995 . The British Gas Corporation ensured that its purchase contracts included sufficient swing to meet most demand variations though some storage was required to meet the 1-in-20 peak day and 1-in-50 severe winter criteria. This was feasible given the shallow water environment in this gas basin and consequent moderate cost base of the field developments.

As an integrated monopoly British Gas built seven gas storage facilities ${ }^{43}$ connected to the high-pressure transmission system before the market was liberalised. These comprised the depleted offshore Rough gas field, the Hornsea salt cavity facility and five LNG storage facilities that were primarily located towards network extremities in order to provide system resilience.

\footnotetext{
${ }^{43}$ Some other facilities were built connected to the regional systems.
} 
When British Gas unbundled its transportation and supply activities in 1994 the storage facilities were treated as a transportation asset and regulated through the gas transporter's (GT) licence though it was operated as a separate business unit within Transco ${ }^{44}$. Third party access to storage was provided and prices were based on a regulated tariff linked to costs (operating and depreciation) plus a return on what transpired to be an unrealistically high regulated asset value (RAV). Shipper balancing rules were not strict (inputs had to equal estimated outputs on a monthly basis) and shippers vary their offtakes under their gas supply contracts in order to remain in balance. As a result non-British Gas use of storage was minimal.

1996 saw the introduction of the Network Code ${ }^{45}$ and a much tighter daily balancing regime with market-based penalties for imbalance. Storage prices were seen as high by most shippers and so the facilities continued to be under-used relative to other sources of swing. Under its Safety Case $^{46}$ Transco had an obligation to minimise the risk of a supply emergency. To meet this in part it held gas in store to meet any predicted shortfall between supplies and forecast demands - this was referred to as "top up" and included "monitor levels" of gas supplies to be maintained in certain storage sites ${ }^{47}$.

In 1999 the then regulator (Ofgas) reviewed the operation of the storage market and concluded that British Gas had a dominant position in storage in a way that hindered the development of competition. Furthermore it considered that prices for storage were too high and the range of services was too limited. It was therefore agreed with Ofgas that the Rough and Hornsea storage facilities should be removed from the transporter's licence and thereafter regulated on the basis of public undertakings. The LNG storage sites remained within Transco and its GT licence. The undertakings included the auctioning of Rough and Hornsea storage capacity, facilitating a secondary market in storage services and the effective separation of the storage business from the rest of BG plc's activities ${ }^{48}$.

In the first storage auctions held in March 1999 all of the Hornsea capacity but only 52\% of Rough capacity was sold - furthermore revenue achieved was significantly below expectation ${ }^{49}$. The auctions therefore exposed the significant degree of oversupply in storage capacity and asset values fell as a result.

The period 2000 to 2002 saw a period of corporate restructuring. In July 2001 the assets in BG Storage (Rough and Hornsea) were sold to the US trading company Dynegy for $£ 420$ million $^{50}$ (the regulatory asset value for these assets had at one stage exceeded $£ 1$ billion), which included the onshore Easington terminal. The undertakings with regard to auctions and secondary markets were transferred to Dynegy ${ }^{51}$. Credit and liquidity problems following the collapse of Enron forced Dynegy into a major restructuring during the latter part of 2002 and the Rough storage field

\footnotetext{
44 Transco, the transportation business was itself a business unit until it was incorporated as BG Transco plc in 1999.

${ }^{45}$ The Network Code is now referred to as the Uniform Network Code (UNC) and is administered by the Joint Office of Gas Transporters http://www.gasgovernance.co.uk/

${ }^{46}$ All gas transporters must have a Safety Case approved by the Health \& Safety Executive - see http://www.hse.gov.uk/gas/supply/emergencies.htm

${ }^{47}$ For a detailed description of the role of top up and how it evolved to its cessation see Ofgem, 2004a

${ }^{48}$ See Ofgem, 2001, p 5

${ }^{49}$ See Table 2 in Hawdon and Stevens 2001

${ }^{50}$ BG Press release, 16 July 2001 http://www.bg-group.com/MediaCentre/PressArchive/2001/Pages/160701sX.aspx

${ }^{51}$ The undertakings are on the OFT website http://www.oft.gov.uk/shared_oft/mergers/dynegyundertakings.pdf
} 
and Easington terminal were sold to Centrica plc $^{52}$ for $£ 316 m$ and the Hornsea salt cavity storage, together with rights to develop the adjacent Aldbrough caverns, to Scottish and Southern Energy $\left(\mathrm{SSE}^{53}\right)$ for $£ 129 \mathrm{~m}^{54}$.

Following the Dynegy disposals a number of new storage projects started to emerge though as described below many of these projects have yet to proceed to construction.

\subsection{The regulation of gas storage in GB}

The main components of storage regulation relate to the access regime which has been largely shaped by the overall approach to market liberalisation, the role and ownership of the Rough storage facility and EU legislation. There are also other aspects of regulation relating to consent to build new storage facilities and technical regulations though these are generally less critical.

Notwithstanding the specific developments with regard to Rough, the Government view was that the gas storage industry had been deregulated and that competition in the market for gas storage services was increasing. On this basis, when the First EU Gas Directive was introduced in 1998 requiring, among other things, non discriminatory access to gas and storage facilities that could be either negotiated or regulated (i.e. nTPA or rTPA), the DTI decided to implement a 'light touch' regime $^{55}$. This comprised negotiated third party access (nTPA) to gas storage with the possibility that Ofgem could exempt storage facilities from the TPA provisions if certain criteria set out in the Gas Act 1986 had been met. During the period that this exemption regime was in place, Ofgem granted exemptions from TPA to three gas storage facilities (Hatfield Moor, Hole House and Humbly Grove) and each of the five LNG storage facilities then owned by Transco LNG. The Rough and Hornsea facilities were both subject to the TPA requirements and Centrica Storage Ltd also provided some written undertakings as described below.

Because of Centrica's dominant position in gas and electricity supply and the importance of Rough as a provider of flexibility to that market the proposed sale was referred to the Competition Commission $^{56}$ (CC). The subsequent report (Competition Commission, 2003) was important for gas storage in GB as it not only set out the requirements for the operation of the largest storage facility in the country but also established an approach to assessing competition in storage that is still the main point of reference for regulators.

The starting point for most regulatory authorities is to define the relevant market in terms of the product that is being sold and the geographic area that comprises the market. In its Rough inquiry, the CC defined the product sold by gas storage facilities as flexibility and the relevant geographic market as being Great Britain. Ofgem has adopted a similar view of the relevant market when considering issues relating to other storage facilities though as described below there is considerable scope for variation in the definitions chosen.

\footnotetext{
${ }^{52}$ Centrica is the demerged part of British Gas plc that owns the GB supply business and the Morecambe Bay gas fields.

${ }^{53}$ SSE (Scottish and Southern Energy) is an integrated electricity company with a gas supply business in Great Britain.

${ }^{54}$ Details can be found at http://processengineering.theengineer.co.uk/scottish-and-southern-energy-acquiresdynegy-hornsea/279908.article

${ }^{55}$ See Ofgem 2004b, p 2.

${ }^{56}$ Competition Commission update http://webarchive.nationalarchives.gov.uk/+/http://www.competitioncommission.org.uk/rep_pub/reports/2003/480centrica.htm
} 
In its specific conclusions the CC stated that the Centrica acquisition would weaken competition in the markets for flexible gas and domestic gas supply and that innovation and investment at Rough would be lower. Overall the CC concluded that, whilst there were some benefits from the transaction, on balance it was likely to be against the public interest. As it is required to, the CC provided a series of remedies that could be applied to address these problems and the transaction was allowed to proceed on the condition that Rough provided third party access as defined in the Gas Act (see below) and that Centrica made a number of undertakings. The TPA requirement meant in effect that Centrica would have to:

- sell Rough's full capacity on non-discriminatory terms;

- auction all capacity remaining unsold no less than 30 days before the start of each storage year, with no reserve price;

- facilitate the efficient operation and development of the secondary market in Rough capacity.

The additional undertakings included a requirement that Centrica must:

- Maintain the existing Storage Services Contract;

- Sell at least $20 \%$ of capacity on annual contracts and provide a range of long term contracts of up to 5 years with both fixed and indexed pricing;

- Not reserve more than $20 \%$ of existing capacity for itself in the first year (2004/05) falling to $15 \%$ over five years;

- Maintain legal, financial and physical separation between its storage business (Centrica Storage Ltd.) and all other parts of the group;

- Ensure that no commercially sensitive information arising from the operation of Rough is passed to other parts of Centrica.

These undertakings were agreed in December 2003 ${ }^{57}$. In April 2010 Centrica submitted a request for a release from the Undertakings ${ }^{58}$ due to changes in market conditions and the legal framework following the introduction of the Third Energy Package requirements for storage operators. In April 2011 the Competition Commission confirmed that the undertakings should remain in place though it did agree to some relaxation of the limits on bookings made by other parts of the Centrica group ${ }^{59}$.

Ofgem's present approach to storage regulation was set out in 2004 follow the adoption of the Second EU Gas Directive ${ }^{60}$. Whilst the existing regulatory regime reflects the requirements of the Directive, many of the provisions were in place prior to the implementation of this legislation. When the Second Gas Directive was issued the DTI took the view (following consultation - DTI, 2004) that as a consequence of the liberalised, competitive market in GB, and the regulatory regime currently in place, the negotiated TPA regime for storage as set out in the Gas Act 1986 would not need to be significantly amended. However, the DTI considered that amendments to the Gas Act 1986 were needed in order to implement the exemption procedure as set out in Article 22 of the Second Gas Directive.

\footnotetext{
${ }^{57}$ The full details of the undertakings are at http://www.centrica-sl.co.uk/files/centrica_undertakings.pdf

${ }^{58}$ OFT Advice to Competition Commission published on 8/11/2010

http://www.oft.gov.uk/shared_oft/mergers_ea02/2010/Centrica-request.pdf

${ }^{59}$ Competition Commission press release, 20/4/2011 http://www.competitioncommission.org.uk/assets/competitioncommission/docs/pdf/non-inquiry/press_rel/2011/april/pdf/2011 cc confirms variations to centrica undertakings

${ }^{60}$ See Ofgem 2004b, p3 onwards
} 
The Second Gas Directive was transposed into GB law by the Gas (Third Party Access) Regulations $2004^{61}$ which came into force on 26 August 2004. The exemption regime for storage facilities made a distinction between existing and new storage facilities - the latter to include significant increases in capacity. As described above, Ofgem had already granted some exemptions and these were unaffected by the new Regulations. Existing storage facilities without an exemption can be granted an exemption but only if use of the facility by other persons is not necessary for the operation of an economically efficient gas market - it would appear that no facilities in GB fall within this definition.

For new or upgraded storage facilities exemption may be granted if either:

- use of the facility by other persons is not necessary for the operation of an economically efficient gas market or

- The follow exemption requirements (which are consistent with the requirements set out in Article 22 of the Second Gas Directive and are referred to as the 19A(8) requirements) are met

- the facility promotes security of supply;

- the investment to construct the facility would not be made without the exemption;

- the facility is owned by a person other than the gas transporter who operates the connected pipeline system;

- charges will be levied on users of the facility;

- the exemption will not be detrimental to competition, the operation of an economically efficient gas market or the efficient functioning of the connected pipeline system; and

- the European Commission approves the exemption.

Ofgem has stated that it will assess any application for exemption against the above criteria rather than the five conditions specified in the Second Gas Directive though it does not consider that there are any material differences between the two sets of criteria. Ofgem has further stated that it will not specify in advance what pricing and/or access arrangements it would consider would facilitate the above six requirements being met and that it will evaluate each exemption application on a case-by-case basis. Relevant issues include the extent to which the facility owner conducts an "open season" process and/or whether effective secondary trading and anti-hoarding mechanisms such as Use It or Lose It (UIOLI) arrangements are in place. (Note these criteria also apply to LNG terminals).

If an exemption is to be granted on the basis that use of the facility by other persons is not necessary for the operation of an economic and efficient gas market (a section 19A(6)(a) application) this will be because both facility owner and primary capacity holder have no appreciable market power. Ofgem define this as being where the party has such a weak position in the relevant market that it could only ever have an insignificant effect on the competitive conditions within that market - a situation Ofgem will assess on a case-by-case basis.

It should be noted that in its definition of Gas Storage Facilities, the Gas Act specifically excludes offshore. The Third Party Access regime applicable to offshore gas storage facilities

\footnotetext{
${ }^{61}$ Details of the legislation can be found at http://www.legislation.gov.uk/uksi/2004/2043/contents/made
} 
was set out in Sections $17 \mathrm{C}-\mathrm{E}$, of the Petroleum Act $1998^{62}$ which effectively extends the Gas Act regime to the offshore area in line with the Energy Act 2004, however this failed to clarify a number of issues. The 2008 Energy Act ${ }^{63}$ set out a clearer regulatory framework for offshore gas storage developments. It extended the Crown's ability to grant leases for offshore gas storage (and for gas unloading platforms) to a maximum of 188 nautical miles within the UKCS - referred to as the gas importation and storage zone and set out licence requirements for both depleted field storage - which required both a Petroleum Act 1998 and an Energy Act 2008 licence - and salt cavity (and other non hydro-carbon structures) storage which required only an Energy Act 2008 licence.

\subsubsection{Criteria for TPA exemption}

Ofgem has adopted a standard approach to assess applications for exemption made under Section 19A(6)(a) of the Gas Act (i.e. on the basis that use of the facility by other persons is not necessary for the operation of an economic and efficient gas market). This requires the definition of the relevant market followed by an assessment of the market share of the participants in that market. An example of how an exemption application is assessed can be found in the application made by Statoil UK and SSE for the Aldbrough storage facility ${ }^{64}$ which was as follows:

- $\quad$ Relevant Market - this is based on the CC Rough study which looked primarily at the market for flexibility. In the Aldbrough application Ofgem notes that the sources for daily flexibility are quite wide ranging and include all forms of storage, part of UKCS production, the IUK and BBL pipelines, LNG terminals, other import pipelines such as Langeled and Vesterled and demand side response.

- $\quad$ Market share assessment - Ofgem then determines the respective market shares that the applicant holds in each of the key flexibility elements over a three year period. In the Aldbrough case Ofgem concluded that under all relevant market definitions, TPA scenarios and time periods, the market shares attained by Statoil UK and SSE were less than $10 \%$ and so exemption from TPA was granted.

In December 2011 Ofgem (2011) published its “Guidance on the Regulatory Regime for Gas

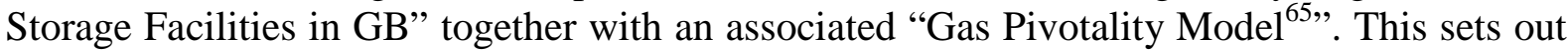
Ofgem's views on compliance with the Third Package relating to gas storage in order to provide greater clarity around the operation of TPA for the benefit of potential investors, users and end consumers. The main features of the guidance cover:

- Capacity allocation should be based on the maximum technical capacity of the facility and auctions or open seasons should be used where possible;

- SSOs should consult on terms and conditions of service provision;

- Where nTPA was provided the undertaking should be legally unbundled from other activities and all SSOs should treat commercially sensitive information appropriately.

Ofgem expects to continue market surveillance to ensure that storage facility owners are complying with the relevant regulatory requirements.

\footnotetext{
${ }^{62}$ Details of the legislation can be found at http://www.legislation.gov.uk/ukpga/1998/17/contents

63 Details of the legislation can be found at http://www.legislation.gov.uk/ukpga/2008/32/contents

${ }^{64}$ Ofgem 2007

65 Ofgem, 2011b, p41
} 


\subsection{Security of supply in the UK}

Gas storage can play an important role in ensuring security of supply and this feature is frequently mentioned in the UK context. This section considers how the security of supply debate has evolved in the UK and the implications this might have for gas storage. The issues are considered from the perspectives of government, regulator, industry participants and independent experts.

\subsubsection{The role of Government}

At the time of liberalisation in the UK market security of gas supply was not seen as a problem. Indeed one of the key drivers was pressure from gas producers who wanted access to markets for their surplus gas supplies. This surplus in turn led to very low prices despite significant increases in the demand for gas - particularly for power generation. The Government view was that as long as the network operator had invested in sufficient capacity the market would ensure that gas supplies were made available. The focus was on competition and asset sweating and Government energy policy, (in the view of one observer), constituted a prolonged period of "benign neglect". ${ }^{6}$

The supply overhang was removed by the construction of the Interconnector between Bacton and Zeebrugge (IUK) which began operation in 1998 and prices began to move towards continental European levels. Energy policy concerns over security of supply started to emerge towards the end of the 1990s. The impending decline in UKCS gas production coupled with worries that the liberalised market might not incentivise appropriate investments were accentuated by the well publicised energy crisis in California and the collapse of energy trader Enron. This led to the establishment of a DTI/Ofgem Working Group on Security of Supply - the Joint Energy Security of Supply Working Group (JESS) and a Performance and Innovation Unit (PIU) report on Energy Security ${ }^{67}$.

In 2003 the DTI published a white paper on Energy (DTI, 2003) that in essence reaffirmed the belief that the liberalised market would signal the need for future investments and suppliers would act accordingly to invest in the required capacity "in particular to meet peak demand in exceptionally cold weather”.

JESS issued regular reports though, as noted by Stern (2010), ${ }^{68}$ these were far from comprehensive. The April 2006 report inexplicably failed to mention the recent fire at the Rough gas storage facility which was one of the most serious supply disruptions ever faced by the GB gas market.

However concern was mounting at the growing exposure of the UK gas supply market and a series of reports were issued as part of the 2006 Energy Review. These included the two Ilex Consulting (now part of Poyry) reports on the cost of gas interruption ${ }^{69}$ and the case for strategic storage $\mathrm{e}^{70}$. This latter document identified a possible supply demand gap under some scenarios that could result in a supply shortfall of 60 to 90 days post 2014 as demand increases and UKCS production continues to fall. The report looked at alternative approaches

\footnotetext{
${ }^{66}$ Helm, D., 2002, page 8

${ }^{67}$ Performance and Innovation Unit, 2002

${ }^{68}$ Ibid p 148

${ }^{69}$ Ilex 2006a

${ }^{70}$ Ilex 2006b
} 
to close this shortfall and calculated that investment in a "Rough equivalent storage facility" could generate a discounted net benefit of $£ 5$ to $£ 6$ billion. It recommended that the DTI develop a timetable with a view to introducing a strategic reserve by 2014 though it noted the potentially damaging impact such a development could have on commercial storage.

The Ilex reports fed into the DTI consultation published in October 2006 on the effectiveness of the current security of supply arrangements ${ }^{71}$. This consultation set out seven possible policies for enhancing gas security of supply. These included licence changes (one of which would require the system operator to invest in strategic storage), increased commercial incentives to invest in storage through a change to the balancing rules and demand side measures such as smart metering, CCGT power stations being required to have distillate back up and inviting large users to bid for interruptible supplies.

The response to this consultation was published in May $2007^{72}$ together with a report from Oxera analysing the various options set out in the initial consultation ${ }^{73}$. Oxera concluded that only demand side bidding from large users and distillate back up for CCGTs returned a positive NPV after including all welfare aspects whilst strategic storage had a negative NPV of £2.1 billion. Based on this analysis and concerns over the negative impact on future commercial storage investments the government explicitly rejected strategic storage as an option.

The next development came in 2008 when the government's Energy Market Outlook ${ }^{74}$ noted the need for additional storage as UKCS production declined and import dependence increased. This requirement was reinforced by two further reports from the UK Energy Research Centre ${ }^{75}$ and by former Energy Minister Malcolm Wicks ${ }^{76}$. The UKERC report tested the long term resilience of the UK energy market to various system shocks and concluded that the storage options provided the fastest pay back compared with other options, though again the danger of intervening in the market was noted. The Wicks report was less equivocal, stating that GB was exposed to:

- the concentration of gas storage in the Rough storage facility and

- the risk of storage capacity owners based outside the UK moving their gas into continental European markets to meet commitments there.

Wicks also urged that very careful consideration be given to the case for strategic storage as an insurance policy in an uncertain world.

The Wicks view was fairly robustly refuted by the April 2010 Security of Supply Policy statement from DECC ${ }^{77}$. The paper specifically ruled out strategic storage though it did flag the case for considering either an enhanced PSO and/or changes to the balancing system cash out provisions. Underpinning this statement but not released until after the May 2010 election was a further report from Poyry on security of supply options ${ }^{78}$.

\footnotetext{
${ }^{71}$ DTI 2006

${ }^{72}$ DTI 2007 a

${ }^{73}$ Oxera, 2007

${ }^{74}$ DECC, 2008, P76

${ }^{75}$ Chaudry et al, 2009

${ }^{76}$ Wicks 2009

${ }^{77}$ DECC,2010

${ }^{78}$ Poyry, 2010
} 
The Poyry Report modeled the impact of a range of supply shocks such as losing the Rough storage facility or a major import terminal. Poyry concluded that GB has sufficient diversity and capacity to receive gas from LNG terminals, Norwegian pipelines, storage and interconnectors to meet all but the most extreme demands. Poyry recognized that capacity is not the same as having gas available so also looked at gas availability from storage, pipelines and global LNG to meet demands in the face of a major supply shock. The results showed that storage projects already committed as at April 2009, the move to a more liberalised gas market in Europe plus some limited demand side response (DSR) should all help improve the supply position. In terms of policy options regarding strategic storage Poyry concluded:

"The policy option of investing in strategic storage to cover the relatively small level of unserved energy identified under the probabilistic analysis would be expensive, and is unlikely to provide sufficient benefit in improving security of supply to justify its costs ${ }^{79} . "$

Overall Poyry concluded that the GB gas market was becoming more resilient to security of supply risks though policy makers should continue to monitor the impact of changes such as treatment of interruption.

The next development was a statement in November 2011 by the Energy Secretary at the time, Chris Huhne, asking Ofgem to report on longer term gas security and whether further action was required to ensure supplies ${ }^{80}$. The nature of this work, which is linked to Ofgem's Significant Code Review, is discussed in the following section.

The announcement by the Secretary of State coincided with the publication of the Annual Statutory Security of Supply Report (DECC, 2011). This report concluded that in the short to medium term, the UK gas supply infrastructure is resilient to all but the most unlikely combination of severe infrastructure and supply shocks. In the longer term there were some scenarios where gas demand increased due to a higher proportion of gas fired power generation and faster economic growth. This could lead to higher peak demand and whilst GB had access to an increasingly large and diverse range of import sources some of this was dependent on new projects that might slip or not proceed.

November 2012 saw a flurry of reports accompanying the draft 2012 Energy Bill ${ }^{81}$. These included the Annual Energy Statement ${ }^{82}$ and, a week later, the government's Gas Generation Strategy $^{83}$. The Annual Energy Statement notes Ofgem's reports on Security of Supply ${ }^{84}$ that confirms the current satisfactory operation of UK gas supply though it notes the increasing interaction with international and EU gas markets. In recognition that there may still be a case for intervention in storage the report states that

"...given the importance of gas to our energy mix and the need to maintain security of supply, the Government will be considering further whether there is a case for providing support for gas storage, and will publish our findings in Spring $2013^{85 \text {, }}$

\footnotetext{
${ }^{79}$ Ibid, P 3

${ }^{80}$ See DECC press release on 8 November 2011.

http://www.decc.gov.uk/en/content/cms/news/pn11_093/pn11_093.aspx

81 The Energy Bill (DECC 2012a) comprised 3 main parts covering electricity market reform, nuclear power and the Government oil pipeline and storage system

${ }^{82}$ DECC $2012 b$

83 DECC 2012c

${ }^{84}$ Ofgem 2012c

${ }^{85}$ DECC 2012b, p 29
} 
The Gas Generation Strategy document seeks to provide certainty for investors in both low carbon and gas generation through, for example, legislating for a capacity market in electricity and improving the wholesale electricity market and planning regime. It sees a continuing role for gas generation with a need for investment in up to $26 \mathrm{GW}$ of new capacity by $2030^{86}$. The strategy includes a section on Ensuring Secure and Affordable Gas Supply ${ }^{87}$, which confirms the intention to investigate further the case for intervention to encourage additional gas storage.

\subsubsection{The role of the regulator}

For many years Ofgem's main focus on security of supply issues was through monitoring the licence obligations of suppliers and transporters. More recently the regulator has taken on a more wide ranging set of initiatives through Project Discovery and the Significant Code Review.

\subsubsection{Licence obligations}

National Grid NTS (NG) is the primary Transmission System Operator (TSO). In common with all gas transporters (GT) NG has a standard licence obligation ${ }^{88}$ to develop its pipeline system in order to meet a peak aggregate daily demand that is only likely to be exceeded in 1 year out of 20 years - often referred to as the 1-in-20 peak day requirement. In addition in order to facilitate an effective gas market, NG is required to establish gas transportation arrangements that provide reasonable economic incentives for shippers and suppliers to meet the 1 in 20 peak day requirement as well as aggregate annual and six-month-period-fromOctober demand, likely to be exceeded only in 1 year out of 50 years (1-in-50 severe winter).

In addition, under the Gas Safety (Management) Regulations 1996 (GSMR) gas transporters must have a safety case approved by the Health \& Safety Executive (HSE) which will include details of how the risk of supply emergencies can be minimised. ${ }^{89}$ NG has an additional role as the Network Emergency Coordinator (NEC). The NEC must submit a separate safety case detailing how it would coordinate the actions of all gas transporters (who are obliged to cooperate with the NEC as necessary) in order to minimise the risk of a gas supply emergency. NG has additional responsibilities that are detailed below.

Responsibility for the 1-in-50 severe winter standard was a supplier licence obligation up to 2007. However it was removed by Ofgem on the basis that it had become effectively unenforceable as inclusion of short term spot gas purchases from the National Balancing Point (NBP) were deemed sufficient to meet the condition. In other words suppliers could satisfy any regulatory enquiry by stating they would buy the gas when and if they needed it. Whilst this obligation has been transferred to the GT via the "reasonable economic incentives" provision as Poyry (2010) points out there is no clarity how this requirement is monitored or enforced.

Separately, suppliers are required to cooperate with GTs in a supply emergency and, in the case of large users, arrange for interruption if necessary.

\footnotetext{
${ }^{86}$ DECC 2012c, p13

${ }^{87}$ Ibid, p43

${ }^{88}$ Condition 16 in the Standard Consolidated Licence Conditions available at http://epr.ofgem.gov.uk/EPRFiles/Gas transporter_SLCs_consolidated\%20-\%20Current\%20Version.pdf

${ }^{89}$ Details can be found on the HSE website http://www.hse.gov.uk/gas/supply/emergencies.htm
} 


\subsubsection{Project Discovery}

Ofgem launched Project Discovery in 2009 to examine the prospects for secure and sustainable energy supplies for GB over a 10-15 year horizon paying regard to the wider global and environmental context ${ }^{90}$. The project developed four scenarios dimensioning the energy supply risks facing GB and the wider European and global markets (Ofgem, 2009). These scenarios were used to review the robustness of existing market arrangements and to determine whether and what changes might be required. The scenarios were based around combinations of alternative economic growth and environmental action levels. The scenarios were then subjected to a series of "stress tests" ${ }^{91}$, such as a Bacton outage, LNG diversions or another Russia-Ukraine dispute, in order to assess the impact of certain "extreme events" and the ability of the market to deal with them.

The stress tests demonstrated a major gas security of supply concern arising from the combination of a severe winter with either LNG supplies being diverted from GB or a new Russia-Ukraine dispute. The scenarios were updated in 2010 (Ofgem, 2010) to take account of lower demand forecasts though the impact of the stress tests did not change materially. The concerns raised by Ofgem through Project Discovery seemed to be at odds with the more sanguine outlook from DECC such as the April 2010 Security of Supply Policy statement. The project now appears to have been subsumed within the Significant Code Review described below.

\subsubsection{The Significant Code Review and "Further Interventions"}

The case for proactive intervention in storage has been recently re-energised by Ofgem's Significant Code review (SCR) related to gas security of supply. The SCR was precipitated by concern over the arrangements for dealing with a gas deficit emergency (GDE) developed at a time when GB was wholly self sufficient in gas supplies. Under these arrangements if a GDE is declared by the Network Emergency Coordinator (NEC) normal market operations are suspended and the cash-out price is frozen. The NEC is authorised to require all domestic supply sources to flow at capacity and not withhold supplies for any reason. The concern is that if the cash out price is frozen there is little incentive on shippers to procure gas from imported sources at high prices as they may be exposed to the difference between these prices and the frozen cash out price ${ }^{92}$. Furthermore the frozen cash out price could be below the price that interrupted consumers would be prepared to pay to secure supplies whilst the shippers' lack of exposure meant there was little incentive on them to make necessary investments (in say storage) or other provisions to prevent a GDE occurring in the first place. In other words the present arrangements were making a GDE, were it to occur, more rather than less likely and more prolonged. Furthermore the costs of the GDE - including the risk of emergency disconnection - lay with customers rather suppliers, the vast majority of whom could do little to mitigate this risk.

Ofgem determined that it was necessary to reform the cash-out mechanism in order to sharpen the incentive on shippers to have sufficient gas resources to deal with supply disruptions. In July 2012 Ofgem published its final proposals (Ofgem 2012a) whereby the cash-out would be set at $£ 20$ per therm (this is based on an estimate of domestic customers

\footnotetext{
${ }^{90}$ A full list of reports and presentations on Project Discovery is on the Ofgem website http://www.ofgem.gov.uk/Markets/WhlMkts/monitoring-energysecurity/Discovery/Pages/ProjectDiscovery.aspx

${ }^{91}$ Ofgem, 2009 page 57

92 Though the NEC process does provide some protection.
} 
"Value of Lost Load" or VoLL) in a GDE once gas supplies to firm customers are curtailed. This exposure was to be capped at one day in the event that physical isolation of the network occurs. Even a one day payment for a supplier with millions of domestic customers could be significant, though as shown in Table 6 the probability of a major outage affecting domestic customers is vanishingly small.

Table 6: Average annual probability of at least one outage

\begin{tabular}{|l|l|l|l|}
\hline & $\begin{array}{l}\text { Current } \\
\text { Arrangements }\end{array}$ & $\begin{array}{l}\text { Extended } \\
\text { infrastructure } \\
\text { loss }\end{array}$ & $\begin{array}{l}\text { Limited LNG } \\
\text { availability }\end{array}$ \\
\hline Firm DM Gas (i.e. large loads) & 1 in 55 & 1 in 21 & 1 in 25 \\
\hline NDM Gas (domestic and small I\&C) & 1 in 167 & 1 in 54 & 1 in 83 \\
\hline
\end{tabular}

Source: Redpoint, in Ofgem 2012

http://www.ofgem.gov.uk/Markets/WhlMkts/CompandEff/GasSCR/Documents1/120731_GasSCR_RP.pdf

Table 6 shows the probability of interruption to consumers before the SCR proposals have been introduced - i.e. under the base case assumptions an interruption to domestic gas consumers is expected to occur once every 167 years. The two sensitivities cover:

- The extended infrastructure loss tests the impact of doubling the base case assumptions on duration, magnitude and probability of outages on key gas supply and storage infrastructure (UKCS supply, NCS supply, IUK, BBL, LNG imports and storage)

- The limited LNG import case is based on an assumption of low UK prices but high, oil linked LNG prices resulting in low LNG imports into GB. Under this scenario the GB system is more vulnerable to negative shocks since BBL and IUK are generally close to full capacity and LNG supplies are not able to respond to a sudden shock quickly enough because of the time it takes to re-route LNG cargoes.

In tandem with the SCR process Ofgem was asked by DECC in November 2011 to assess whether further action was needed to ensure the security of medium to long-term gas supplies. This is referred to as "further interventions" work. Ofgem has grouped the possible alternative approaches as follows ${ }^{93}$ :

- Technology non-specific interventions:

o an information obligation to require suppliers to provide demand and supply information to NG and/or to Ofgem;

o a licence condition for suppliers to ensure that they meet the demand of domestic customers;

o reliability contracts that seek to price in the risk of periods of high gas prices.

- $\quad$ Demand side interventions:

o standard contracts for interruption to facilitate greater negotiation of interruptible contracts between suppliers and larger Daily Metered (DM) customers;

o a DSR auction to be held by NG to facilitate coordinated DSR from DM customers.

- $\quad$ Storage interventions:

0 new build of a regulated or semi-regulated storage facility - the capacity could be

${ }^{93}$ See Appendix 3 of Ofgem 2011a 
held outside the market as strategic storage though Ofgem believes it makes economic sense to allow TPA. Ofgem notes the impact this approach could have on existing storage projects and so this may lead to approaches such as underwriting annual storage prices if they fall below a certain level.

o a storage obligation, either on suppliers or the system operator to hold an amount of gas in storage - Ofgem notes that there are a number of complex design issues associated with this option.

Ofgem reported the effectiveness and net benefit/cost of the alternatives including an assessment of the risks and unintended consequences in November $2012^{94}$. The conclusions of the main report were:

- A confirmation that only the most extreme circumstances would result in large scale physical interruption to domestic customers and smaller businesses. Such circumstances would entail starting the winter with storage only $50 \%$ full and incurring a 60-70\% loss of supply, which is equivalent to losing all LNG imports and imports via BBL and IUK plus 50\% of UKCS supplies.

- Less extreme circumstances (25-30\% supply loss and storage 50\% full) could result in a curtailment of gas supplies to power stations which in turn could result in electricity supply interruptions.

- Whilst it is difficult to insulate GB consumers from international prices (and indeed price spikes play an important role in attracting gas and incentivising investment) the relative lack of storage could mean that they were more exposed than neighbouring markets.

- The cash out reforms proposed under the SCR would still not fully reflect the value of security of supply to consumers and this plus a range of other factors (for example behavioural and institutional factors, the challenge of financing long term investments such as strategic storage, moral hazard and the impact of inconsistent incentives such as PSOs in other countries) suggest further measures may be justified. However given the danger of unintended consequences a "much fuller and more rigorous assessment of the risks, costs and benefits of that measure would be needed. ${ }^{95,}$

Ofgem is presently assessing the efficiency of the GB gas interconnectors and intends to work with the industry to assess the case for other measures including enhanced information provision.

\subsubsection{The role of the industry}

\subsubsection{The role and view of the transporter}

In addition to its licence obligations and as described above Transco/NG was required to book "top up" storage if necessary until 2004. The top up regime was discontinued in 2004 as Ofgem considered it too expensive and could reduce the incentives on suppliers - for example via their 1 in 50 obligations (though as noted above these too have now been dropped). Safety monitors ${ }^{96}$ were introduced in 2004 to replace the so-called 'top-up' monitors, which had existed since 1996. The safety monitors define levels of storage that must be maintained

\footnotetext{
${ }^{94}$ Ofgem produced a Security of supply report (Ofgem, 2012b) plus three associated documents covering the design of further measures (Ofgem, 2012c), risk and resilience (Ofgem 2012d) and details of the modelling work (Redpoint, 2012)

${ }^{95}$ Ofgem 2012b, p 8

${ }^{96}$ See National Grid 2010b
} 
through the winter period. The focus of the safety monitors is public safety rather than security of supply (i.e. the safety consequences of having gas at inadequate pressures in the network) acting as a trigger mechanism for taking direct action to avoid a potential gas supply emergency.

It is a requirement of National Grid's safety case that it operates this monitor system and takes action to ensure that storage stocks do not fall below the defined levels. The levels of storage established by the safety monitors are those required to underpin the safe operation of the gas transportation system - defined as the preservation of supplies to domestic customers, other non-daily metered (NDM) customers and certain other customers who could not safely be isolated from the gas system.

The monitors define minimum levels of stored gas required in each type of storage facility, on each day of the winter. National Grid monitors the level of gas in each of the three storage facility types (i.e. LRS, MRS and SRS) throughout the winter to ensure that the actual stock level does not fall below the relevant monitor level. If it looked as if stocks were going to fall below this level - for example as a result of a prolonged cold spell or sustained loss of key supplies, NG would advise the market with the objective of encouraging mitigating action. If necessary, however, the Network Emergency Co-ordinator (NEC) may require the relevant storage operators to reduce or curtail flows of gas out of storage. The events described have never occurred, though storage operators and capacity owners remain concerned that they could be exposed in the event that system security is compromised and they are required to restrict activities by the NEC.

Separately NG publishes so called Firm Gas Monitors - these represent the storage levels required to support firm demand in a severe winter. These are always much higher than the safety monitor levels and are published for information only. An example of the firm and safety space monitor levels is shown in Figure 4.

\section{Figure 4: Firm and Safety space monitors - 2010/11}

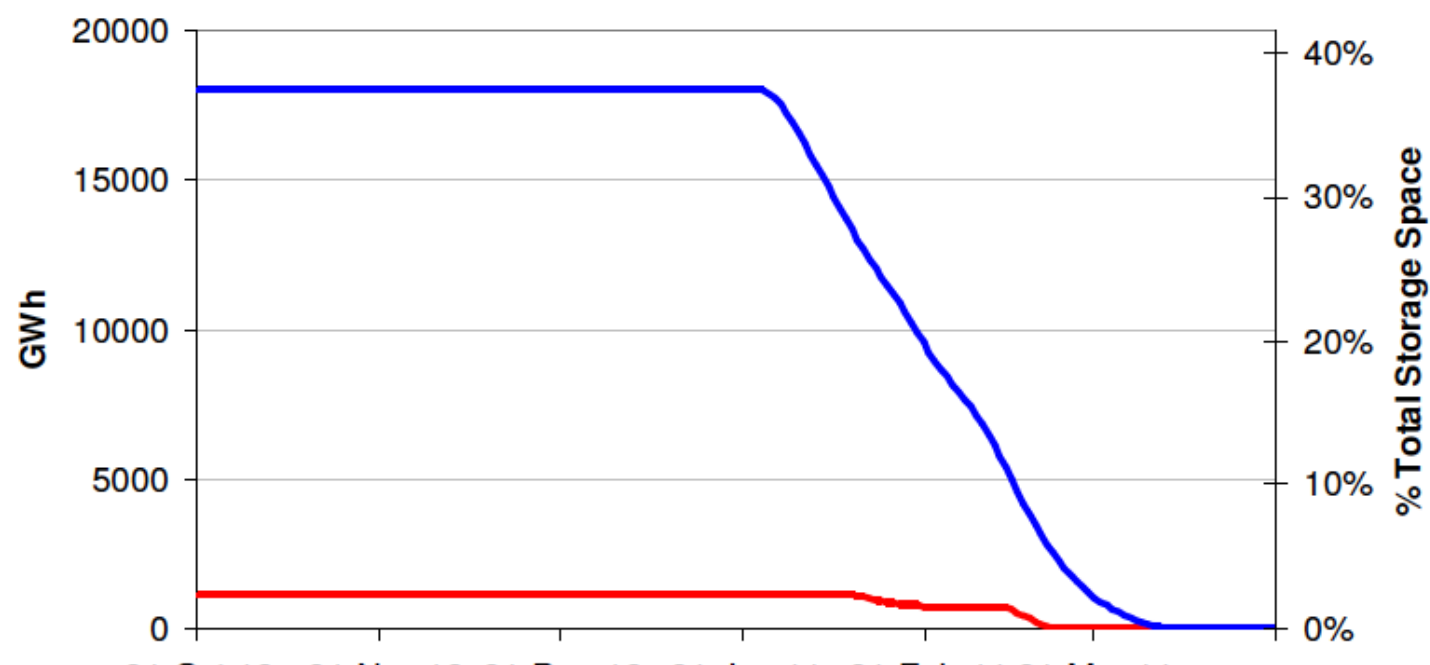

01-Oct-10 01-Nov-10 01-Dec-10 01-Jan-11 01-Feb-11 01-Mar-11

$$
\text { Space Safety Monitor } \longrightarrow \text { Space Firm Monitor }
$$

Source: National Grid: http://www.nationalgrid.com/NR/rdonlyres/EE344897-2842-4D20-8078-

872727637C02/43347/StorageMonitorsSeptember2010.pdf 


\subsubsection{The suppliers' view}

As explained above, gas suppliers also have security of supply licence obligations. Their view is normally articulated by the Gas Forum which commissioned a report from Poyry in $2010^{97}$. This concluded that the market had delivered the required additional capacity to date and that already planned storage projects would deal with all but the most extreme combination of demand and supply shocks.

The Gas Forum has maintained this position during the more recent SCR debate and in its response to the SCR consultation the Forum made the following comments with regard to strategic storage:

"The Forum believes it is right that the amount of storage in the GB market is driven by market requirements. It is possible to create "strategic storage" and to lock gas in storage sites, as practiced in a number of other Member States. However, such arrangements are costly, limit competition and impact trading. Indeed, Ofgem was keen to remove previous storage top-up arrangements, which are analogous to strategic storage, as it viewed them at the time as exposing customers to unjustifiable costs which outweighed any benefits which may have accrued. It should be noted that the recent cold weather has seen mid-range storage sites cycling significant volumes of gas, which have helped shippers, and the system, balance and contributed to market liquidity. Ofgem would have to be very clear that stopping or limiting such self balancing type activities would be efficient and economic ${ }^{98}$."

The Forum also points out that imposing additional obligations may create barriers to market entry as not all suppliers will have a credit rating sufficient to purchase storage capacity.

In a subsequent response to the Draft Policy Decision ${ }^{99}$ the Forum states its opposition to any form of PSO, which it views as only being appropriate in a poorly functioning market with limited access to storage. It points out that the GB market has delivered a number of independently owned storage facilities and PSOs run the risk of asset stranding and crowding out new investment.

\subsubsection{The storage operator's view}

In GB the collective view of SSOs is represented by the SBGI Storage Operator's Group (GSOG). Unsurprisingly the GSOG supports the view that GB Gas Storage capacity needs to be increased ${ }^{100}$ pointing out the disparity in storage provision between the UK and other European gas importing countries such as France and Germany. GSOG also states that regulatory and policy uncertainty is one of the major challenges facing the sector.

In terms of individual SSO views a number of reports have been commissioned to articulate the case for more gas storage. Examples include the Energy Contract Company's report for Portland Gas in 2008 (ECC, 2008) and Stag Energy, owners of the Gateway storage project, which published a synopsis of the need for additional gas storage in the $\mathrm{UK}^{101}$.

\footnotetext{
${ }^{97}$ Poyry, 2010

${ }^{98}$ Gas Forum 2011

${ }^{99}$ Gas Forum 2012

${ }^{100}$ See for example http://www.industrytoday.co.uk/energy_and_environment/uk-gas-storage-capacity-must-beincreased-/7554

101 The synopsis is available on the Stag Energy website http://www.stagenergy.com/images/stories/se/stagenergysynopsisofimplicationsfromagasstorageobligation.pdf
} 
Most recently Centrica Storage Ltd commissioned two reports on the issue. A review of the further interventions being considered by Ofgem undertaken by Frontier Economics (Frontier, 2012) and analysis by Eclipse Energy Group of the impact on future prices post 2020 under stressed demand and supply conditions (Eclipse, 2012).

The Frontier report makes it clear that it is not making the case for intervention to support either security of supply or mitigate the price impacts of security of gas supply issues. It is rather, an assessment of how best to intervene if policy makers decide they wish to do so. Frontier notes that there are a number of possible interventions to support storage ranging from market orientated approaches such as a storage obligation placed on suppliers through to fully regulated strategic storage, though all suffer from the fact they would impact on the gas storage market. On balance Frontier concludes that if a more interventionist approach was required a semi-regulated option would be preferred. This would take the form of market based storage receiving financial support, if for example, summer-winter price spreads fell below a certain level. This option was preferred as it was likely to guarantee new investment at the lowest cost to gas consumers and have the least impact on the wider gas market.

The Eclipse study is intended to provide a forecast of GB's "security of price" for the period 2020 to 2026. The study is based on a predicted tightening of the GB gas market as global LNG demand outpaces growth in LNG projects and Dutch and Norwegian supply is in decline. As a result under high demand conditions or supply disruptions GB is exposed to progressively higher peak prices. The impact of a $3 \mathrm{bcm}$ long range storage facility is then modelled against these scenarios and the resultant reduction in price spikes demonstrated.

\subsubsection{The independent view}

In addition to the reports and studies already mentioned a number of academic and other experts have examined the GB security of supply issue and the role of storage in recent years. Some examples of the conclusions drawn are presented here.

Stern (2010) has argued that the lack of storage provision in the GB gas market amounts to a case of market failure and large scale disconnections of customers have only been avoided by sheer luck ${ }^{102}$. However he also goes on to state that whilst the market has failed to deliver sufficient storage it has provided an abundance of pipeline and LNG import capacity and this, coupled with analysis of recent winters, could suggest the business case for new storage capacity has been undermined. With regard to strategic storage Stern notes that given the cost and lead times involved (at least 5 years), the fact that the import capacity that has been created could be seen as a form of such storage, and given continued disagreement as to how it might be used he doubts it would ever be built ${ }^{103}$.

Rogers (2011) has extensively modelled the impact of various supply scenarios on the GB gas market for differing levels of gas storage ${ }^{104}$. He has demonstrated that under a low storage scenario GB would increasingly rely on domestic production, Norwegian imports, LNG imports and on the ability of the IUK and BBL lines to operate without technical problems. There would also be a reliance on there being sufficient availability of seasonal storage in North West Continental Europe and the effective functioning of traded gas markets in the region to ensure the transmission of price signals attracting gas from that storage.

\footnotetext{
102 Page 129 onward

103 Ibid p 157

${ }^{104}$ Page 29 onward
} 
Rogers gives a number of examples of how the GB gas market has become increasingly impacted by unforeseen events, some occurring on the other side of the globe. He suggests that given supply uncertainty facing GB coupled with the increasing need for seasonal flexibility as domestic production continues to decline, Government policy should incorporate measures to facilitate the development of seasonal storage capacity of at least $10 \%$ of annual consumption in order to mitigate critical infrastructure failures of the type observed in the last decade.

Noel (2012) has concluded that the conventional political wisdom is that import dependency equates to supply insecurity and the perceived solution is that GB needs more storage. This has precipitated a requirement for Ofgem to deliver a storage obligation which seems to be strongly supported by ministers. His analysis of markets suggests that structural trends are helping GB's access to gas. These include:

- Oil indexation in European gas markets is disappearing and North-West Europe is becoming a traded market with hub based pricing;

- The NW European market is itself being integrated into the global market via the UK;

- The global resource base is expanding with additional LNG projects and the prospect of US exports.

Whilst this means increased supplies GB is exposed to international prices and price spikes are an inevitable consequence of this. Noel says it is then a decision for politicians as to whether price spikes should be mitigated and, if they so decide, they could ask Ofgem to explore the technical means of delivering solutions such as subsidising storage or introducing demand response. Whilst there may be a political case for insuring against price spikes this should not be allowed to translate into developing strategic storage as a means of emergency self sufficiency for GB.

\subsection{Summary and conclusions on storage in the GB gas market}

The role and value of gas storage in GB has undergone radical shifts as the market has evolved. Regulation played an important part in separating storage from transportation though more recently interventions have been largely confined to controlling dominant positions. As GB has become increasingly reliant on gas imports security of supply considerations have become increasingly prominent in government and regulatory pronouncements though to date intervention has not materialised - despite some strong lobbying. In order to understand the merits of the case for additional storage the following chapter examines in detail how GB storage operates today. 


\section{How storage operates today in the GB gas market}

\subsection{Overview}

Figure 5: Map of key GB gas infrastructure showing terminals and storage facilities

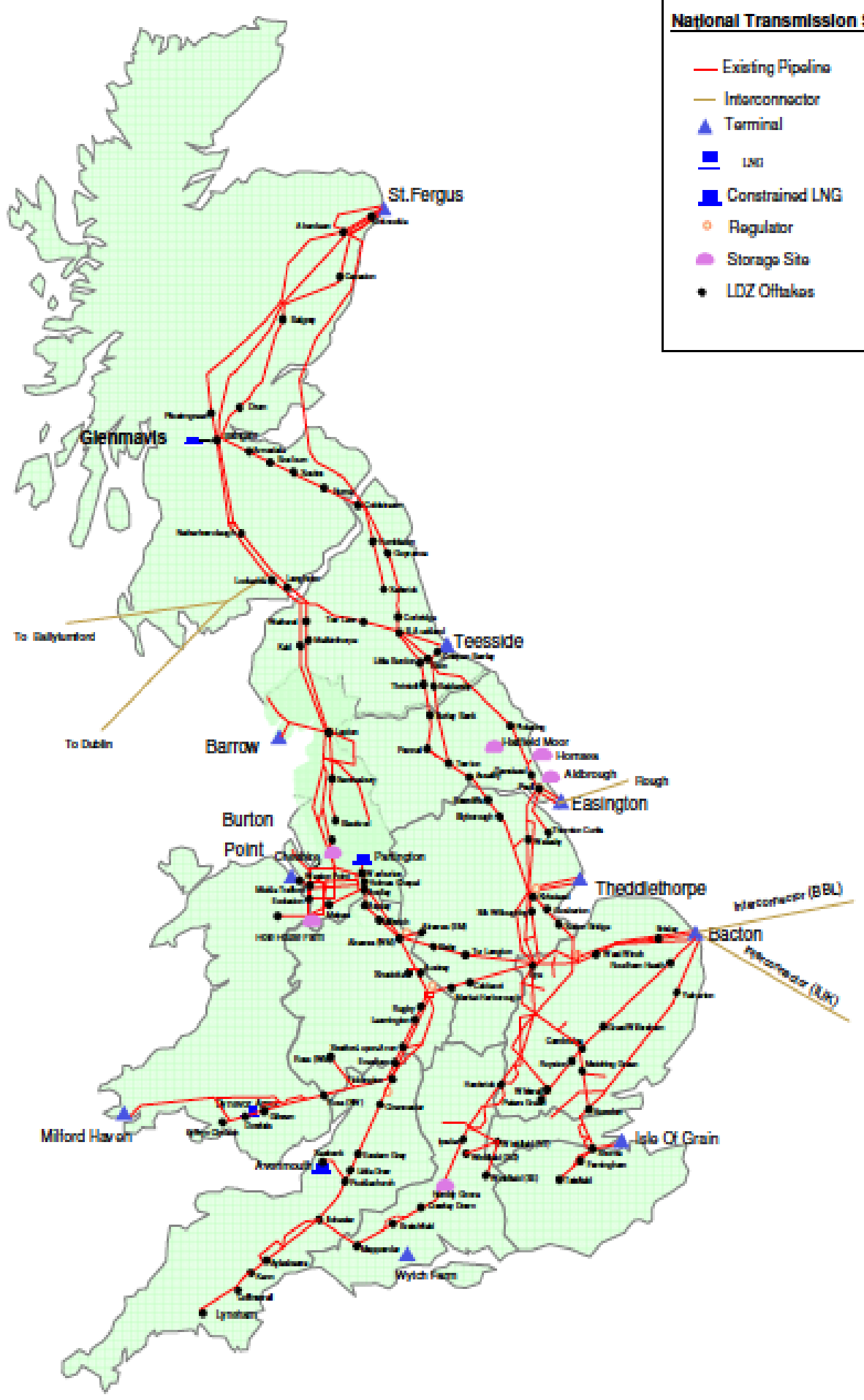

Source: National Grid 
The map in Figure 5 illustrates the key infrastructure components in GB including the location of import terminals, interconnectors and storage facilities. The preponderance of UKCS supplies in the North Sea led to a concentration of terminals on the east coast of Great Britain and the import pipelines and main gas storage facilities (Rough, Hornsea and Aldbrough) are similarly located. This situation changed radically with the completion of LNG import terminals in the Isle of Grain, Kent and at Milford Haven bringing major new

sources of supply into the West and South of the network. As a result the traditional north to south flow pattern in the network has been replaced by a much more diverse pattern with west to east and south to north flows emerging ${ }^{105}$. National Grid point out that as supply points are more evenly distributed overall system security has been enhanced though more active management of the system is required as there is much greater variability in flow patterns across the network from day to day.

The following sections describe how gas supplies in GB have evolved and the role played by storage and other sources of flexibility. The existing storage facilities are described and how they operate with reference to recent experience is also explained.

\subsubsection{The evolution of GB gas supplies}

Figure 6 illustrates the source and destination of UK gas supply by month over the period January 2000 to June 2012. The seasonality of demand is clearly apparent as is the diminishing contribution of UKCS production over the past decade. Imports exceeded UKCS supply for the first time during the winter of 2010/11 $1^{106}$. The decline in UKCS production was initially met by imports from Norway with contributions from BBL and, increasingly, LNG imports, in recent years. It is apparent that storage plays a key role in meeting seasonal demand peaks whilst imports from the Interconnector (IUK) have also played an important role on occasions. It is notable that IUK exports have continued to flow - even during the winter months - reflecting the important role of GB as a land bridge for gas imports to continental Europe.

\footnotetext{
105 See page 41 of National Grid, 2011

${ }^{106}$ National Grid, 2011 Figure 4.2A, Page 39
} 
Figure 6: UK Gas sources and destinations January 2000-June 2012

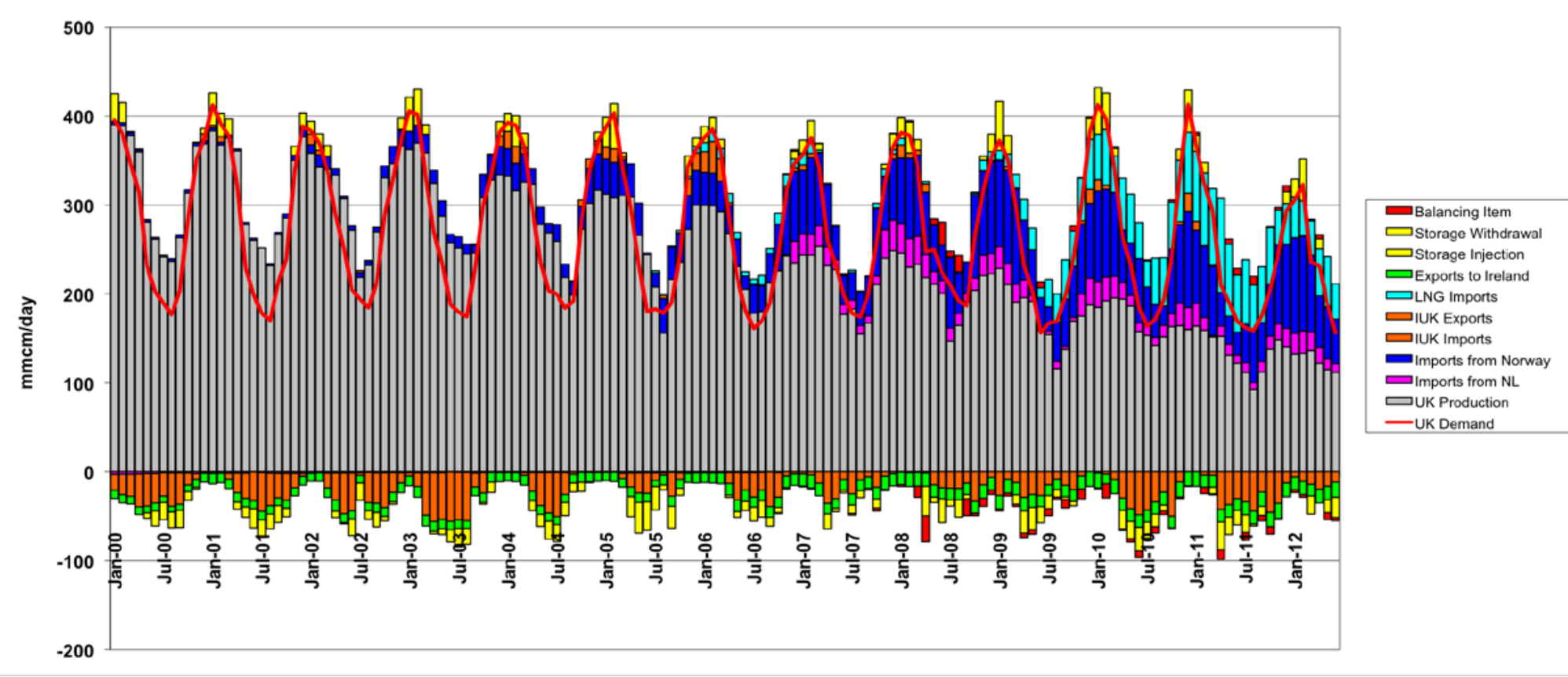

Source: Updated version of Figure 7, page 16 in Rogers, 2011

\subsubsection{Existing storage facilities}

Since 2000 a number of new storage facilities have come on stream (Humbly Grove, Hole House, Holford and most recently Aldbrough), but available storage capacity in GB has changed very little in recent years. Table 7 shows the existing GB storage facilities.

Table 7: Existing GB storage facilities

\begin{tabular}{|l|l|l|l|l|l|l|}
\hline Facility & Owner & Type & Location & $\begin{array}{l}\text { Working } \\
\text { Capacity } \\
\text { mcm }\end{array}$ & $\begin{array}{l}\text { Delivery } \\
\mathrm{mcm} / \mathrm{d}\end{array}$ & Cycles ${ }^{107}$ \\
\hline Rough & Centrica & Depleted field & $\begin{array}{l}\text { Offshore } \\
\text { Easington }\end{array}$ & 3,650 & 44 & 1.3 \\
\hline Hatfield Moor & Scottish Power & Depleted field & Yorkshire & 115 & 2 & \\
\hline Humbly Grove & Star Energy & Depleted field & Hampshire & 262 & 7 & 5.2 \\
\hline Hole House & EDF Trading & Salt Cavity & Cheshire & 44 & 8 & 8.3 \\
\hline Hornsea & SSE & Salt Cavity & Yorkshire & 270 & 18 & 18 \\
\hline Aldbrough & SSE/Statoil & Salt Cavity & Yorkshire & 192 & 20 & 38 \\
\hline Holford/Byley & E.On & Salt Cavity & Cheshire & 147 & 17 & 19.7 \\
\hline LNG Storage & National Grid & LNG & Avonmouth & 49 & 13 & 1.7 \\
\hline Total & & & & 4,727 & $129^{109}$ & \\
\hline
\end{tabular}

Source: National Grid Ten Year Statement, 2011 p 34 and Storage and LNG Operator Information as at October 2012 on http://www.nationalgrid.com/uk/Gas/Data/storage/ Columns may not sum due to rounding

${ }^{107}$ Calculated on the basis of days to inject full working volume plus days to withdraw divided into 350

108 Aldbrough is expected to reach full working capacity during 2012

109 This is "nameplate" capacity which can differ from proven performance. NG's latest assessment in the 2012/13 Winter Outlook is for an assumed total deliverability of $108 \mathrm{mcm} / \mathrm{d}$ and space of $\sim 4.7 \mathrm{bcm}$. 


\subsubsection{Recent winters in detail}

Each year NG produces a consultation document outlining its analysis and views of supply and demand for the coming winter together with a review of the previous winter. This section looks at the experience of recent winters and the role played by storage.

The key demand characteristics of the last four winters are summarised below:

- $\quad 2008 / 9$ - an average winter in terms of the last 81 years but the coldest winter since 1993. The winter was characterised by a number of cold spells but no one day was exceptionally cold.

- $\quad 2009 / 10$ - an average winter with a very cold spell from mid-December to mid-March with warm spells either side of this. The three months from December to February were the coldest since 1978/79.

- 2010/11 - an average winter in terms of the last 83 years. The weather in October and early November fluctuated around seasonal normal but then temperatures dropped towards the end of November resulting in the coldest day in November and the coldest December on record.

- $\quad 2011 / 12$ - mostly warm with only two weeks of significantly cold weather. Overall the winter was the second warmest after 2006/7 in the last 84 years. In addition power generation demand was lower than forecast due to the relative attractiveness of coal prices. There was also some suggestion of reduced residential demand due to higher prices.

The last four winters can be seen to give a reasonable range of cold weather demand patterns to which the supply system had to respond. The supply sources used to meet these demand requirements are shown in Table 8. This shows the actual contribution of each supply source over each of the last four winters (defined as the period October to March).

Table 8: Winter gas supply by source 2008/9 to 2011/12

\begin{tabular}{|l|l|l|l|l|l|l|l|l|}
\hline Source & \multicolumn{2}{l}{$2008 / 9$} & \multicolumn{2}{l|}{$2009 / 10$} & \multicolumn{2}{l|}{ 2010/11 } & \multicolumn{2}{l|}{ 2011/12 } \\
\hline & BCM & $\%$ & BCM & $\%$ & BCM & $\%$ & BCM & $\%$ \\
\hline UKCS & 33.3 & 55 & 28.0 & 44 & 23.9 & 39 & 21 & 39 \\
\hline Norway & 17.8 & 29 & 15.3 & 24 & 15.2 & 25 & 16 & 31 \\
\hline Continent & 4.6 & 8 & 6.1 & 10 & 5.3 & 9 & 4 & 8 \\
\hline LNG imports & 1.6 & 3 & 8.9 & 14 & 13.0 & 21 & 8 & 15 \\
\hline Storage & 3.9 & 6 & 4.7 & 7 & 4.1 & 7 & 3 & 6 \\
\hline Total & 61.1 & & 63.0 & & 61.5 & & 53 & \\
\hline
\end{tabular}

Source: National Grid Winter Consultations at http://www.nationalgrid.com/uk/Gas/TYS/outlook/

Table 8 shows that the make up of supply sources has changed significantly over even a relatively short period. UKCS production has continued to decline and the growing role of LNG imports is particularly notable.

Table 8 shows the aggregate picture over 6 months - to understand the precise dynamics it is necessary to see how each of the supply components performs on a day to day basis. This is shown in the graphs Figure 7 to Figure 9 for the last three winters (2009/10, 2010/11 and 2011/12). 
Figure 7: 2009/10 Supply Performance

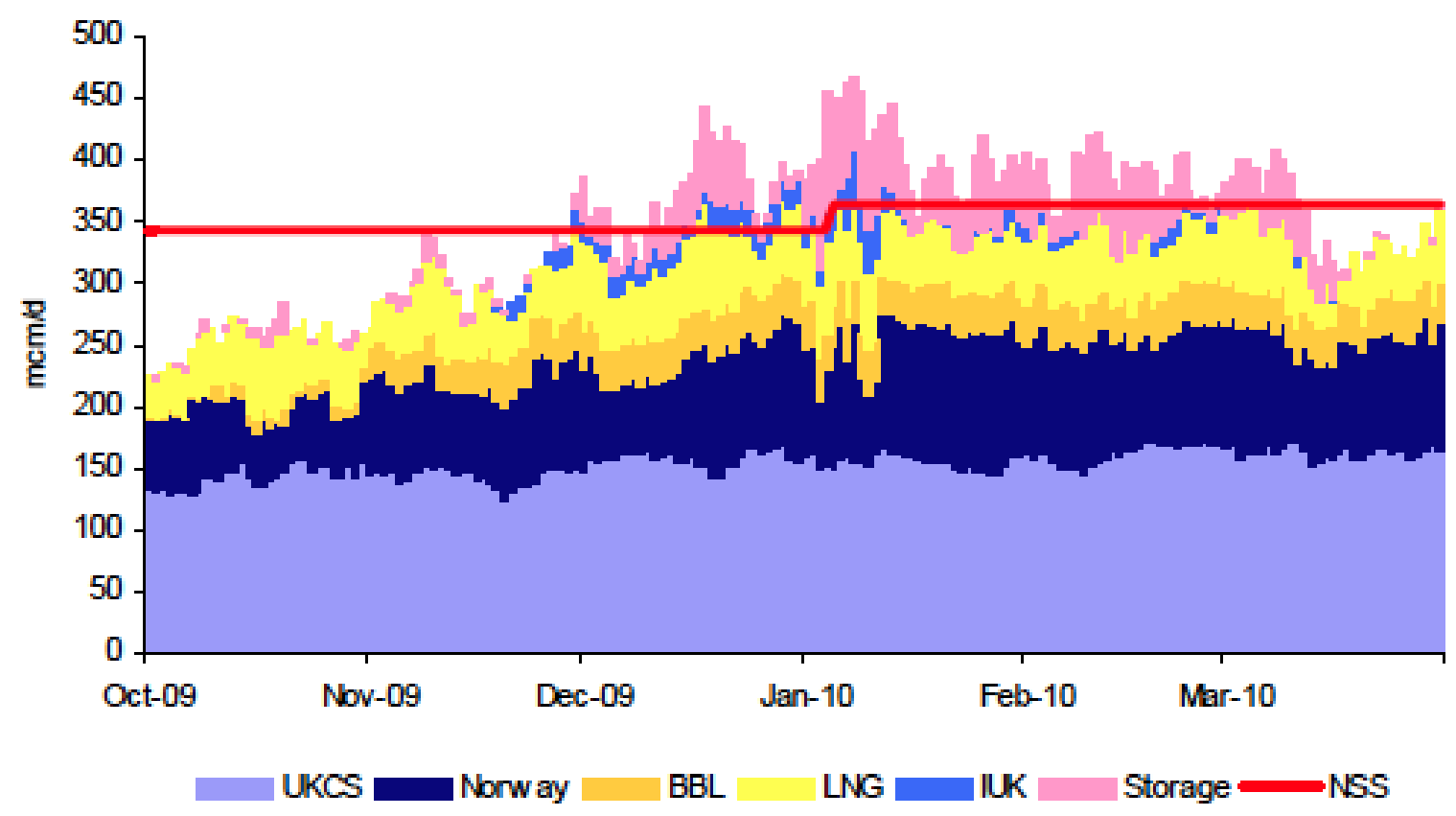

Source: National Grid Winter Consultation 2010/11

\section{Figure 8: 2010/11 Supply Performance}

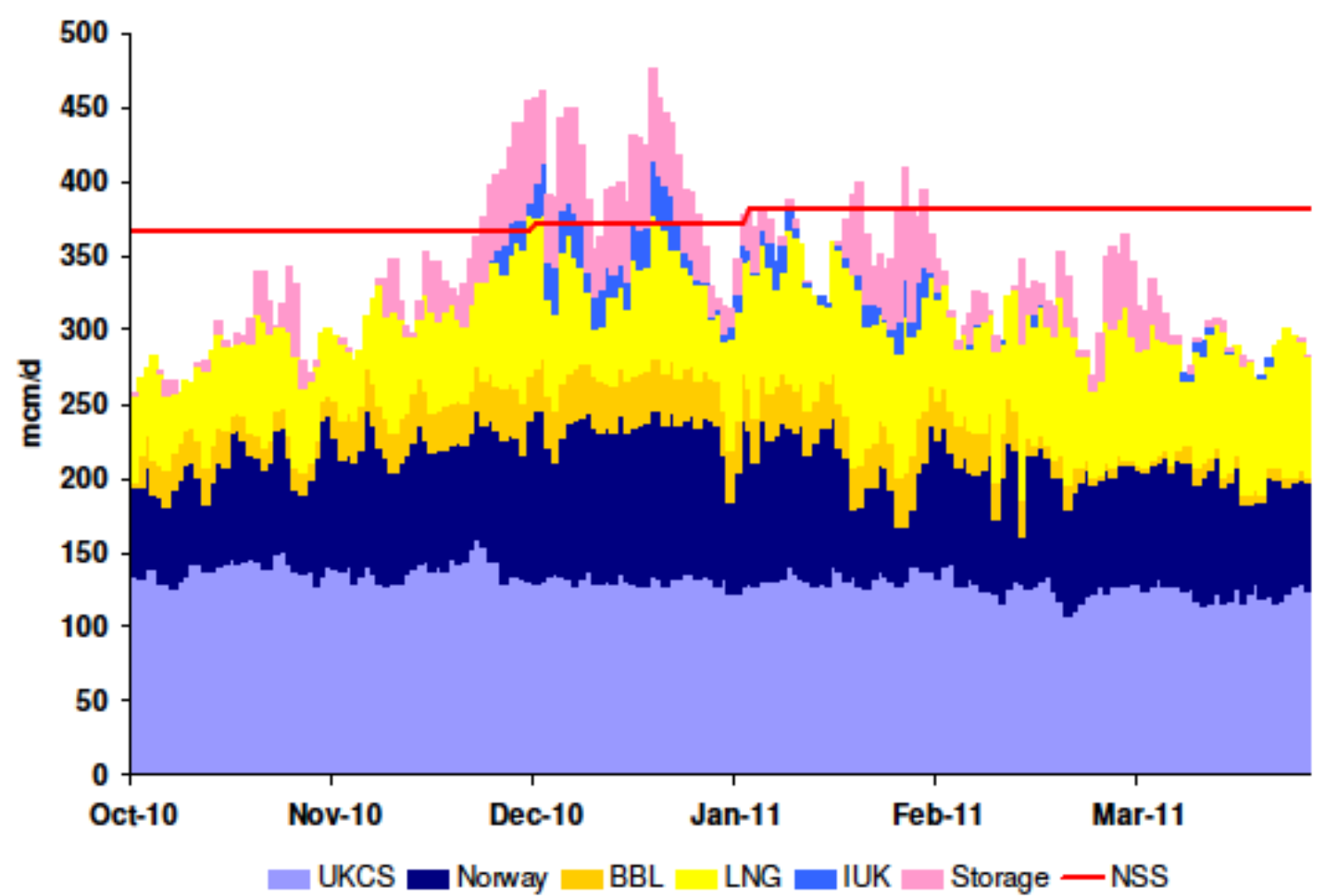

Source: National Grid Winter Consultation 2011/12 
In the supply performance graphs the red lines represent the level of non storage supply (NSS) used to calculate the gas balancing alert (GBA) trigger ${ }^{110}$. In the 2009/10 winter the increase in this level from $343 \mathrm{mcm} / \mathrm{d}$ to $363 \mathrm{mcm} / \mathrm{d}$ reflects the higher than expected flows that were being received from IUK and LNG imports. The 2010/11 increase in this level from $367 \mathrm{mcm} / \mathrm{d}$ to $372 \mathrm{mcm} / \mathrm{d}$ during the winter reflects the higher than forecast deliverability from LNG terminals.

The 2009/10 winter is of particular interest because of the events in early January $2010^{111}$. Cold weather led to a demand forecasts of $440 \mathrm{mcm} / \mathrm{d}$ and this coincided with a significant loss of supplies from Norway leading to a projected deficit at the end of the day of over 60 $\mathrm{mcm} / \mathrm{d}$. A within day GBA was declared because there had been a within day supply loss of $25 \mathrm{mcm} / \mathrm{d}$ or more and National Grid had a reasonable expectation that there would be an end of day imbalance between supply and demand. Supplies from LNG terminals and IUK increased. A further three GBAs were issued during the week. The impact of these events on storage use is described below.

\section{Figure 9: 2011/12 Supply Performance}

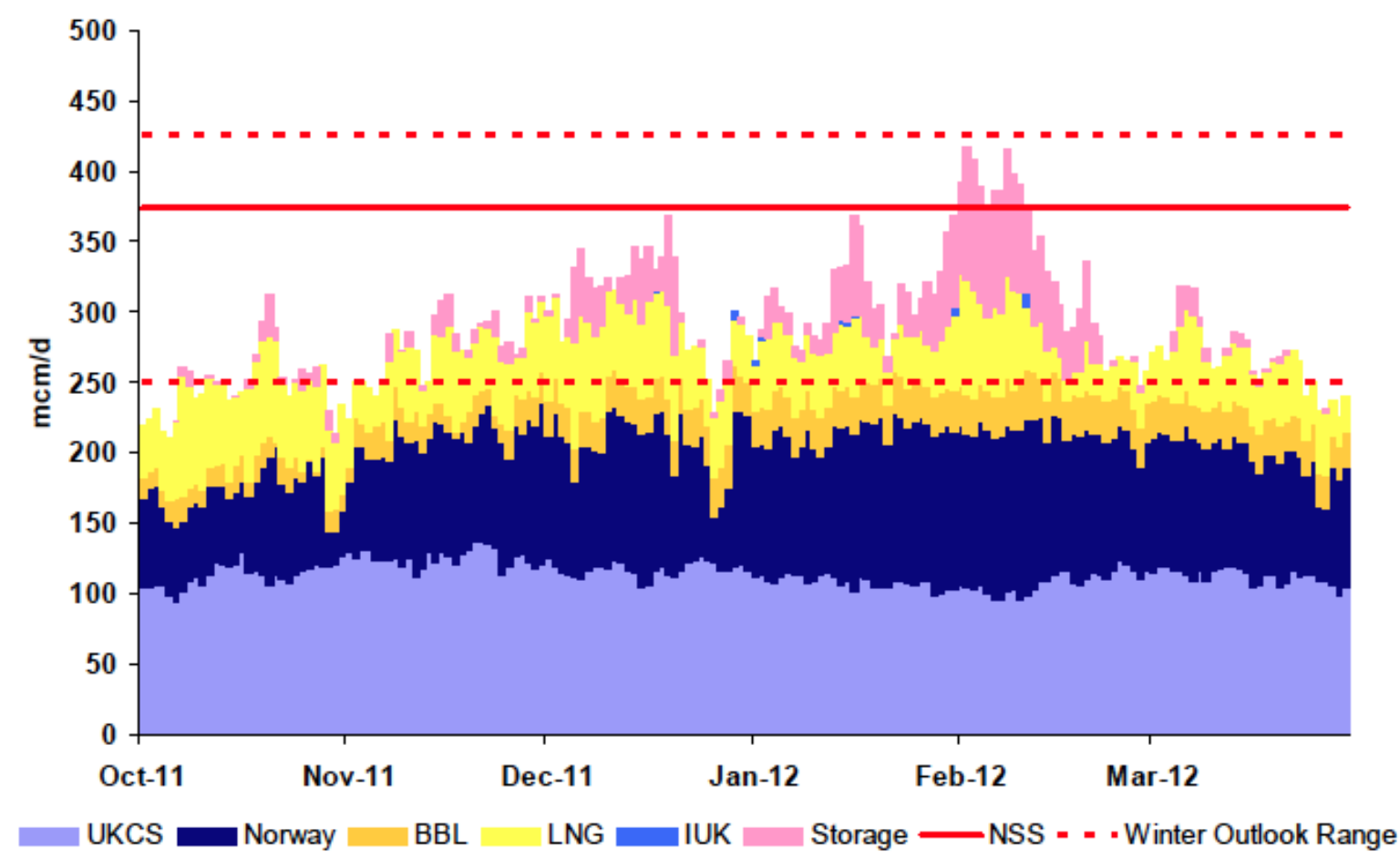

Source: National Grid Winter Consultation 2012/13

In Figure 9 in addition to the NSS supply level referred to above the dotted lines represent the range of possible non-storage supplies estimated by NG. Demand peaked during the cold spell in February 2012 which coincided with very cold weather throughout Europe and disruptions to supply from Russia.

${ }^{110}$ A GBA provides a signal to the market that demand-side reduction and/or additional supplies may be required to avoid the risk of entering into a Network Gas Supply Emergency. The trigger level will be based on the NSS plus all storage sites with 2 or more days of deliverability

111 See National Grid 2010a, p 31 
Looking across the last three winters a number of features can be observed:

- UKCS supplies vary slightly but not in response to demand - e.g. in February 2012 they appear to dip when demand peaks. This reflects the wide range of UKCS sources. Changes are most likely to be a result of individual field or facility shut downs.

- Norway is a key source of supply throughout the winter though there are noticeable occasions where supplies have fallen sharply. This reflects the critical role of the Langeled pipeline and the impact on supplies if this line or associated facilities are disrupted.

- The role of LNG imports is increased, though deliveries were lower in 2011/12 than the preceding year. LNG terminal send outs seem to be generally responsive to increased demands.

- Flows through BBL seem relatively constant whilst those through IUK vary significantly and only seem to play a role at higher levels of demand.

- $\quad$ As would be expected, storage plays a key role at the highest levels of demand though storage deliveries are also evident when demand is below the total NSS level. This suggests that suppliers will use storage withdrawals in preference to other supply sources when merited by the market conditions.

This somewhat subjective set of conclusions is confirmed by NG analysis of responsiveness to higher demands during the 2010/11 winter $^{112}$ :

- $\quad$ UKCS supply is generally not responsive;

- $\quad$ Norwegian imports respond but have been affected by supply losses;

- $\quad$ There is some response from BBL for demands between 360 and $400 \mathrm{mcm} / \mathrm{d}$;

- $\quad$ There is a noticeable response from storage, IUK and LNG terminals up to 400 $\mathrm{mcm} / \mathrm{d}$ and from IUK and LNG terminals above that level of demand;

- $\quad$ As noted below, storage is increasingly being used as part of a flexible supply base rather than just as the last source of supply.

NG has compared the supply mix in 2002/3 and 2010/11 for similar days of high demand this is illustrated in Table 9 which again shows major changes in the contribution of domestic and imported supplies. For the purposes of comparison NG's 2012/13 forecasts of supply required to meet demands above $400 \mathrm{mcm} / \mathrm{d}$ are included.

Table 9: GB Supply sources on days of very high demand

\begin{tabular}{|l|l|l|l|}
\hline Source $(\mathrm{mcm} / \mathrm{d})$ & $8 \mathrm{Jan} 2003$ & 21 December 2010 & $2012 / 13$ forecasts \\
\hline UKCS & 341 & 132 & 124 \\
\hline Norway & 19 & 113 & 105 \\
\hline Continent & 13 & 66 & 50 \\
\hline LNG imports & 0 & 94 & 80 \\
\hline Storage & 79 & 50 & 80 \\
\hline Total & 450 & 456 & 439 \\
\hline
\end{tabular}

Source: National Grid Winter Consultation, 2011 and Winter Outlook, 2012/13

NG also provided analysis of how storage is used during the winter. This is contained in the graphs showing withdrawals and injections during three winters 2009/10 (Figure 10), 2010/11 (Figure 12) and 2011/12 (During the 2011/12 winter demand and storage withdrawals were generally below average. It can be seen that there were many days on

${ }^{112}$ National Grid 2011a, p 29 
which both withdrawal and injection occurred. Over the winter period MRS withdrawals were $1.3 \mathrm{bcm}$ whilst $1.0 \mathrm{bcm}$ was injected. NG notes that the trend for storage to withdraw and inject during the same day made demand forecasting increasingly challenging. This trend was expected to continue as more fast-fill storage sites were commissioned. LNG storage was little used throughout the winter. However, because GB gas and electricity prices were below those on the Continent both the gas interconnector (IUK) and the electricity interconnector (IFA) were in export mode at the time of the highest winter demand. This led to higher utilisation of GB storage, notably from medium range storage and Rough though also from LNG storage, at the end of the February cold spell and GB storage was in effect supporting demand on the Continent.

Figure 10: Storage withdrawals, winter 2009/10

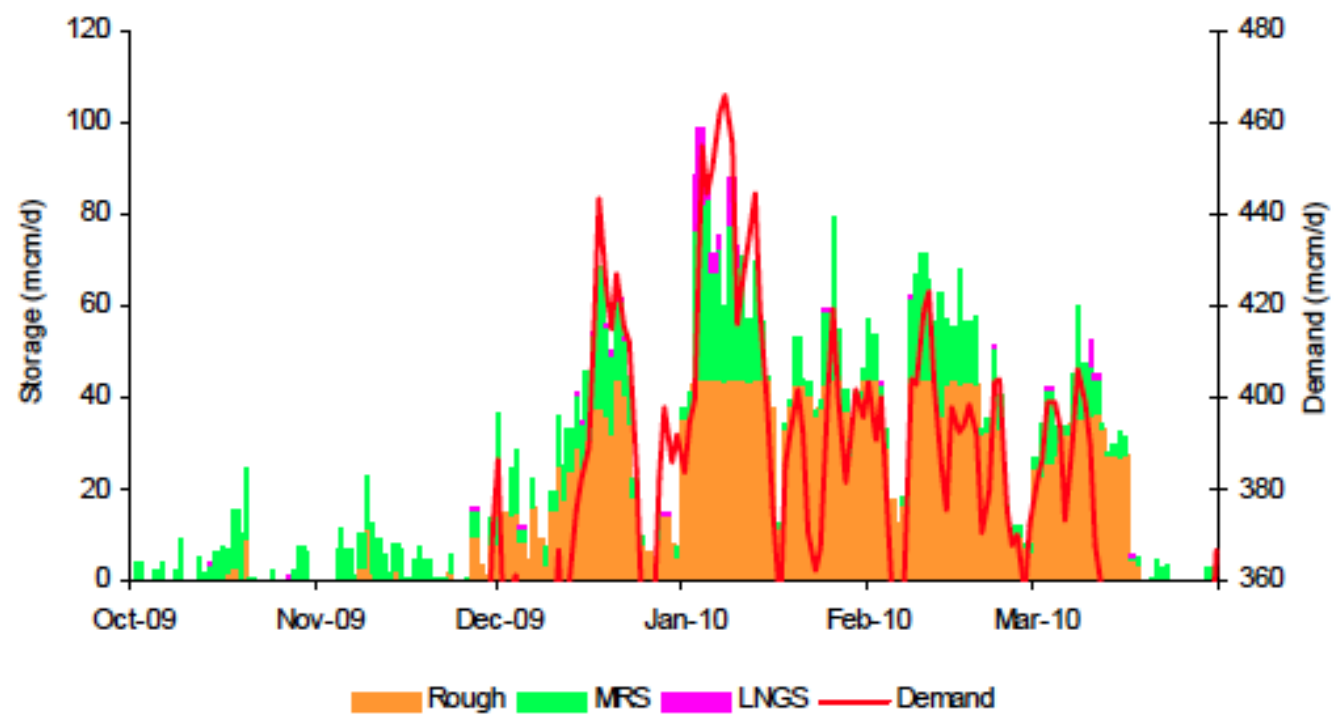

Source: National Grid Winter Consultation 2010/11

Figure 10 shows the extensive use of storage after mid December which included considerable 'cycling' within the winter in some facilities as a result of the supply difficulties in early January described above. NG reports that in aggregate total storage use was $4.7 \mathrm{bcm}$, including $3.3 \mathrm{bcm}$ from Rough (93\% of pre-winter stock), $1.3 \mathrm{bcm}$ from MRS (145\% of prewinter stock of $917 \mathrm{mcm}$ ) and $0.07 \mathrm{bcm}$ (40\% of pre-winter stock) from LNG storage. The cycling impact can be seen from Figure 11 which shows the decay of storage stocks over the winter. NG point out that the chart does not show that some storage facilities were nearly completely depleted at times of high withdrawal and were subsequently refilled within the winter $^{113}$.

${ }^{113}$ National Grid, 2010a, page 30 
Figure 11: 2009/10 Storage stocks

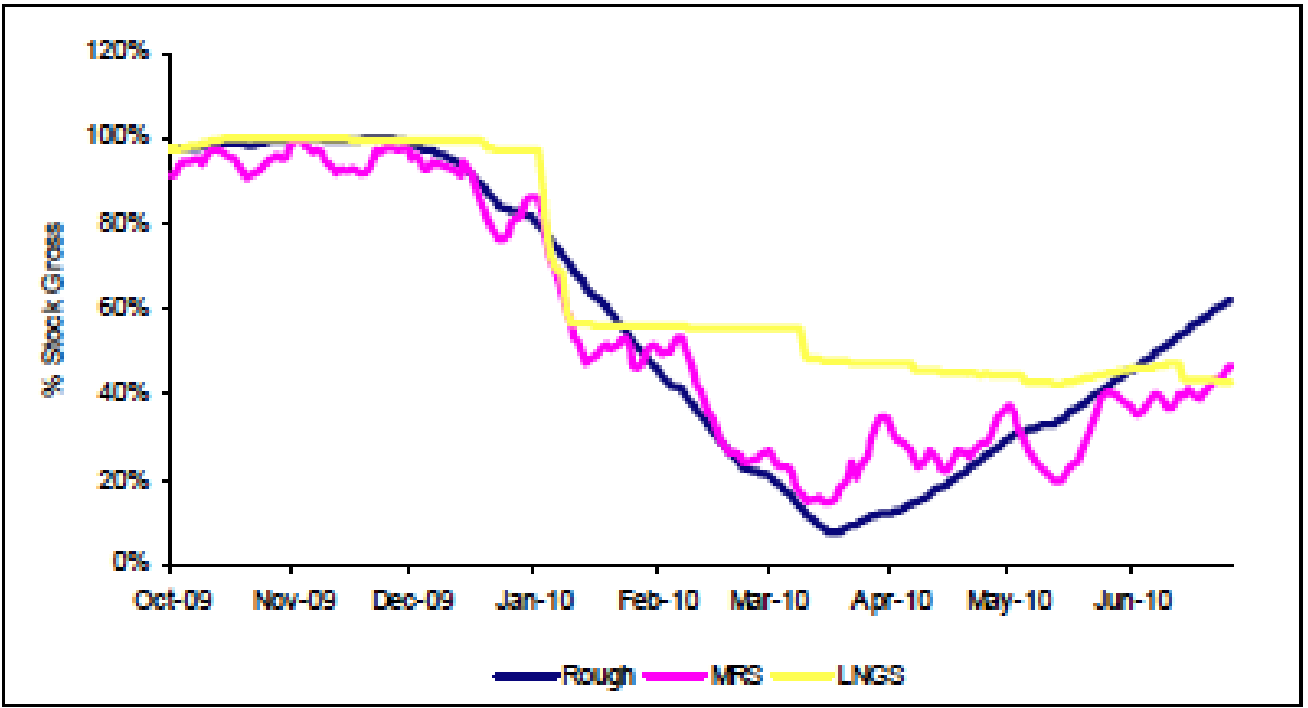

Source: National Grid Winter Consultation 2010/11

\section{Figure 12: Storage withdrawals, winter 2010/11}

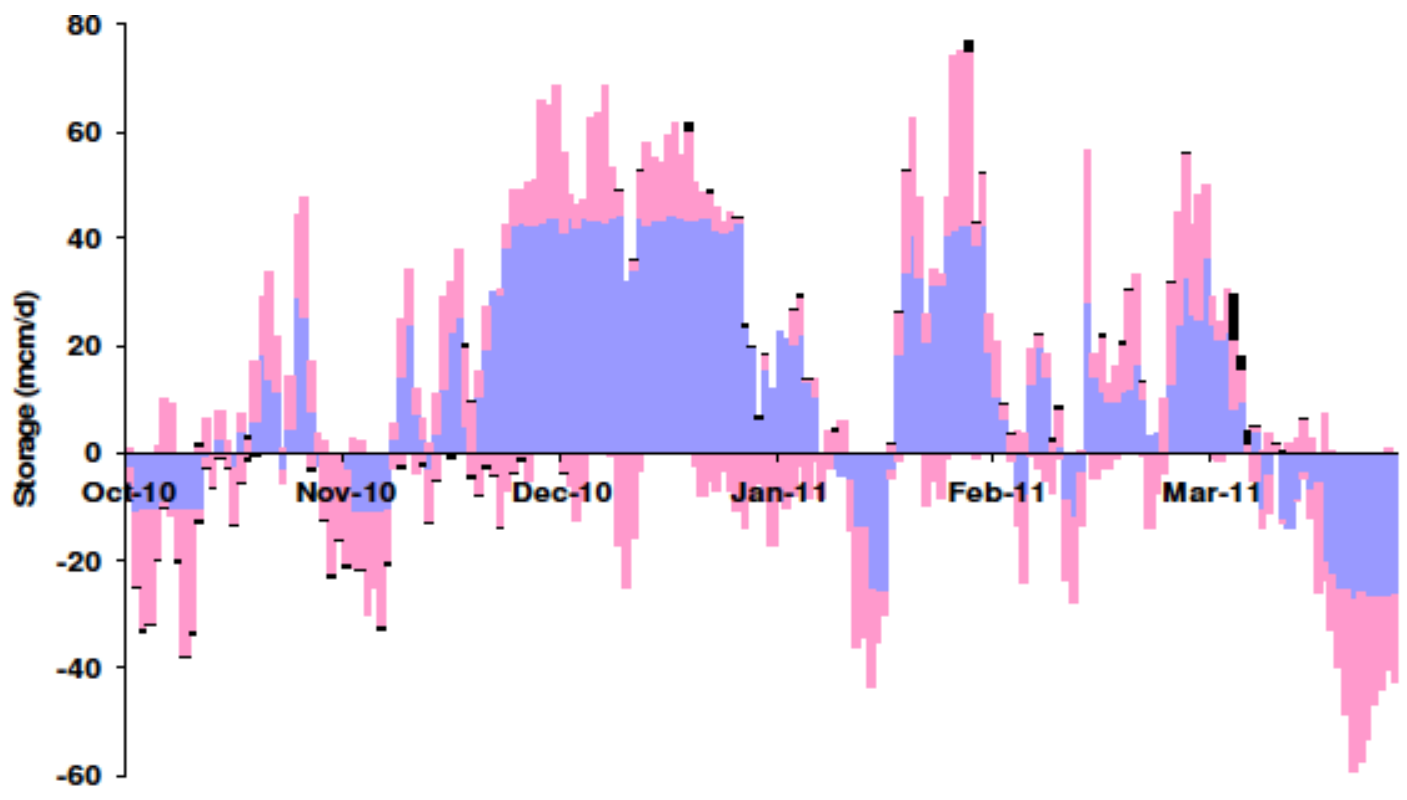

nough $\square$ MRS $\boldsymbol{\square}$ LNGS

Source: National Grid Winter Consultation 2011/12

In 2010/11 high demands during November and December led to a high level of withdrawals and storage stocks fell throughout this period. By late December total stock levels were at $50 \%$ with over $2 / 3$ rds of the winter still to run. At the same time LNG importation terminal stocks also reached their lowest levels at below $300 \mathrm{mcm}$. This represented $25 \%$ of available tank space or about 3 days of supply. Milder weather in January then allowed some storage injection (including at Rough) and the rate of stock decline decreased. It is likely that if the high levels of demand had continued beyond December storage stocks would almost certainly have been effectively depleted before the end of the winter requiring some form of intervention from NG. However it should be noted that NG points out that during the cold 
weather period storage was not operating as the last source of supply but as part of a flexible supply base. This, NG states, reflects market confidence in the UK's supply diversity.

During the 2011/12 winter demand and storage withdrawals were generally below average. It can be seen that there were many days on which both withdrawal and injection occurred. Over the winter period MRS withdrawals were $1.3 \mathrm{bcm}$ whilst $1.0 \mathrm{bcm}$ was injected. NG notes that the trend for storage to withdraw and inject during the same day made demand forecasting increasingly challenging. This trend was expected to continue as more fast-fill storage sites were commissioned. LNG storage was little used throughout the winter. However, because GB gas and electricity prices were below those on the Continent both the gas interconnector (IUK) and the electricity interconnector (IFA) were in export mode at the time of the highest winter demand. This led to higher utilisation of GB storage, notably from medium range storage and Rough though also from LNG storage, at the end of the February cold spell and GB storage was in effect supporting demand on the Continent.

\section{Figure 13: Storage withdrawals, winter 2011/12}

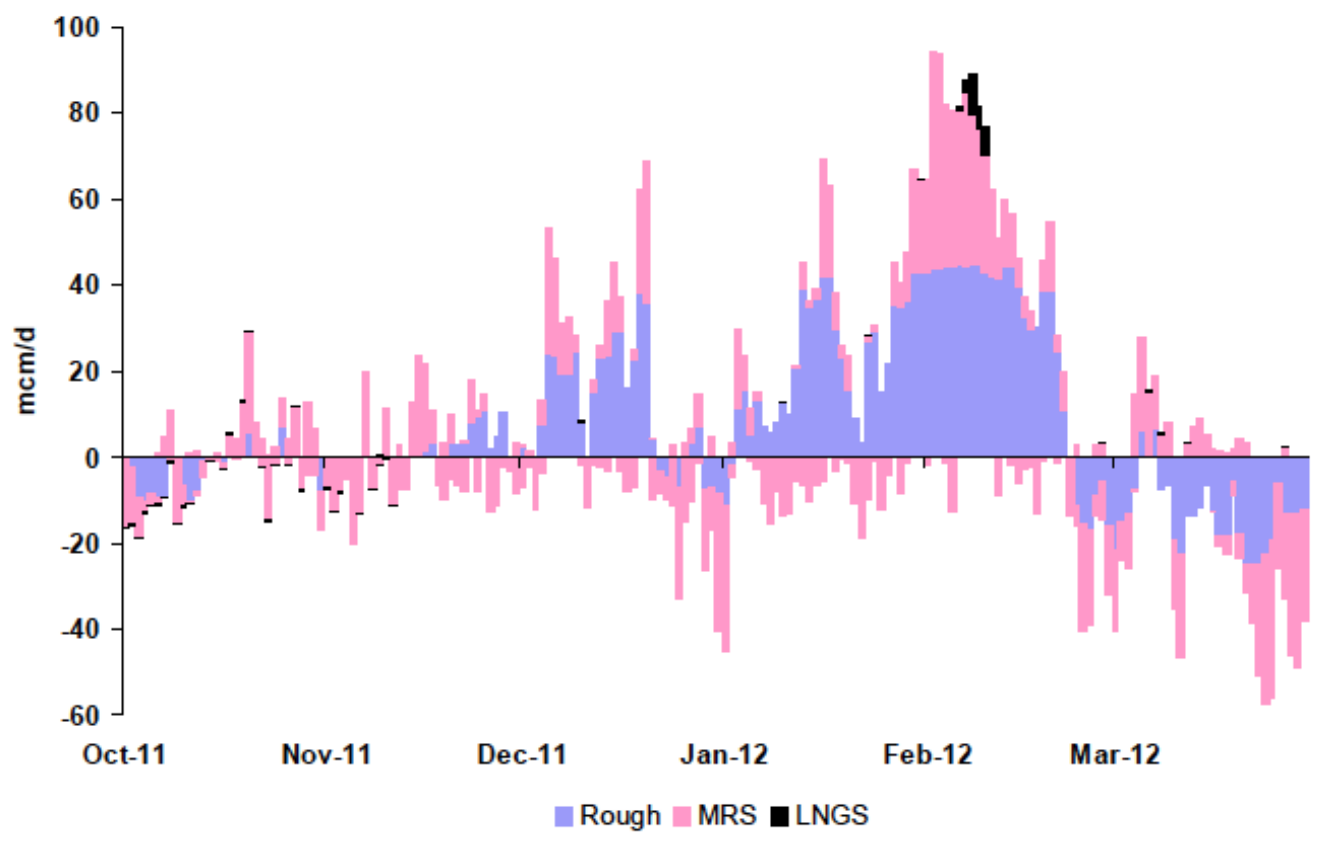

Source: National Grid Winter Consultation 2012/13

The last three winters have therefore seen a wide range of demand and supply conditions. There have been extreme weather events and major disruptions to supply, though these have not resulted in any significant disruption to gas supplies to end consumers. The GB system has had to become increasingly flexible and responsive - a challenge that to date it seems to be meeting.

\subsubsection{Supply disruptions}

Table 10 highlights the main disruptions to GB gas supply since 2000. 
Table 10: Major disruptions to GB gas supply since 2000

\begin{tabular}{|l|l|l|}
\hline Description & Date & Impact \\
\hline $\begin{array}{l}\text { Fire on the Rough } \\
\text { platform resulting in an } \\
\text { unplanned outage for } \\
\text { over 4 months }\end{array}$ & $\begin{array}{l}\text { February } \\
2006\end{array}$ & $\begin{array}{l}\text { Prices peaked at around 70p/therm though went to } \\
\text { 259p/therm during March 2006 when there was a } \\
\text { cold snap and a Gas Balancing Alert was issued. } \\
\text { This resulted in significant demand side } \\
\text { response }\end{array}$ \\
\hline $\begin{array}{l}\text { CATS pipeline shut for } \\
\text { 64 days following } \\
\text { damage by ship's } \\
\text { anchor }\end{array}$ & $\begin{array}{l}\text { July } \\
2007\end{array}$ & $\begin{array}{l}\text { No impact on supplies as occurred during a period } \\
\text { of low demand - significant impact on price } \\
\text { levels and volatility as prices were low at the } \\
\text { time }\end{array}$ \\
\hline $\begin{array}{l}\text { Fire at the Shell Bacton } \\
\text { sub-terminal }\end{array}$ & $\begin{array}{l}\text { February } \\
2008\end{array}$ & $\begin{array}{l}\text { Immediate loss of supply of around 30 mcm/d } \\
\text { leading to an increase in prices of around } 25 \% \\
\text { within day and 10\% thereafter. Supplies were } \\
\text { restored within 4 days }\end{array}$ \\
\hline $\begin{array}{l}\text { Russia/Ukraine crisis } \\
\text { disrupted supplies to } \\
\text { continental Europe }\end{array}$ & $\begin{array}{l}\text { January } \\
2009\end{array}$ & $\begin{array}{l}\text { No impact on GB supplies or prices though did } \\
\text { lead to an increase in exports to the continent }\end{array}$ \\
\hline $\begin{array}{l}\text { Norwegian supply } \\
\text { interruptions during a } \\
\text { period of high demand } \\
\text { and continental Europe }\end{array}$ & $\begin{array}{l}\text { January } \\
2010\end{array}$ & $\begin{array}{l}\text { Significant supply losses led to a series of Gas } \\
\text { Balancing Alerts being called. One NTS } \\
\text { consumer was interrupted and within day prices } \\
\text { peaked at 64 p/therm and end of day at below 50 } \\
\text { p/therm compared to an average NBP price for the } \\
\text { winter of 31 p/therm }{ }^{120}\end{array}$ \\
\hline $\begin{array}{l}\text { Source: See footnotes } \\
\text { No physical restrictions on supplies though NBP } \\
\text { prices rose sharply from around 55-60 p/therm to } \\
\sim £ 1 / \text { therm in line with other European hubs }\end{array}$ \\
\hline 2012
\end{tabular}

Source: See footnotes

Table 10 shows that there have been a number of disruptions ranging from localised facility outages to wider events that have impacted on gas markets throughout Europe. The main

\footnotetext{
${ }^{114}$ A description of the damage caused by the fire was provided by Centrica Storage and this is at http://www.centrica-sl.co.uk/files/pressrelease/240406_InterimRecoveryReport.pdf

${ }^{115}$ See Ofgem 2006

116 http://www.upstreamonline.com/incoming/article137258.ece

117 National Grid: 2007 Page 13

${ }^{118}$ National Grid 2008, page 27

119 Pirani et al, 2009

${ }^{120}$ National Grid 2010a, p 31 and page 42 of this report

${ }^{121}$ Henderson and Heather, 2012, page 7
} 
impact of these disruptions has been on price and whilst the effect of this on end users should not be discounted there has been minimal interruption to physical supplies.

From a storage perspective the most serious incident was the fire at the Rough offshore facility in 2006 which removed over $80 \%$ of GB's working volumes during part of the winter period. Analysis by Giuletti et al (2010) ${ }^{122}$ shows that supplies responded to price impacts and there was no "non-price rationing". The price impact was, however, significant and the authors suggest the additional charge on consumers was around $£ 250 \mathrm{~m}$ as a result of Rough being out of action.

\subsection{GB storage value and profitability}

This section examines the commercial basis for storage investments in the GB market.

\subsubsection{Theoretical models}

The economic value of gas storage facilities in liberalised markets comprises both intrinsic and extrinsic elements. Intrinsic valuation can be simply derived in the basis of seasonal spreads though as described earlier extrinsic calculations are more complex and have the tendency to result in over-valuations.

In order to understand the impact of the key cost and revenue drivers behind intrinsic value a simple cash flow model has been developed by the author. This is aimed at providing profitability indicators for different types of storage before tax and financing. It can be used to test for the sensitivity to key parameters such as seasonal spreads and the cost/level of cushion gas. Two types of storage have been assessed - salt cavern and depleted field - for an assumed working capacity of $500 \mathrm{mcm}$. Whilst this working capacity is smaller than most depleted field projects it enables a common basis for comparison. Standard capital cost metrics (excluding cushion gas) have been used to reflect the lower unit capital cost of depleted fields and the key input parameters are shown in Table 11.

Table 11: Key assumptions for economic evaluation

\begin{tabular}{|c|c|c|c|c|}
\hline $\begin{array}{l}\text { Storage } \\
\text { Facility }\end{array}$ & $\begin{array}{l}\text { Capital cost for } \\
500 \mathrm{mcm} \\
\text { working } \\
\text { capacity }\end{array}$ & $\begin{array}{l}\text { Cushion } \\
\text { gas/working } \\
\text { volume }\end{array}$ & $\begin{array}{l}\text { Churn } \\
\text { rate }^{123}\end{array}$ & Other assumptions \\
\hline $\begin{array}{l}\text { Seasonal - } \\
\text { Depleted field }\end{array}$ & $£ 200-400 \mathrm{~m}$ & $100 \%$ & 1 & \multirow{2}{*}{$\begin{array}{l}\text { Variable opex of 0.8p/therm, } \\
\text { plus annual fixed opex of } \\
£ 5 \mathrm{~m} \text {. Depleted field includes } \\
£ 40 \mathrm{~m} \text { abandonment cost }\end{array}$} \\
\hline $\begin{array}{l}\text { Fast Cycle- } \\
\text { Salt Cavern }\end{array}$ & $£ 300-600 \mathrm{~m}$ & $50 \%$ & 1.2 & \\
\hline
\end{tabular}

Source: Industry publications and author's estimates

\footnotetext{
122 Page 129

123 This is intended to reflect the likely higher cycling of salt cavity storage and could be taken as a proxy for the extrinsic value element.
} 
The assumptions have been used to determine indicative net present values (NPV) and internal rates of return to test the sensitivity to the following variables:

- $\quad$ Seasonal spreads - this generates the revenue line as it is assumed that annual revenue is derived from working volume times the seasonal spread times the churn rate, ${ }^{124}$

- $\quad$ Gas price - this determines the cost of cushion gas and is assumed to be independent of seasonal spreads,

- $\quad$ Capital cost - existing and planned project cost information has been analysed where available to develop upper and lower estimates of capital cost per unit of working volume.

The results of the analysis are shown in Table 12. The table shows the pre-tax NPV at a discount rate of $5 \%$ in $£$ million for the base case and for the sensitivities.

Table 12: Economic evaluation of storage - NPV at 5\% discount rate in $\mathrm{Em}$

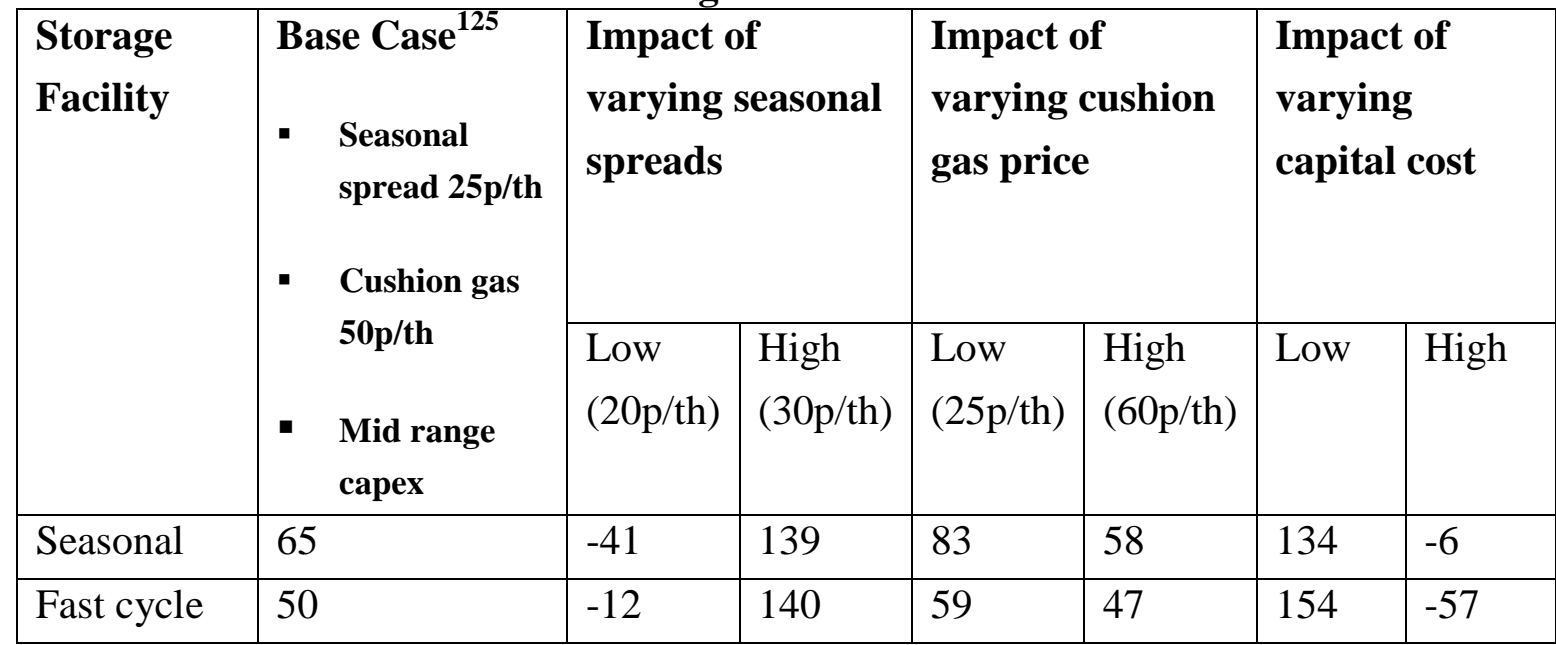

Source: Author's analysis

The results in terms of IRR are shown in Figure 14

Figure 14: Variation in internal rate of return by spread

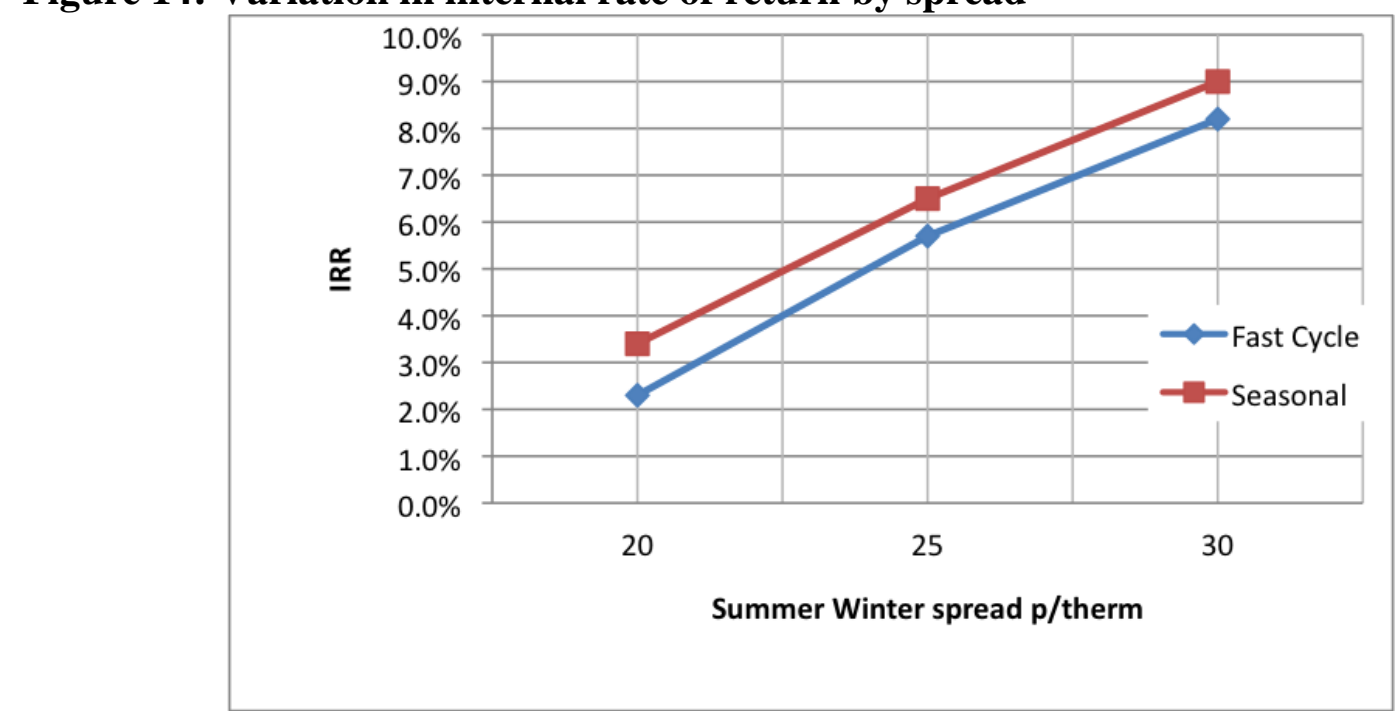

Source: Author's analysis

\footnotetext{
${ }^{124}$ Whilst in practice the full working volume may not be utilised it is assumed that all of the capacity is sold.

125 Seasonal spread 25p/therm, Cushion gas cost 50p/therm and mid range capex
} 
The following conclusions can be drawn from the analysis:

- Under base case assumptions depleted field storage is marginally more profitable than salt cavern storage - this reflects the lower unit capital cost of depleted fields outweighing the benefits of lower cushion gas requirements and faster cycling from salt cavity storage. The "gap" starts to close at seasonal spreads of around 30p/therm. Furthermore the analysis used a relatively conservative churn of 1.2 to reflect the impact of faster cycling. Increasing this rate to 1.25 improves the NPV of fast cycle caverns to $£ 69 \mathrm{~m}$ with an IRR of $6.2 \%$ compared to base case numbers of £50m and $5.7 \%$ respectively.

- As would be expected, profitability is very sensitive to the assumed level of seasonal spreads, and breakeven spreads at a 5\% discount rate are around 22p/therm for depleted fields and $24 \mathrm{p} /$ therm for salt caverns.

- Seasonal storage is more sensitive to the cost of cushion gas in line with the higher cushion gas requirements for this type of storage.

- Both types of facilities are sensitive to capital cost and at the higher range of present estimates neither type of storage is profitable at the base case spread of 25p/therm.

There is an important caveat to the slightly better profitability of depleted storage facilities demonstrated by the analysis. The results were based on a notional working volume of 500 $\mathrm{mcm}$ in order to provide a basis for comparison. Whilst this is a realistic number for salt cavity schemes in GB the depleted field projects are for much larger working volumes of 1.7 bcm in the case of Baird and 4.5 for the Deborah project ${ }^{126}$. New projects of this size are likely to exert significant downward pressure on both spreads and volatility so the higher potential profitability of large seasonal storage investments may, in reality, be unattainable.

How do these results compare with other studies? Rogers (2011) in his analysis of the results from an Oxera study (Oxera, 2010) concludes that:

- Onshore salt cavern storage schemes have more robust economics compared with offshore seasonal projects.

- All projects benefit from higher levels of daily price volatility.

- At a seasonal spread level of 10 pence per therm all projects require daily price volatility above $100 \%$ in order to be economically attractive.

Some recent analysis by Timera ${ }^{127}$ of the economics of depleted fields calculates a breakeven spread of $16 \mathrm{p} /$ therm. This is based on capital and operating cost estimates slightly below the range used in the analysis above and a $20 \%$ uplift in revenues (i.e. equivalent to a churn of 1.2 used in this analysis) to account for extrinsic value.

Discussions with storage operators suggest that the spread required to achieve an acceptable return would be above 20p/therm though it might be slightly below this for some onshore fast cycle plant.

Finally a Frontier Economics ${ }^{128}$ report on modelling by Centrica Storage suggests that for an investment the size of Baird to deliver an IRR of $8.5 \%$ (nominal) would require a guaranteed spread of $16.4 \mathrm{p} /$ therm.

\footnotetext{
126 See Table 16

127 See http://www.timera-energy.com/uk-gas/the-challenges-of-investing-in-gas-storage/

${ }^{128}$ Frontier 2012, p 52
} 


\subsubsection{Revealed valuations}

There have been a number of transactions involving storage assets in GB over recent years. These are summarised in the Table 13which includes values where these have been reported.

Table 13: Transactions involving storage facilities in Great Britain

\begin{tabular}{|c|c|c|c|c|c|c|}
\hline Asset & Date & Buyer & Seller & $\begin{array}{l}\text { Conside } \\
\text { ration } \\
\text { Em }\end{array}$ & $\begin{array}{l}\text { Volume } \\
\text { mcm }\end{array}$ & Comments \\
\hline Hornsea & Sept 2002 & SSE & Dynegy & 129 & 320 & $\begin{array}{l}\text { Included cushion gas and option on } \\
\text { Aldbrough }\end{array}$ \\
\hline Hole House & Oct 2002 & $\mathrm{EdF}$ & Utilicorp & 22 & 75 & Not developed at time of sale \\
\hline $\begin{array}{l}\text { Aldbrough } \\
\text { South }\end{array}$ & Dec 2002 & Statoil & Intergen & - & $170-230$ & $\begin{array}{l}\text { Not developed at time of sale - buyer } \\
\text { Statoil already had position in the } \\
\text { area }\end{array}$ \\
\hline Rough & Dec 2002 & British Gas & Dynegy & 304 & 2776 & $\begin{array}{l}\text { Included } 5.3 \mathrm{Bcm} \text { (1.8 Billion } \\
\text { therms) of cushion gas. }\end{array}$ \\
\hline Byley & May 2005 & E.On & $\begin{array}{l}\text { Scottish } \\
\text { Power }\end{array}$ & 96 & 165 & $\begin{array}{l}\text { Not developed at time of sale and } \\
\text { transaction value is estimated. It was } \\
\text { also estimated that a further } £ 100 \mathrm{~m} \\
\text { expenditure was required }\end{array}$ \\
\hline Hatfield Moor & $\begin{array}{l}\text { Dec } \\
2006\end{array}$ & $\begin{array}{l}\text { Scottish } \\
\text { Power }\end{array}$ & $\begin{array}{l}\text { Edinburgh Oil } \\
\text { \& Gas }\end{array}$ & 11 & 115 & $\begin{array}{l}\text { Depleted field so included cushion } \\
\text { gas. Seller looking to concentrate on } \\
\text { exploration }\end{array}$ \\
\hline Star Energy & $\begin{array}{l}\text { Dec } \\
2007\end{array}$ & Petronas & Star & 354 & 4767 & $\begin{array}{l}\text { Comprises a mix of storage and E\&P } \\
\text { assets many of which not developed } \\
\text { at time of sale }\end{array}$ \\
\hline Stublach $^{129}$ & Aug 2007 & GdF & Ineos & - & 400 & $\begin{array}{l}\text { Not developed at time of sale though } \\
\text { total cost could amount to } £ 350 \mathrm{~m}\end{array}$ \\
\hline Caythorpe $^{130}$ & Sept 2008 & Centrica & $\begin{array}{l}\text { Warwick } \\
\text { Energy }\end{array}$ & 70 & 212 & $\begin{array}{l}\text { Not developed at time of sale }-\mathrm{a} \\
\text { further } £ 100 \mathrm{~m} \text { required to develop }\end{array}$ \\
\hline Baird $^{131}$ & Feb 2009 & Centrica & Perenco & $25+12$ & & $\begin{array}{l}70 \% \text { controlling interest with Perenco } \\
\text { retaining the rest. A further } £ 1.2 \text { bn } \\
\text { required to develop }\end{array}$ \\
\hline $\begin{array}{l}\text { Hill Top } \\
\text { Farm }^{132}\end{array}$ & July 2009 & EdF & British Salt & 90 & $\begin{array}{l}36 \mathrm{~m} \\
\text { therms }\end{array}$ & $\begin{array}{l}\text { Adjacent to existing EdF storage } \\
\text { facility. Assets comprised } 10 \text { cavities } \\
\text { filled with brine - a further } £ 200 \mathrm{~m} \\
\text { investment required }\end{array}$ \\
\hline Portland ${ }^{133}$ & Oct 2010 & eCorp & Infrastrata & 22.9 & 1000 & $\begin{array}{l}50 \% \text { interest, payment to cover the } \\
\text { next } £ 25.9 \mathrm{~m} \text { of spend on the project } \\
\text { to match that spent by owners to date }\end{array}$ \\
\hline Gateway $^{134}$ & Dec 2010 & Petrofac & Gateway & 33 & 1500 & $\begin{array}{l}20 \% \text { interest. Sum includes payments } \\
\text { contingent on key project milestones } \\
\text { and further equity sales. }\end{array}$ \\
\hline $\begin{array}{l}\text { Island Magee, } \\
\mathrm{NI}^{135}\end{array}$ & Jan 2012 & $\begin{array}{l}\text { BP Gas } \\
\text { Marketing }\end{array}$ & Infrastrata & 0.4 & & Option for $50.5 \%$ \\
\hline
\end{tabular}

Source: Company websites

\footnotetext{
${ }^{129}$ http://www.ineos.com/new_item.php?id_press=175

${ }^{130} \mathrm{http}$ ://www.centrica-sl.co.uk/index.asp?PageID=22\&Year=2008\&NewsID=86

${ }^{131}$ Purchase price was $£ 25 \mathrm{~m}$ with a further $£ 12 \mathrm{~m}$ required prior to FID. See http://www.centricasl.co.uk/index.asp?PageID=22\&Year $=2009 \&$ NewsID $=92$

132 http://www.edfenergy.com/media-centre/press-news/EDF-ENERGY-to-invest-in-UK-Gas-Storage-

Facility.shtml

133 http://www.infrastrata.co.uk/images/stories/PressReleases/ecorp_legal_041010.pdf

${ }^{134}$ http://www.gatewaystorage.co.uk/index.php?option=com_content\&view=article\&id=72\%3A06122010-

gateway-gas-storage-secures-new-investor-petrofac-acquires-20a-interest-\&catid=1\%3Alatest-news\&Itemid=59

135 http://www.infrastrata.co.uk/images/stories/PressReleases/bpgm_option_200112.pdf
} 
Overall it would appear that the market has gone through three distinct phases in the past decade.

- Ownership restructuring precipitated by or coinciding with the Dynegy sales in 2002,

- Outright sales by project promoters to suppliers/traders during the period 2005 to 2009

- Partial equity sales to suppliers and energy sector investors from 2010 onwards

It is also clear that over time the degree of completion of a project at the time of sale has markedly reduced. Recent transactions often include an element where part of the consideration is linked to further progress with the project and the buyers are essentially buying an option. It should be noted that Table 13 does not include long term sales of capacity where no change in ultimate ownership is involved. Whilst these deals are not common, Star Energy did sell a share of its capacity in the Humbly Grove facility to Vitol in 2005 though this reverted to subsequent owner Petronas in April 2011 ${ }^{136}$. In April 2012 E.On Storage leased all of the capacity in its Holford storage facility (due on stream in 2013) to asset owner Nobel Clean Fuels Ltd. for a 5 year period ${ }^{137}$. The consideration for this purchase has not been disclosed.

In terms of how consideration has evolved over time it is possible to derive an estimate of price paid per cubic metre of working volume. This generates numbers that typically fall in the range of $£ 0.1$ to $£ 0.4$ per cubic metre of working volume though this is a very crude measure as it does not reflect the various stages that the projects had achieved at the time of the transaction. Storage capital costs reviewed as part of the economic analysis suggest total project capital costs in the range $£ 0.4$ to $£ 1.2$ per cubic metre of working volume.

\subsubsection{Profitability of storage undertakings}

The two companies with operating storage in GB that report profits separately for these activities are Centrica Storage Ltd. (CSL) and Scottish and Southern Energy. The annual operating profits for the period 2004 to 2011 is shown in Table $14^{138}$.

Table 14: Storage company operating profits $\mathrm{Em}$

\begin{tabular}{|l|l|l|l|l|l|l|l|l|}
\hline $\begin{array}{l}\text { operating } \\
\text { profit }\end{array}$ & $\mathbf{2 0 0 4}$ & $\mathbf{2 0 0 5}$ & $\mathbf{2 0 0 6}$ & $\mathbf{2 0 0 7}$ & $\mathbf{2 0 0 8}$ & $\mathbf{2 0 0 9}$ & $\mathbf{2 0 1 0}$ & $\mathbf{2 0 1 1}$ \\
\hline CSL & 69 & 154 & 228 & 240 & 195 & 168 & 169 & 75 \\
\hline $\begin{array}{l}\text { As a \% of total } \\
\text { profit }\end{array}$ & 5.0 & 10.0 & 16.4 & 12.3 & 9.7 & 9.0 & 7.0 & 3.1 \\
\hline SSE & 18 & 27 & 56 & 51 & 43 & 42 & 23 & 24 \\
\hline
\end{tabular}

Source: Company websites ${ }^{139}$

The profile of profits broadly follows the summer-winter spread profiles and the highest level of profits around 2006 and 2007 broadly coincide with the highest level of acquisitions

\footnotetext{
${ }^{136}$ http://www.petronasenergy.com/news-and-events/5/78/PETRONAS-to-expand-European-gas-trading-desk

${ }^{137} \mathrm{http}: / /$ pressreleases.eon-uk.com/blogs/eonukpressreleases/archive/2012/04/30/1817.aspx

138 Data is from Centrica and SSE (for 12 months ending in March of following year) company presentations of annual results http://www.centrica.com/index.asp?pageid=26\&year=2012 and http://www.sse.com/Investors/Reports_And_Results/

${ }^{139}$ Annual reports available at http://www.centrica.com/index.asp?pageid $=26$ and http://www.sse.com/Investors/Reports_And_Results/
} 
activity. It is interesting to note that in 2006 CSL accounted for $16.4 \%$ of Centrica plc's operating profit - in 2001 this had fallen to $3.1 \%$.

\subsection{Summary and conclusions on how storage operates today in the GB gas market}

In physical terms GB gas storage continues to play a key role in supplying the market. Analysis of events during the last three winters - which included extreme weather events and major disruptions to supply - shows that storage has become increasingly flexible and responsive to changing market conditions though surplus import capacity has also played an important role in providing flexibility and responsiveness. In commercial terms new storage facilities require a break-even summer-winter spread of at least 20p/therm. There is evidence that returns to storage owners peaked around 2006 and 2007 and have declined in recent years in line with narrowing spreads. The implications of this decline and the impact of other factors on future storage investments are considered in the next chapter.

\section{The future outlook for storage}

\subsection{Planned GB storage projects}

The British Geological Survey ${ }^{140}$ notes that whilst in theory there is scope for gas storage in the UK in depleted fields, salt and chalk caverns and aquifers it is only the first two options that have been seriously pursued. Depleted field storage will necessarily be concentrated in existing oil and gas fields and most of the activity has focused on gas fields in the Southern North Sea. Salt cavern storage potential exists within (thick) bedded salt sequences onshore Britain and in offshore salt domes in the southern North Sea or East Irish Sea and most activity has focused on onshore salt (halite) deposits as shown in the map at Figure 15.

${ }^{140}$ HSE, 2008, Section 5 
Figure 15: Main Halite basins and planned storage projects (in 2008)

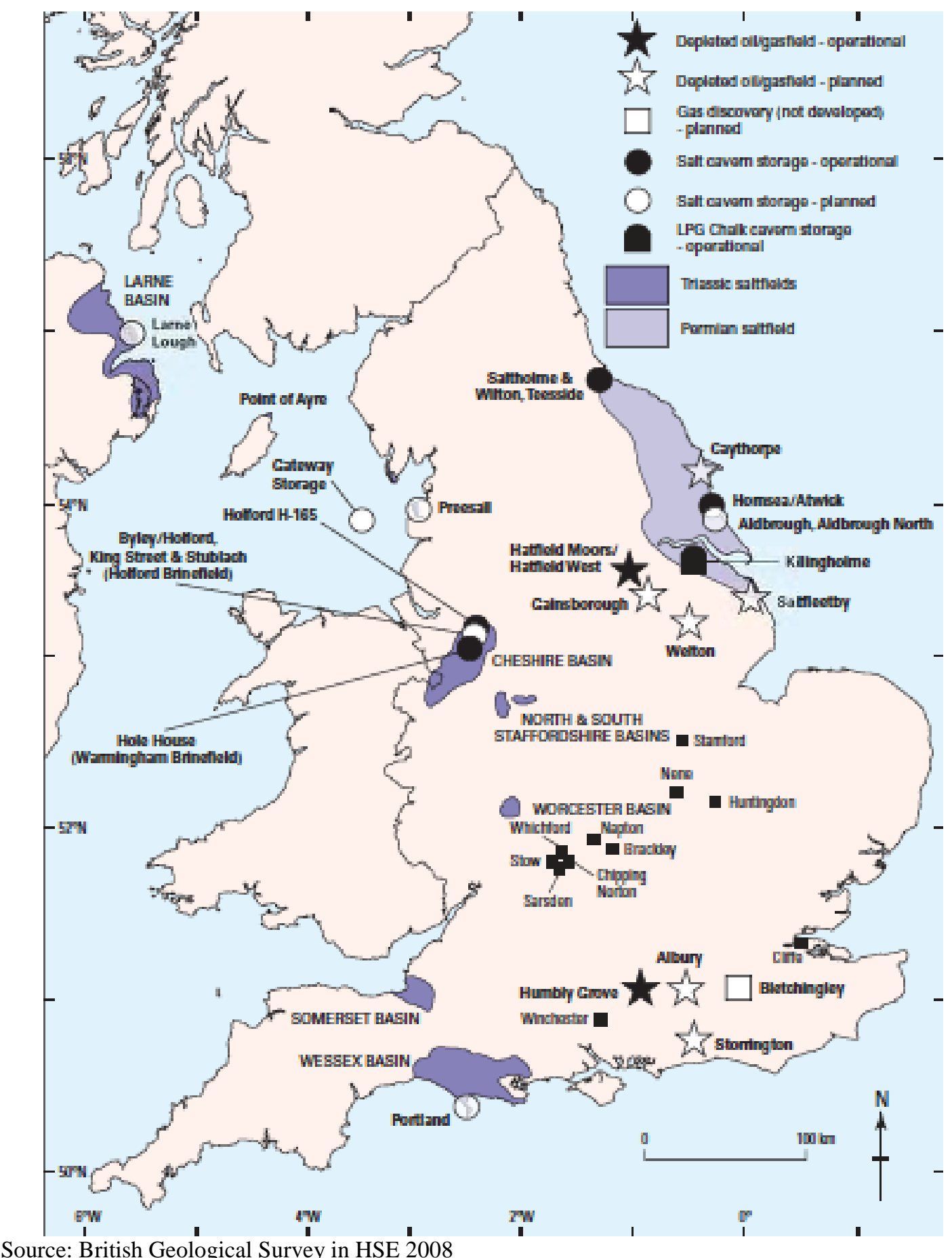

Source: British Geological Survey in HSE 2008

Table 15 shows the present status of storage projects under construction and Table 16 the status of those that are proposed. Projects in the latter category are split between those that have planning permission and those where either planning permission has been refused or has not yet been sought. 
Table 15: Storage projects in progress

\begin{tabular}{|l|l|l|l|l|}
\hline Facility & Promoter & $\begin{array}{l}\text { Working } \\
\text { Capacity } \\
\text { (mcm) }\end{array}$ & $\begin{array}{l}\text { Deliverabili } \\
\text { ty (mcm/d) }\end{array}$ & Present status \\
\hline Hill Top Farm & EdF & 100 & 15 & $\begin{array}{l}\text { Expected to commence } \\
\text { operations in winter } \\
\text { 2012/13 }\end{array}$ \\
\hline $\begin{array}{l}\text { Holford } \\
\text { Expansion }\end{array}$ & E.On & 180 & 22 & $\begin{array}{l}\text { In operation - all } 8 \\
\text { caverns due to start in } \\
\text { 2013 }\end{array}$ \\
\hline $\begin{array}{l}\text { Aldbrough } \\
\text { Expansion }\end{array}$ & SSE/Statoil & 140 & 20 & $\begin{array}{l}\text { In operation - } \\
\text { additional capacity } \\
\text { expected to be } \\
\text { available in 2012 }\end{array}$ \\
\hline Stublach & $\begin{array}{l}\text { Storengy (GdF } \\
\text { Suez) }\end{array}$ & 400 & 32 & $\begin{array}{l}\text { Under construction. } 2 \\
\text { caverns expected on } \\
\text { stream by winter 2013, } \\
\text { all 20 by 2018 }\end{array}$ \\
\hline Total & & & & \\
\hline
\end{tabular}

Source: National Grid 2011 and company web sites

It should be noted from

Table 15 that the projects under construction increase total working capacity from 4,727 $\mathrm{mcm}$ to $5,547 \mathrm{mcm}$ and deliverability from $129 \mathrm{mcm} / \mathrm{d}$ to $218 \mathrm{mcm} / \mathrm{d}$ - an increase of $17 \%$ and $69 \%$ respectively. In other words the new projects make a disproportionately higher contribution to meeting peak as opposed to seasonal requirements. If the experience from the 2011/12 winter - when gas withdrawal volumes were around $1.3 \mathrm{bcm}$ and injection volumes were $1 \mathrm{bcm}$ over the six month winter period145 - is indicative of future usage the effective working capacity is likely to be increased with these new, fast cycle projects.

\footnotetext{
${ }^{141}$ Initial deliverability expected to be 5 to $8 \mathrm{mcm} / \mathrm{d}$ with a working volume of $20 \mathrm{mcm}$. See www.energyteam.co.uk/pdfs/marketMONITOR.pdf

142 http://www.thisisnoble.com/index.php?option=com content\&view=article\&id=1330\%3Aeon-gas-storageuk-and-noble-agree-holford-gas-storage-tie-up\&catid=21\%3Aannouncements\&Itemid=664\&lang=en $\frac{14}{143}$

http://www.sse.com/uploadedFiles/SSE_Microsites/Aldbrough/Controls/Lists/Community/AldbroughGasStorag eCommunityUpdate.pdf

$\frac{144}{14 t t p: / / s t o r e n g y . c o . u k / A b o u t-S t o r e n g y / P r o j e c t s . p h p ~}$

${ }^{145}$ National Grid 2012a, page 27
} 
Table 16: Storage projects not yet in progress but with planning permission

\begin{tabular}{|c|c|c|c|}
\hline Facility & Promoter & $\begin{array}{l}\text { Working } \\
\text { Capacity } \\
(\mathbf{m c m})\end{array}$ & Present status \\
\hline $\begin{array}{l}\text { Aldbrough } \\
\text { Phase } 2\end{array}$ & SSE / Statoil & 0.3 & $\begin{array}{l}\text { No FID - some planning issues } \\
\text { outstanding }\end{array}$ \\
\hline Bains & Centrica & 0.6 & $\begin{array}{l}\text { No FID, In Feb } 2012 \text { Centrica } \\
\text { abandoned this project }{ }^{146}\end{array}$ \\
\hline Caythorpe & Centrica & 0.2 & No FID \\
\hline Gateway & Stag Energy & 1.5 & No FID \\
\hline Hatfield West & $\begin{array}{l}\text { Scottish } \\
\text { Power }\end{array}$ & 0.06 & No FID \\
\hline King Street & $\begin{array}{l}\text { King Street } \\
\text { Energy }\end{array}$ & 0.3 & No FID \\
\hline Portland & $\begin{array}{l}\text { Infrastrata } \\
\text { Plc }\end{array}$ & 1.0 & $\begin{array}{l}\text { No FID, Project has been } \\
\text { rescoped and application for use } \\
\text { as CCS project has now been } \\
\text { submitted }^{147}\end{array}$ \\
\hline Saltfleetby & Wingas & 0.7 & $\begin{array}{l}\text { No FID. Full consent expected in } \\
\text { 2013. Temporarily resumed gas } \\
\text { production in October } 2012^{148}\end{array}$ \\
\hline Deborah & ENI & 4.6 & No FID \\
\hline Baird & $\begin{array}{l}\text { Centrica/ } \\
\text { Perenco }\end{array}$ & 1.7 & No FID \\
\hline $\begin{array}{l}\text { Islandmagee } \\
\text { (NI) }\end{array}$ & $\begin{array}{l}\text { InfraStrata } \\
\text { /Mutual } \\
\text { Energy/BP } \\
\end{array}$ & 0.5 & $\begin{array}{l}\text { Planning application and TPA } \\
\text { exemption granted }^{149}\end{array}$ \\
\hline
\end{tabular}

Source: National Grid 2011 and company websites

Of the projects listed in Table 16 Bains and Portland have been abandoned/rescoped, and so can be excluded from future consideration. The depleted field projects Deborah and Baird require major investments and are unlikely to be profitable without some direct form of Government intervention or support. It is understood that the remaining projects could be introduced relatively quickly if the commercial conditions improved so up to $3 \mathrm{bcm}$ of working capacity could be introduced in a 3 to 5 year time horizon.

There are a further set of projects that have not received planning permission and these are shown in Table 17. Many of these projects face major obstacles before progress can be made

\footnotetext{
146 http://www.centrica-sl.co.uk/index.asp?pageid=19

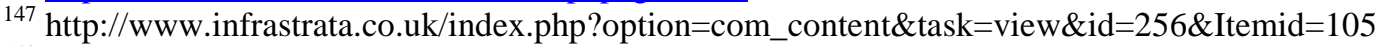

$148 \mathrm{http}: / /$ www.wingas-storage.com/121019_gas_production_resumed.html

149 http://www.uregni.gov.uk/uploads/publications/2012-07-05_IMSL_TPA_decision_paper.pdf and http://www.islandmageestorage.com/index.php?option=com_content\&task=blogcategory\&id=47\&Itemid=106
} 
Table 17: Storage projects not yet in progress without planning permission

\begin{tabular}{|l|l|l|l|}
\hline Facility & Promoter & $\begin{array}{l}\text { Working } \\
\text { Capacity } \\
\mathbf{( m c m})\end{array}$ & Present status \\
\hline $\begin{array}{l}\text { White Hill } \\
\text { Farm Yorkshire }\end{array}$ & E.ON & 0.4 & $\begin{array}{l}\text { Planning applications submitted in } \\
2011^{150}\end{array}$ \\
\hline Preesall & Halite Energy & 1.2 & $\begin{array}{l}\text { Recommendation by Planning } \\
\text { Inspectorate due by January } \\
2013^{151}\end{array}$ \\
\hline $\begin{array}{l}\text { Esmond Forbes } \\
\text { Gordon }\end{array}$ & Encore/Star & 4.0 & $\begin{array}{l}\text { Forbes field reportedly being } \\
\text { evaluated by Star Energy }\end{array}$ \\
\hline Corvette & Shell / Esso & 2.5 & $\begin{array}{l}\text { Offshore Bacton - early stage } \\
\text { project }\end{array}$ \\
\hline Larne (NI) & BGE/Storengy & Not known & $\begin{array}{l}\text { Now discontinued following } \\
\text { unsuccessful drilling campaign }\end{array}$ \\
\hline
\end{tabular}

Source: National Grid 2011 and company websites

Overall it is clear that whilst there have been a large, and growing, number of planned storage projects the number actually progressing to the final investment decision stage have been very few.

Figure 16: Evolution of planned storage projects 2007-2010

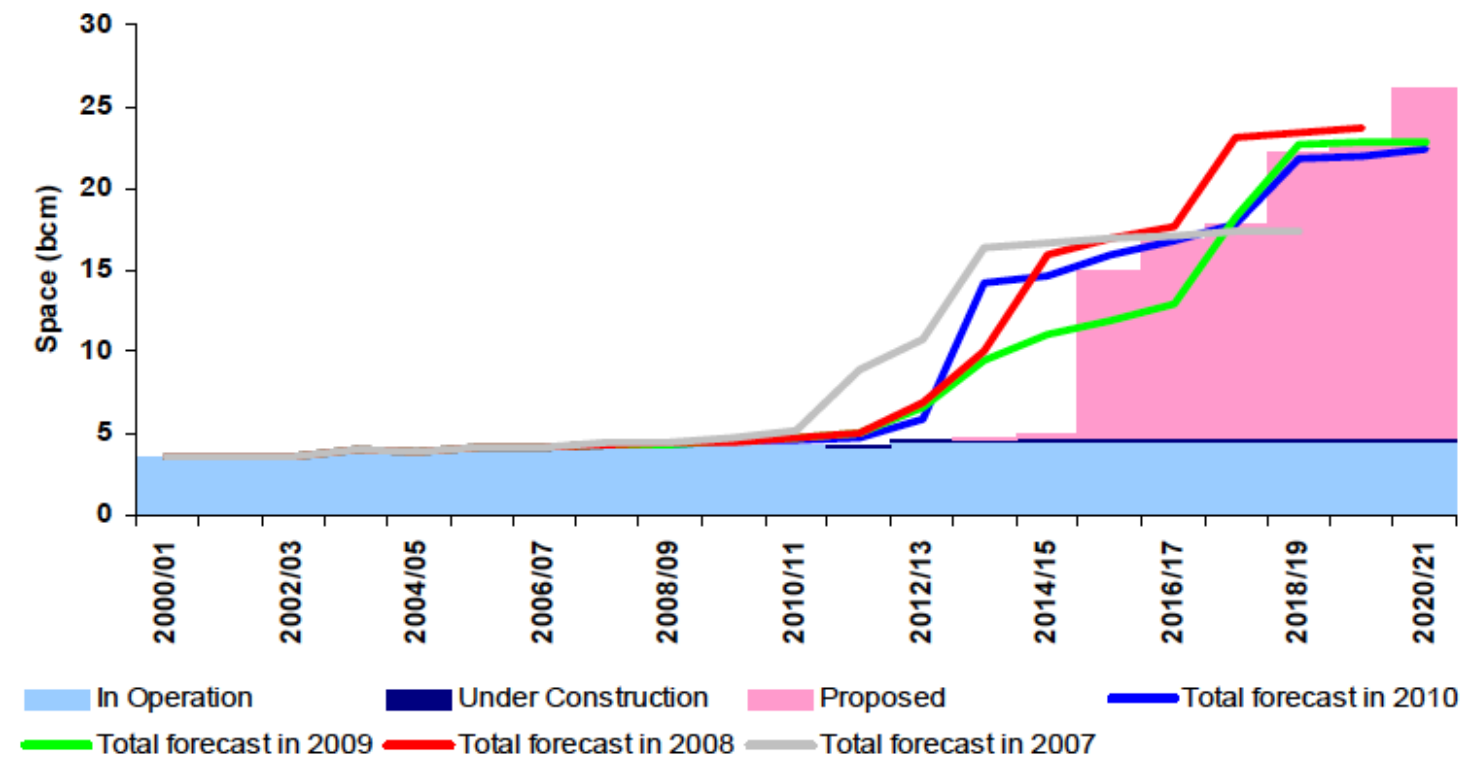

Source: National Grid 2011

\footnotetext{
${ }^{150}$ http://www.eon-uk.com/generation/whitehill.aspx

151 The Planning Inspectorate completed its examination on 26 October 2012. Conclusions and recommendations will be sent to the Secretary of State within 3 months. See

http://infrastructure.planningportal.gov.uk/wp-content/ipc/uploads/projects/EN030001/2.\%20Post-

Submission/Procedural\%20Decisions/121026_EN030001_S99\%20Close\%20of\%20Examination\%20Letter.pdf

$152 \mathrm{http} / / / \mathrm{www} . u p s t r e a m o n l i n e . c o m / h a r d c o p y /$ news/article125311.ece?service=print

153 http://www.bordgais.ie/corporate/index.jsp?p=731\&n=778
} 
Figure 16 indicates that the vast majority of proposed storage projects have been "pushed forwards" in successive years and a limited amount of additional space is likely to come on stream before 2015. The graph does, however, suggest that the amount of total planned storage capacity has remained relatively constant. In fact there had been a degree of churn amongst the projects with some being discontinued and others taking their place. Projects that have been discontinued were primarily those being promoted by Star Energy (now owned by Petronas) and included Albury, Welton, Bletchingly and Gainsborough accounting for over 2 bcm of working capacity in total.

\subsection{Barriers to storage project implementation}

The foregoing section has demonstrated that a large number of projects have been progressed to an advanced stage and in many cases have obtained planning permission - an often very lengthy and expensive process. However a large number of projects have also failed to proceed to final investment decision (FID) whilst some projects have been abandoned. This section seeks to identify the main factors preventing storage projects proceeding to completion. The analysis is based on discussions with a number of storage operators and project promoters and a review of published material. The barriers identified have been grouped into commercial, institutional and other factors.

\subsection{Commercial factors}

Discussions with project promoters indicate that the single biggest obstacle to project implementation has been the combined effect of the collapse in summer-winter spreads and the reduction in price volatility ${ }^{154}$. (Note that if volatility is below say $1 \mathrm{p} /$ therm it is unlikely that the fuel cost of injection/withdrawal would be covered.) Figure 17 illustrates how the summer-winter spread has evolved over the period January 2003 to January 2012. Each line refers to a specific summer-winter spread (e.g. the price in Q1 2007 minus the price in summer 2006) and tracks how the spread has changed over time.

\section{Figure 17: Summer-winter price spreads and storage profitability break-even}

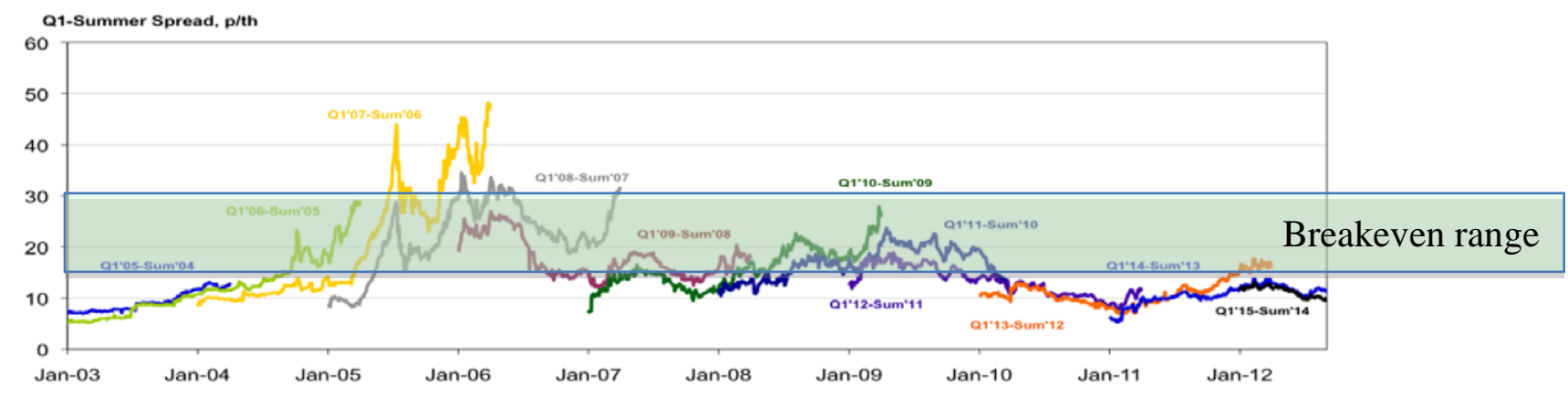

Source: Centrica Storage Ltd and author's analysis

${ }^{154}$ This view is confirmed by analysis such as Escobar and Arteaga, 2011 
Figure 17 shows that spreads were generally above 20p/therm during the period January 2005 to summer 2007 - as demonstrated above and shown on the graph this is the sort of consistent spread that is required to ensure a break-even return on new storage investments. FIDs for the projects listed in Table 15 were made during this period. The period also coincided with a number of acquisitions, often at prices many respondents considered to be excessive. Respondents stated that a further problem was the limited visibility of future spreads with forward curves being unreliable beyond two to three years.

Figure 17 also indicates a general decline in volatility, suggesting a reduction in extrinsic value from holding storage capacity. Analysis by Alterman ${ }^{155}$ indicates that the period November 2005 to November 2007 was one of high volatility for NBP prices and one that coincides with high summer-winter spreads. The factors driving up spreads and volatility were broadly the same and included ${ }^{156}$ :

- Cold weather in November 2005 leading to pressure on supplies with flows from the continent being constrained by a reluctance to release gas from storage and LNG terminals and UKCS deliveries performing below expectations;

- A fire on the Rough storage facility in February 2006 leading to an unplanned outage for the rest of that winter;

- Continuing concerns over the lack of transparency on the availability of supplies from continental sources exacerbated by a dispute between Russia and Ukraine in January 2006 temporarily restricting some flows to Europe.

Alterman shows that NBP price volatility has declined since 2007 and suggests this is due to increased convergence with continental prices and reduced demand caused by the economic slowdown. These factors are also likely to be part of the explanation for the reduction in summer-winter spreads. For example continental oil-linked prices will not exhibit seasonal features due to the time lags in the contract formulae. The other main factor leading to lower spreads is increased flexibility from other sources of supply including the impact of LNG cargoes. LNG terminal availability is determined by a range of factors including Asian demand and is said to create uncertainty over both summer and winter prices, depressing seasonal spreads.

This change in flexibility over recent years is illustrated in Table 18 which shows the maximum potential deliverability by source compared to the forecast peak day for selected years since 2005 .

\footnotetext{
${ }^{155}$ Alterman, 2012, P30

${ }^{156}$ Ofgem 2006
} 
Table 18: Forecast maximum peak day supply \& demand ${ }^{157}$

\begin{tabular}{|l|l|l|l|l|l|l|}
\hline Source & \multicolumn{3}{|l|}{$2005 / 6$} & $2009 / 10$ & $2012 / 13$ & \\
\hline & Mcm/d & $\%$ & Mcm/d & $\%$ & Mcm/d & $\%$ \\
\hline UKCS & 327 & 63.9 & 183 & 33.9 & 137 & 26.0 \\
\hline Norway & - & & 118 & 21.9 & 115 & 21.9 \\
\hline Continent & 48 & 9.4 & 55 & 10.2 & 66 & 12.5 \\
\hline LNG imports & 17 & 3.3 & 60 & 11.1 & 100 & 19.0 \\
\hline Storage & 120 & 23.4 & 124 & 23.0 & 108 & 20.5 \\
\hline Total & 512 & 100 & 540 & 100 & 526 & 100 \\
\hline $\begin{array}{l}\text { Forecast peak } \\
\text { day }\end{array}$ & $540^{158}$ & 105.5 & 502 & 93.0 & 516 & 98.1 \\
\hline HHI & 4727 & & 2329 & & 2019 & \\
\hline
\end{tabular}

Source: National Grid Winter Outlooks and author's calculations

It is clear that whilst the contribution of the UKCS as a source of flexibility has declined in line with reduced production the number and capacity of alternative sources has increased. The deliverability of storage has declined marginally as the reduced number of LNG peak shaving plants ${ }^{159}$ has offset the small increase in salt cavity storage. Overall the proportion of flexibility provided by storage has fallen and, perhaps more importantly, the range of different sources has increased. Furthermore the major increase in LNG import capacity has provided what is in effect a major increase in fast-cycle storage capacity.

The growth in supply source diversity is demonstrated by the $\mathrm{HHI}^{160}$ measure which has been calculated on the basis of the percentage shares in Table 18 taking IUK and BBL as separate entities. This is a very approximate measure of the degree of concentration of flexibility as it fails to distinguish between individual terminals or capacity holders but it does show that concentration levels have fallen and is further demonstration of the likely causes of the decline in spreads and volatility.

Other commercial factors highlighted by project promoters included:

- Scale and uncertainty of costs - whilst there was little evidence of major cost inflation being a factor some respondents pointed to the large scale of many projects particularly those offshore which could be in the range of $£ 800$ million to $£ 1.7$ billion. There were also concerns that cost estimates were subject to a great deal of uncertainty and out turn costs could be higher.

- Financing issues were a concern from a number of perspectives. Financing would not be available without long term contracts in place with fixed prices - these were difficult to obtain due to the prevailing market conditions described above. In any event, long term contracts were under increased scrutiny and the credit risk of counter parties was a particular issue. Lenders were looking for five year pay backs whereas storage projects required seven to ten years and finally sub-surface projects were

\footnotetext{
${ }^{157}$ Norwegian imports are included within UKCS for 2005/6, Continent comprises IUK and BBL.

${ }^{158}$ Based on cold weather analysis - NG assume demand side response would suppress demand to match supplies - see http://www.nationalgrid.com/NR/rdonlyres/B9DC52C9-0F4E-4C83-9F5F41A7822C5B80/4988/WORautumn2007.pdf

${ }^{159}$ These facilities were decommissioned by NG primarily due to the radically altered flow patterns across the NTS arising from developments such as the new LNG import terminals.

${ }^{160}$ Hirschmann Herfindal Index - see glossary
} 
particularly difficult to finance as they were seen as akin to upstream oil and gas developments.

- Competition from competing projects was also cited as a factor. Many companies were evaluating storage projects in competition with other, including upstream, prospects and in this context the returns were unattractive.

- Overvaluation - the review of transactions shown in Table 13 indicates that most took place during the period 2006-8 when both summer-winter spreads and volatility were high. Prices paid in some cases are understood to have reflected a significant element of extrinsic value as well as the intrinsic elements. The decline in volatility and the tendency for some models to overestimate extrinsic values has, in the view of some players, led to a gap in expectations between project promoters and buyers, creating a barrier to deal execution.

- Project completion issues - even those projects that have proceeded have encountered delays in completion. For example Aldbrough was originally due to come on stream in 2007/8 with a working capacity of $420 \mathrm{mcm}$. The project was finally commissioned in 2011 with a reduced working capacity of $192 \mathrm{mcm}$. The Holford storage project was originally due to come on stream in 2007/8 with a working capacity of $300 \mathrm{mcm}$. The project was finally commissioned at the end of 2011 with an initial working capacity of $60 \mathrm{mcm}$ though this is planned to reach $160 \mathrm{mcm}$ by $2013^{161}$.

\subsection{Institutional factors}

For some time it had been suggested that planning requirements were a significant barrier to project implementation. It is undoubtedly the case that planning delays caused some projects to stall that might otherwise have progressed, though it is less clear that these were the defining factor. Promoters suggested that this was seen as less of an issue today - in part because companies understood the process and what was required but also because the establishment of the Infrastructure Planning Commission (now superseded by the Planning Inspectorate) had articulated a clearer case for gas storage to local authorities. It should be noted that a large number of potential projects have secured planning permission so this may also not be a future barrier, though it was suggested that there was less scope for alteration in the new planning process and this may lead to over rigid or sub-optimal development plans.

- $\quad$ Two tax issues were cited as reducing the financial case for storage:

- Whilst the authorities had recognised in 2009 that cushion gas could be treated as an asset and depreciated for tax purposes this was to be on the basis of a $10 \%$ annual charge rather than $20 \%$ as the gas did not "wear out"; 162

- The fact that salt cavern creation could not be capitalized as it was seen as not man made.

The Ofgem TPA exemption process was seen as a fairly straightforward albeit lengthy process and as an acceptable part of the overall process. There had been some initial concerns

\footnotetext{
${ }^{161}$ See press release on Noble Energy website 30 April 2012

http://www.thisisnoble.com/index.php?option=com_content\&view=article\&id=1330\%3Aeon-gas-storage-ukand-noble-agree-holford-gas-storage-tie-

up\&catid=21\%3Aannouncements\&Itemid=664\&lang=en\&device=desktop

${ }^{162}$ Details at http://www.ukbudget.com/UKBudget2010/business/UKBudget2010-business-Cushion-gas.cfm
} 
that rental charges from the Crown Estates for offshore facilities would act as a barrier to investment ${ }^{163}$ though this was not cited as an issue by project promoters.

\subsection{Other influences}

The other main concern identified by project promoters was the continuing uncertainty regarding government intervention. All new storage projects were effectively on hold until it was clear whether there was scope for seeking some form of development assistance. Lack of clarity over broader energy policy was also cited as a potential obstacle with the future role of gas and renewable power being particular issues.

Other factors that were noted as potential issues were:

- The extended periods now required to arrange connections to the NG system;

- The possible impact of the reform of booking arrangements for NTS exit capacity (known as exit reform ${ }^{164}$ ) on the availability of future capacity for storage injection;

- Uncertainty over the impact of renewable intermittency and electricity interconnectors on gas storage requirements;

- The impact of public service obligations (PSOs) in other EU countries on the willingness of investors to commit in the UK.

The role of PSOs is discussed further below.

\subsection{Summary and conclusions on the future outlook for storage}

A large number of storage projects have been formulated over the past decade though very few have reached the final investment decision stage. Those projects that are proceeding are fast cycle facilities built by existing gas suppliers. A number of other projects have received planning permission and could be termed as "shovel ready" though the present market conditions suggest that very few will proceed. The next chapter assesses the likely need for future storage in GB and whether this project hiatus represents a significant threat to security of supply.

\section{Future requirements for storage}

\subsection{GB forecasts}

There are two basic approaches for determining the future storage requirements for GB:

- Develop forecasts for expected 1 in 20 and 1 in 50 requirements based on future demand and supply projections - this is the approach undertaken by NG:

- Use a more subjective approach that factors in import dependency and the possibility of extended disruption to gas supplies.

Looking at the first approach, the latest NG forecasts were presented at the UK Future Energy

\footnotetext{
163 http://www.energy-pedia.com/news/united-kingdom/high-rents-from-crown-estate-threatens-eni-hewett-gasstorage-project

164 The Ofgem website provides some background to the exit reform process http://www.ofgem.gov.uk/Pages/MoreInformation.aspx?docid=73\&refer=Networks/Trans/GasTransPolicy
} 
Scenarios seminar on September $272012^{165}$. The UK Future Energy Scenarios gas forecast is shown in Figure 18. This is under the "slow progression" scenario which is based on higher power generation gas demand as new gas-fired power generation capacity replaces coal and oil plant closed due to the Large Combustion Plant Directive ${ }^{166}$. The gas share of power generation is expected to decline from the mid-2020s due to higher production from new nuclear and renewable capacity plus greater continental imports.

\section{Figure 18: GB total gas demand forecast (Slow Progression scenario)}

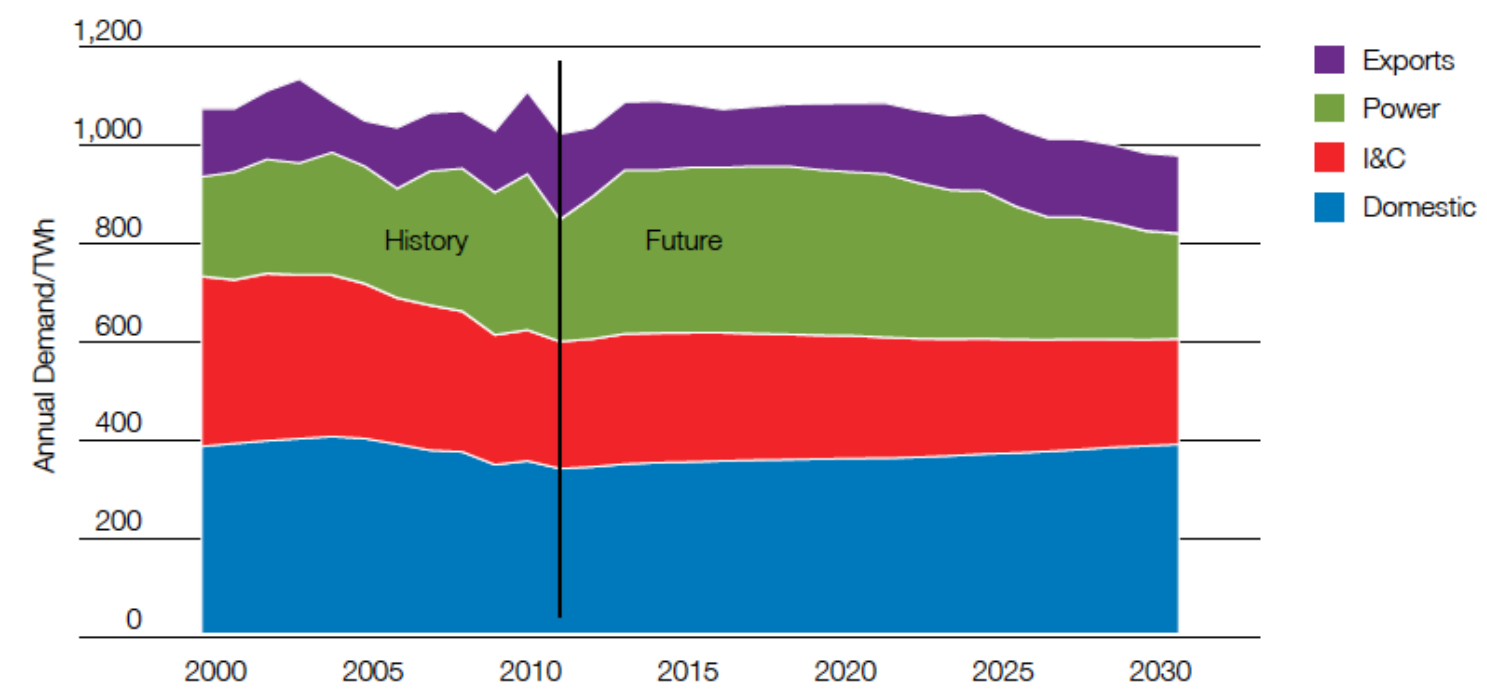

Source: National Grid 2012c, Figure 35, p 66

The peak demand forecast arising from this and the other scenarios is shown in Figure 19.

\section{Figure 19: GB peak gas demand forecasts}

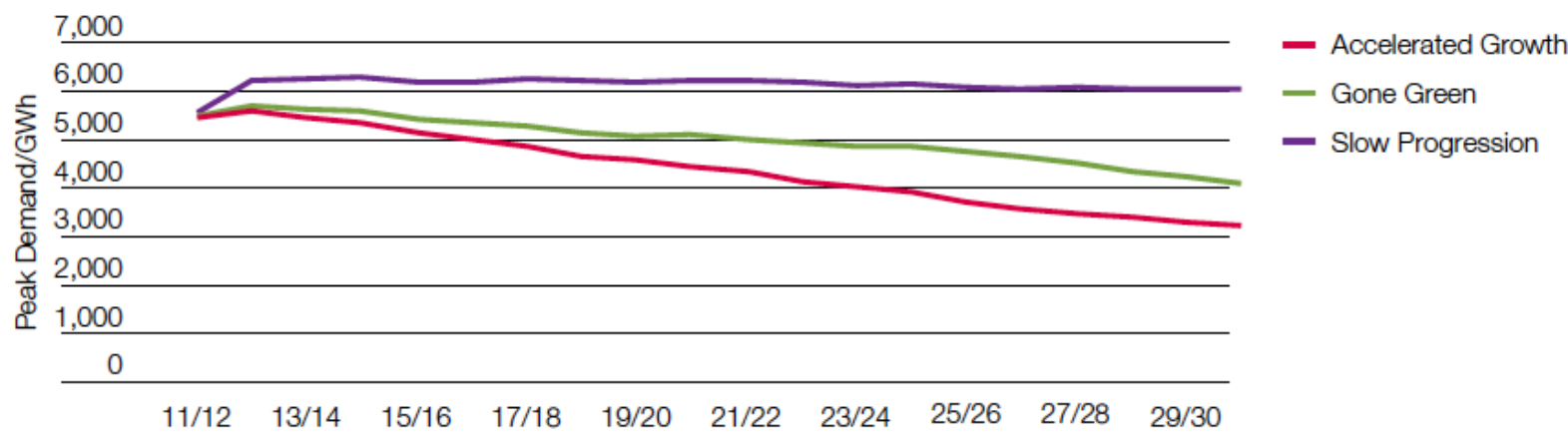

Source: National Grid 2012c, Figure 38, p 68

The highest peak demand is under the Slow Progression scenario which envisages increased power generation in the short to medium term. The impact on storage requirements/forecasts

\footnotetext{
165 See National Grid 2012c and http://www.nationalgrid.com/uk/Gas/Operationalinfo/TBE

${ }^{166}$ See http://www.defra.gov.uk/industrial-emissions/eu-international/lcpd/
} 
is shown in Figure 20 for space and in Figure 21 for deliverability. Under the Slow Progression case NG assume that new seasonal storage developments are undertaken in order to meet market needs and provide some cover for high import requirements. Some additional flexible storage is assumed to be built under the Gone Green scenario which envisages gasfired power being used to underpin intermittent renewable generation, though virtually no new storage is required under the Accelerated Growth scenario (i.e. low gas demand) as under-utilised import capacity is likely to be a cheaper source of flexible supplies than new storage.

\section{Figure 20: Forecast storage requirements - space bcm}

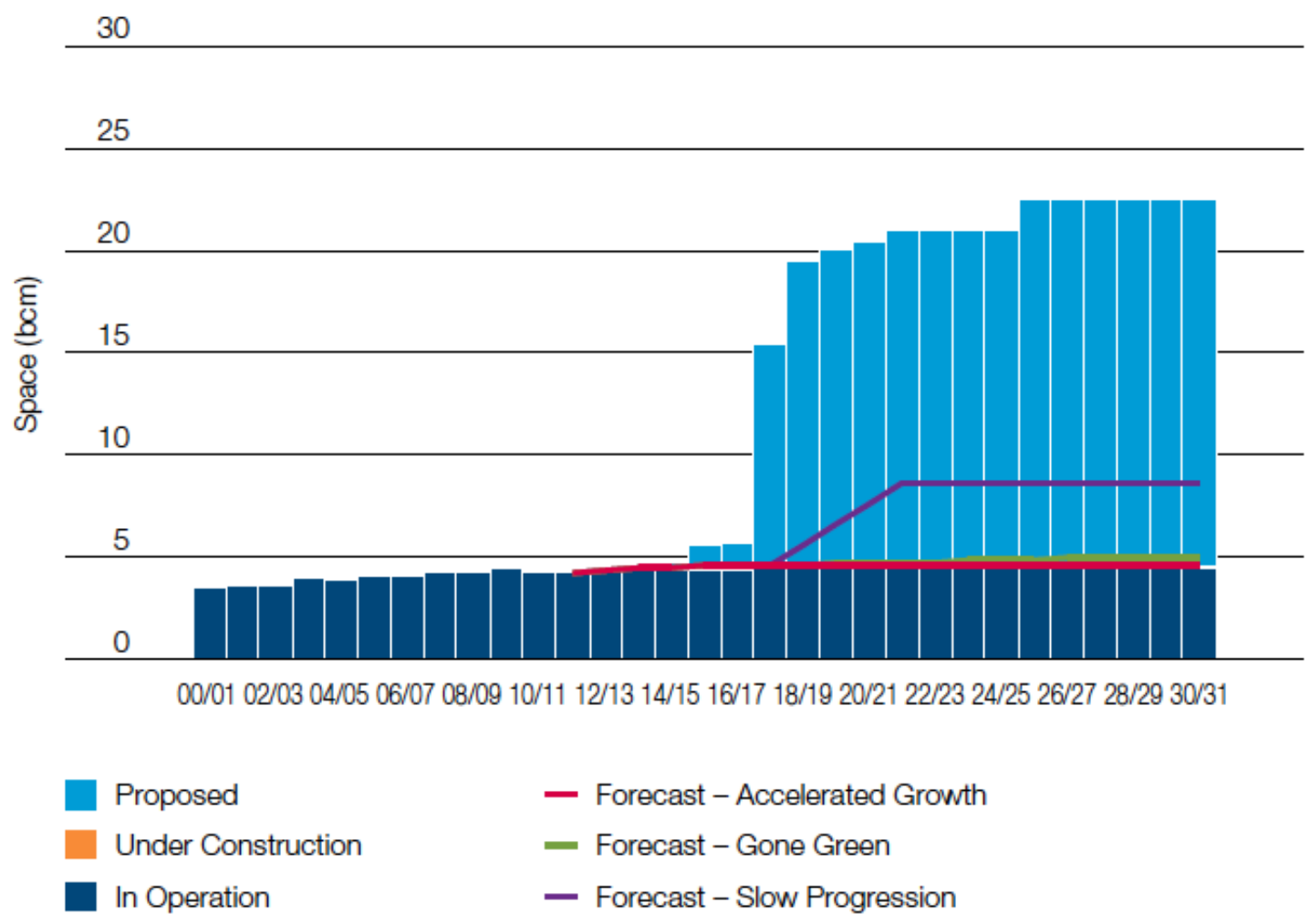

Source: National Grid 2012c, Figure 48, p 80 
Figure 21: Forecast storage requirements - deliverability in $\mathbf{m c m} / \mathbf{d}$

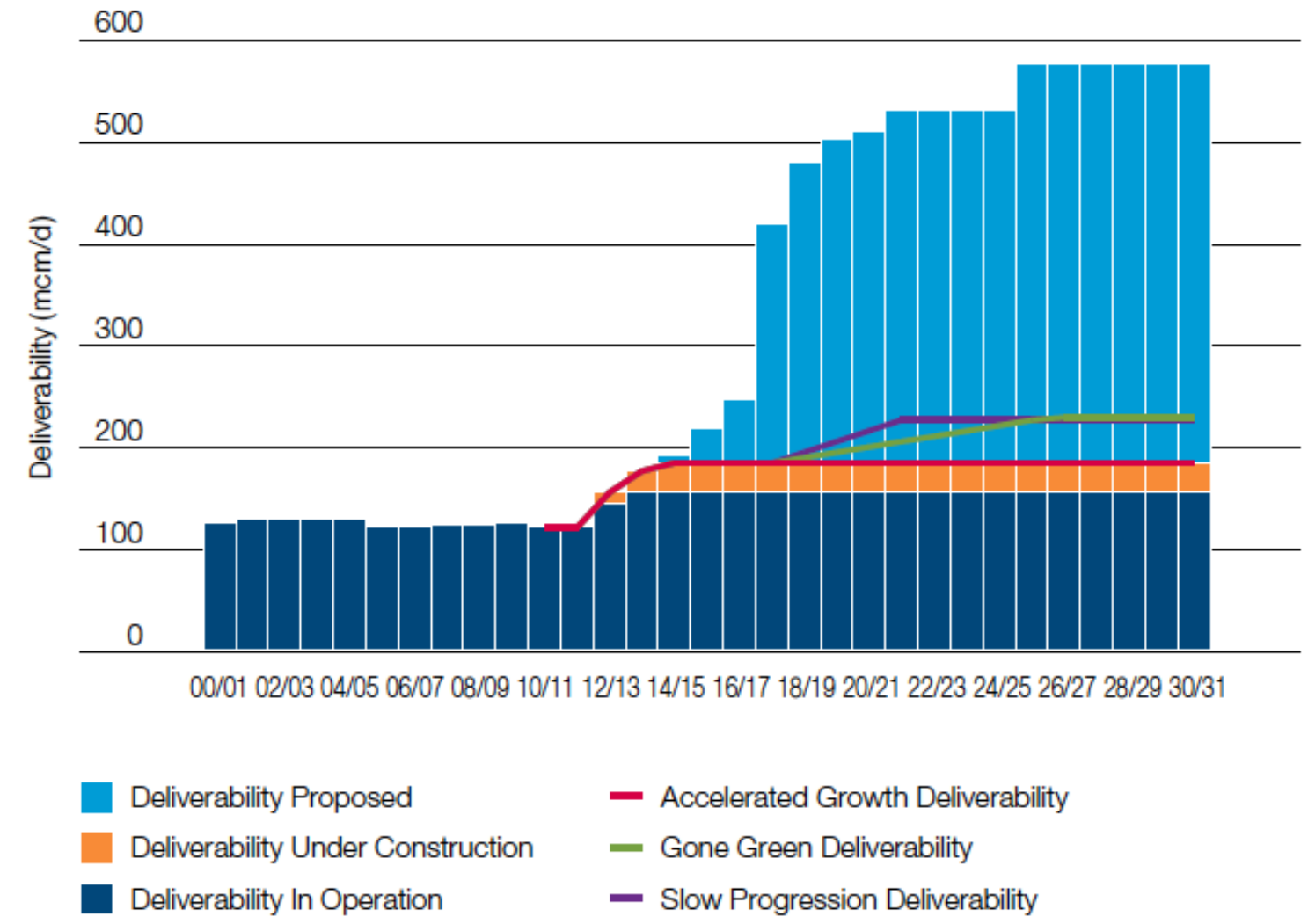

Source: National Grid 2012c, Figure 49, p 81

The overall forecasts for future peak demands and projected peak supplies are shown in Figure 22 for the Slow Progression (i.e. higher gas demand) scenario.

Figure 22: NG Peak demand and supply forecast for the Slow Progression scenario

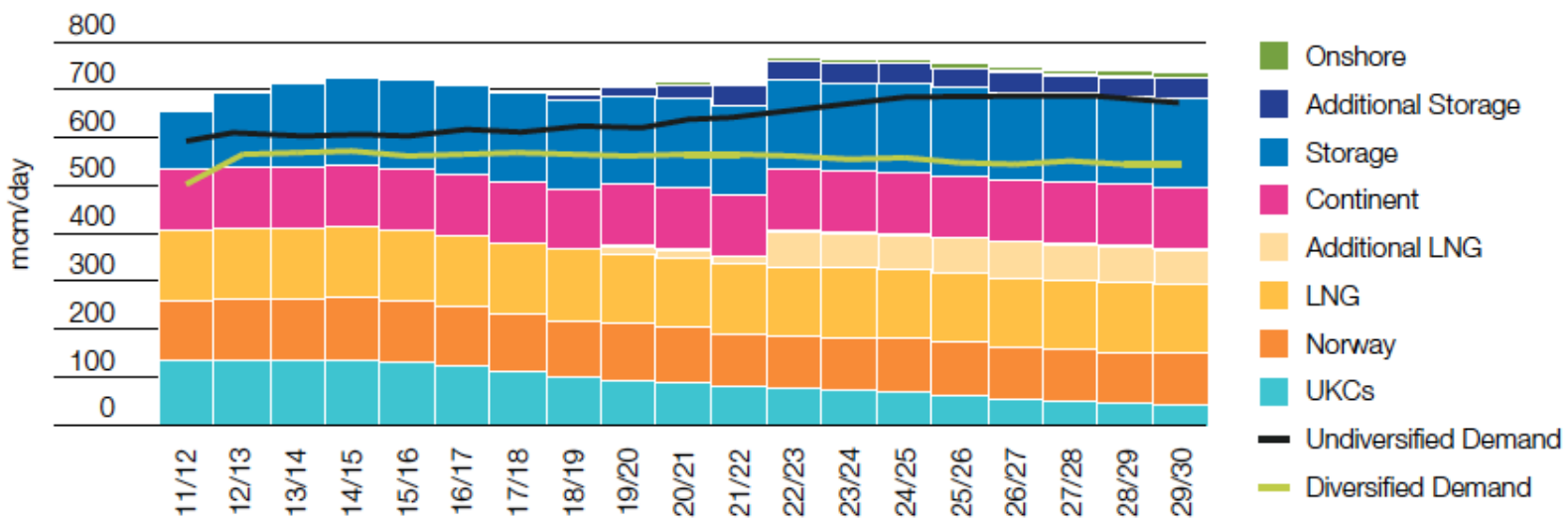

Source: National Grid 2012c, Figure 50 p 82

Throughout the forecast period there appears to be a significant excess of supply capacity over forecast peak demand - even if the predicted new storage projects are not built. However NG points out that the chart may overstate the situation as imports are shown at capacity and storage is shown at maximum deliverability. NG notes that in many storage sites 
maximum deliverability may be restricted to just a few days and in the winter storage stocks may be depleted in advance of any peak day - though of course it is equally possible, given the fast cycle, that facilities will be able to reinject.

The NG forecasts of future gas demand are primarily built around a range of scenarios that contrast different paths for GB power generation - with accordingly increased or reduced use of gas.

An alternative approach to determining future storage needs has been advanced by Knight (2012). Looking at the forecast annual supply/demand balance in 2021 he concludes that on this basis, annual storage is adequate. Looking then at the flexibility requirements he forecasts an anticipated peak day demand in 2020/21 of $472 \mathrm{mcm}$ which could mean a storage requirement of between 55 and $184 \mathrm{mcm} / \mathrm{d}$. This latter level suggests a need for 8.1 bcm working capacity (though this does not seem to take account of the higher deliverability from new storage facilities). Knight has also analysed the intermittency impact. He assumes by 2020 up to $25,000 \mathrm{MW}$ of wind power may be installed which is equivalent to 90 to130 $\mathrm{mcm} / \mathrm{d}$ of supply to gas fired power stations which could equate to $4 \mathrm{bcm}$ of high deliverability gas storage to provide up to 30 days support.

Rogers (2011) has modelled the requirement for additional storage to provide flexible gas for the power sector as wind capacity grows to just over 25,00MW by 2020. His analysis suggests that, an additional 1-2 bcm of salt cavern storage would be required, although this does not take into account the need to provide for localised transient conditions within parts of the overall GB gas network given the differing locations of load, wind generation and CCGT plant.

As stated above it is possible to develop a more subjective approach to determine storage requirements based on increased intermittency, import dependency and the possibility of extended disruption to gas supplies. NG has sought to combine these impacts in the latest Ten Year Statement (National Grid, 2011b) and this is shown in Figure 23. In this chart the blue line shows the maximum expected variation in daily demand as a result of temperature variation - the variation is declining with time due to the decrease in demand for gas for residential heating and other efficiencies. The green line shows the maximum potential variation in demand for gas-fired power generation as a result of variations in wind power (the so called intermittency issue) which is increasing with time as a result of increased reliance on wind-powered generation. The lavender area combines these effects (taking account of diversity) to show how demand could vary on a given day due to a combination of temperature and wind variation - for example going from a mild windy spell to a severe cold spell with high pressure. This could reach $140 \mathrm{mcm} / \mathrm{d}$ by 2030/31. The green shaded area shows the impact of losing a major piece of supply infrastructure such as the Langeled pipeline. The top of the green area represents the maximum impact of a loss of windpowered generation coupled with temperature driven demand increases and a sudden supply loss from a major import source. This could result in a sudden increase in demand from other sources of around 180mcm/d by 2020 and over $200 \mathrm{mcm} / \mathrm{d}$ by 2030 . 


\section{Figure 23: Potential maximum day to day variation in daily national demand}

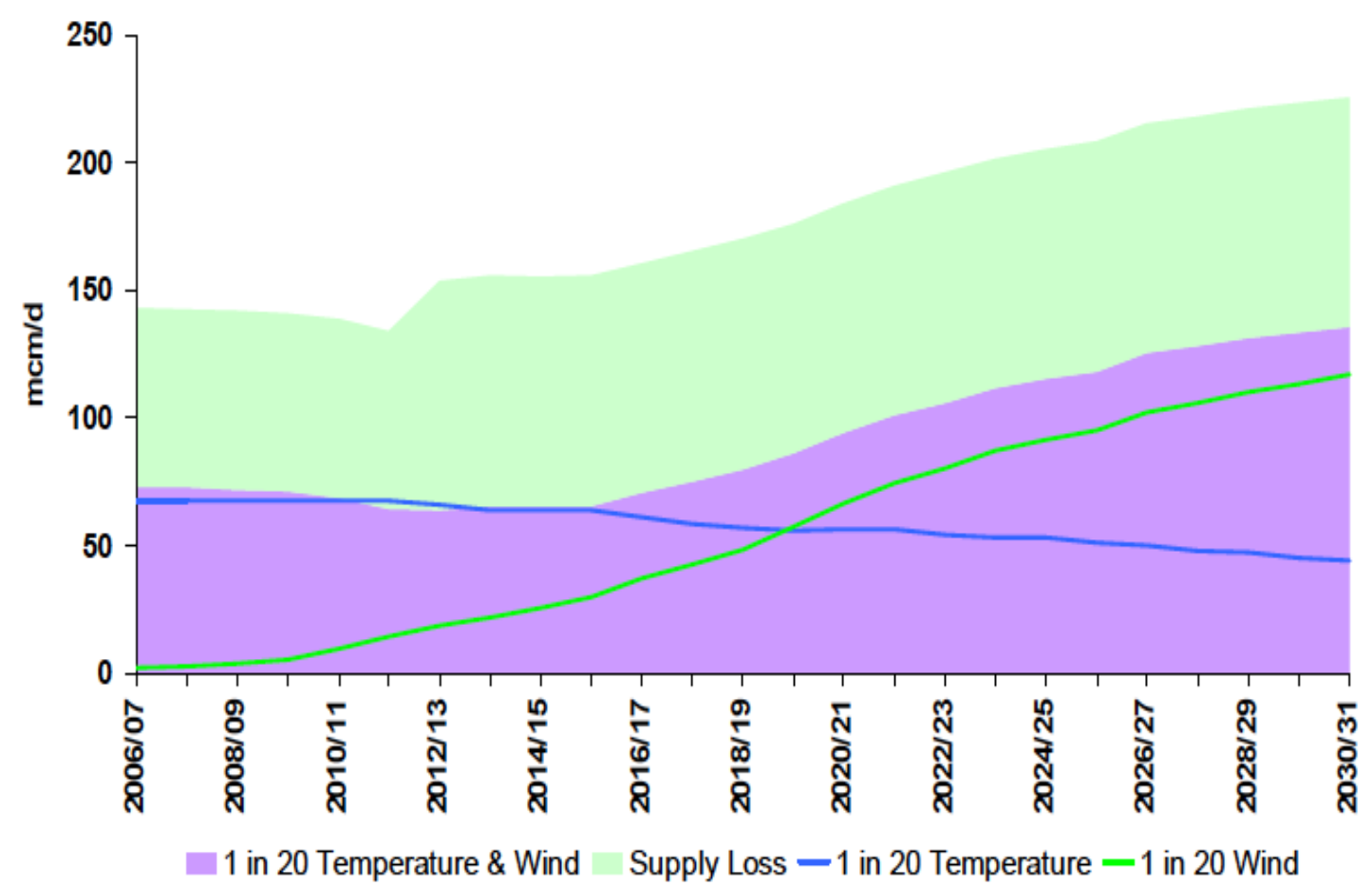

Source: National Grid 2011b, Figure 3.4A, p 36

NG acknowledges that this approach, which combines a one in 20 demand event with a major loss of supply does present an extremely unlikely worst case scenario. However, this approach does provide indications of potential future requirements for additional supply flexibility. Storage is seen as one important component though it flags the point that the new projects provide deliverability but are less suitable for dealing with a sustained supply loss. If LNG terminal load factors increase this may further reduce flexibility though the opposite would apply to Norwegian supplies if they decline as forecast. The other important source of flexibility and security is likely to come from the BBL and IUK Interconnectors which could provide increasing levels of flexibility with the possibility of greater access to Continental storage and transmission.

The Ten Year Statement also looks at the impact on storage requirements of increased intermittency alone. NG has assumed an extreme event in 2020/21 with total wind generation at $30 \mathrm{GW}$ and a decrease in wind generation load factor from $84 \%$ to $15 \%$ over a 15 hour period. If all of this reduction in wind generation is met by an upturn in CCGT generation, instantaneous gas demand would increase by roughly $90 \mathrm{mcm} /$ day. NG expects this increased variation will continue to drive up the need for mid range, fast cycle storage "which is anticipated to increase from $30 \mathrm{mcm} / \mathrm{d}$ in $2010 / 11$ to over $100 \mathrm{mcm} / \mathrm{d}$ by 2021 , with most of this in place by 2015 " 167 .

Stern (2010) has suggested an additional 7 to $9 \mathrm{bcm}$ of commercial storage might be necessary to mitigate all of the risks from potential outages, though he acknowledges this was unlikely to materialize so that price rationing during supply shortages would be inevitable. Similarly Rogers (2011) suggests the development of seasonal storage capacity of at least $10 \%$ of annual consumption - i.e. around 8-10 bcm working capacity - in order to mitigate

${ }^{167}$ National Grid, 2011b, p 46 
critical infrastructure failures. Knight (2012) indicates that to meet security of supply requirements in the event that one import stream fails for 30 days and assuming half of the existing storage capacity has already been depleted would require $7 \mathrm{bcm}$.

All of the foregoing projections have excluded any significant contribution from unconventional gas supplies in GB. Whilst it is still too early to assess whether a "shale revolution" along the lines of the USA are likely in GB there have been developments that suggest the potential may be larger than anticipated hitherto. The Gas Generation Strategy ${ }^{168}$ published in December 2012 includes a section on developing shale gas resources and this notes that the British Geological Survey analysis of the Bowland shale suggests a very substantial quantity of gas in place (in line with Cuadrilla's estimate of $6 \mathrm{tcm}^{169}$ ) though it is not possible to determine the economic viability of these reserves at present. In a recent report Poyry ${ }^{170}$ have modelled the impact of a production profile provided by Cuadrilla that reaches 12 bcm/a by 2020 and 20 bcm/a by 2035 which could mean a 21\% decrease in import dependence. If a flat annual delivery profile is assumed indigenous supplies could be increased by $33 \mathrm{mcm} / \mathrm{d}$ in 2020 and $55 \mathrm{mcm} / \mathrm{d}$ by 2035. This represents a material increase in deliverability from a localised source.

In addition to the potential role of indigenous production, as NG points out, the role of continental storage could become increasingly important and this is addressed in the next section.

\subsection{GB storage and the NW European context}

The increased degree of interconnectedness between GB and NW continental Europe - both physically and commercially through trading hubs - raises the question of how much capacity and gas might be available from the continent to underpin GB requirements. This section looks at comparative measures of storage capacity, interconnectedness and utilisation in NW Europe.

Table 19 illustrates some of the key storage metrics for major NW European countries. The relatively low proportion of storage relative to total demand is notable for both GB and the Netherlands - though when considering deliverability the difference is less marked in the case of GB and as already noted, this aspect is expected to grow significantly over the next few years.

\footnotetext{
${ }^{168}$ DECC, 2012c, p52

${ }^{169} \mathrm{http} / / /$ www.cuadrillaresources.com/benefits/energy-security/

${ }^{170}$ Poyry, 2012
} 
Table 19: Key storage indicators for main European gas countries

\begin{tabular}{|c|c|c|c|c|c|c|c|}
\hline \multirow[t]{2}{*}{ Country } & \multicolumn{2}{|c|}{$\begin{array}{l}\text { Total working } \\
\text { capacity }(\mathrm{BCM})\end{array}$} & \multicolumn{2}{|c|}{$\begin{array}{l}\text { WC/total } \\
\text { demand }\end{array}$} & \multicolumn{2}{|c|}{$\begin{array}{l}\text { WC/imported } \\
\text { gas }\end{array}$} & \multirow{2}{*}{$\begin{array}{l}\text { Daily } \\
\text { deliverability/peak } \\
\text { winter demand } \\
2012 \text { forecast }\end{array}$} \\
\hline & 2004 & 2011 & 2004 & 2011 & 2004 & 2011 & \\
\hline Germany & 19.5 & 19.5 & $22.7 \%$ & $26.9 \%$ & $69.5 \%$ & $62.5 \%$ & $84.0 \%$ \\
\hline Netherlands $^{171}$ & 2.1 & 2.1 & $5.0 \%$ & $5.4 \%$ & $\mathrm{n} / \mathrm{a}$ & $\mathrm{n} / \mathrm{a}$ & $17.7 \%$ \\
\hline GB & 4.8 & 4.8 & $4.9 \%$ & $5.9 \%$ & $>100 \%$ & $13.5 \%$ & $28.0 \%$ \\
\hline France $^{172}$ & $\mathrm{n} / \mathrm{a}$ & 12.5 & $\mathrm{n} / \mathrm{a}$ & $30.9 \%$ & $\mathrm{n} / \mathrm{a}$ & $30.9 \%$ & $54.1 \%$ \\
\hline Italy & 14.9 & 15.6 & $20.2 \%$ & $21.9 \%$ & $24.6 \%$ & $24.5 \%$ & $35.9 \%$ \\
\hline
\end{tabular}

Source: GSE Website, BP 2012, ENTSOG

Gas Storage Europe ${ }^{173}$ provides detailed information on storage capacity and utilisation aggregated by regional hubs. Table 20 summarises the key physical parameters for European storage.

Table 20: Storage Capacity at European Hubs as at September 2012

\begin{tabular}{|l|c|c|c|c|}
\hline Hub Area & $\begin{array}{l}\text { Working } \\
\text { Capacity } \\
\text { BCM }\end{array}$ & $\begin{array}{l}\text { Injection } \\
\text { rate mcm/d }\end{array}$ & $\begin{array}{l}\text { Withdrawal } \\
\text { rate mcm/d }\end{array}$ & $\begin{array}{l}\text { Average Cycles } \\
\text { per annum }\end{array}$ \\
\hline $\begin{array}{l}\text { Baumgarten } \\
\text { (AT/CZ/SK/HU) }\end{array}$ & 17.1 & 165 & 241 & 2.0 \\
\hline France & 12.5 & 125 & 217 & 2.2 \\
\hline Germany & 20.4 & 241 & 445 & 2.7 \\
\hline Spain & 2.5 & 11 & 20 & 1.0 \\
\hline NBP (GB) & 4.8 & 98 & 135 & 4.2 \\
\hline Italy & 15.9 & 134 & 180 & 1.7 \\
\hline TTF (NL/DK) & 2.1 & 18 & 80 & 2.4 \\
\hline Zeebrugge & 0.7 & 8 & 16 & 2.7 \\
\hline
\end{tabular}

Source: GSE Aggregated Storage Inventory http://transparency.gie.eu.com/ and author’s calculations

From Table 20 it is notable that GB storage has a much higher theoretical cycling capability than in any other country, with The Netherlands and Germany coming some way behind. Whilst storage facilities would not reach these levels in practise it is quite possible that actual

\footnotetext{
${ }^{171}$ The Netherlands is a net gas exporter. The numbers should also be treated with caution due to the exclusion of some upstream storage facilities, the separate Hi-Cal and Lo-cal systems and the impact of Groningen as a swing producer.

1722004 storage capacity figures are not reliable and so this metric has been excluded

173 http://transparency.gie.eu.com/

174 This is a theoretical measure used to illustrate the relative flexibility of storage - it is calculated as follows: (365-14)/(days to fill working volume + days to empty working volume) where 14 represents the number of days the facility is unavailable for maintenance.
} 
cycling rates could increase as the use of storage becomes more market responsive in these countries as has already happened in GB.

Another factor is the extent to which storage is emptied during each season. Table 21 shows the position for last three winters.

Table 21: Degree of fullness of storage at European Hubs

\begin{tabular}{|c|c|c|c|c|c|c|c|c|c|}
\hline \multirow{3}{*}{$\begin{array}{l}\text { Hub Area } \\
\begin{array}{l}\text { Baumgarten } \\
\text { (AT/CZ/SK/HU) }\end{array}\end{array}$} & \multicolumn{9}{|c|}{$\begin{array}{l}\text { Percentage fullness as at Oct } 1 \text {, Jan } 1 \\
\text { and Mar } 31 \text { in: }\end{array}$} \\
\hline & \multicolumn{3}{|c|}{ 2009-10 } & \multicolumn{3}{|c|}{ 2010-11 } & \multicolumn{3}{|c|}{ 2011-12 } \\
\hline & 91 & 87 & 45 & 92 & 71 & 42 & 89 & 74 & 40 \\
\hline France & 83 & 75 & 28 & 84 & 48 & 23 & 86 & 66 & 21 \\
\hline Germany & 93 & 85 & 31 & 94 & 66 & 43 & 96 & 83 & 48 \\
\hline Spain & 93 & 84 & 32 & 92 & 61 & 44 & 96 & 85 & 61 \\
\hline NBP (GB) & 87 & 83 & 17 & 87 & 46 & 33 & 96 & 88 & 59 \\
\hline Italy & 88 & 79 & 45 & 91 & 79 & 49 & 98 & 79 & 49 \\
\hline TTF (NL/DK) & 85 & 78 & 34 & 86 & 66 & 56 & 90 & 86 & 59 \\
\hline Zeebrugge & 93 & 68 & 30 & 92 & 72 & 17 & 100 & 75 & 33 \\
\hline
\end{tabular}

Source: GSE Aggregated Storage Inventory https://transparency.gie.eu.com/daily_history.php

As noted in 0 the three winters were very different in terms of demand with 2009/10 being particularly severe in weather terms. This is reflected in the degree of variation in storage depletion in some countries over the years - notably Germany, Spain, Netherlands and GB. In the latter case depletion was actually down to 9.9\% on 18 March 2010 before facilities started to re-inject. It is also noticeable that in many cases storage is still over one quarter full at the end of the winter season and last year it was around half full or more in most countries. There would therefore appear to be adequate storage capacity in most regimes.

Furthermore it is clear that in some countries storage is still being used in a traditional manner with injections only during the summer and withdrawals only during the winter. The difference between this and a market responsive regime is evident from Figure 24 which contrasts the storage profiles between GB and Italy for the period January 2010 to September 2012. 
Figure 24: Storage profiles (degree of fullness in \%) for NBP and PSV (Italy)

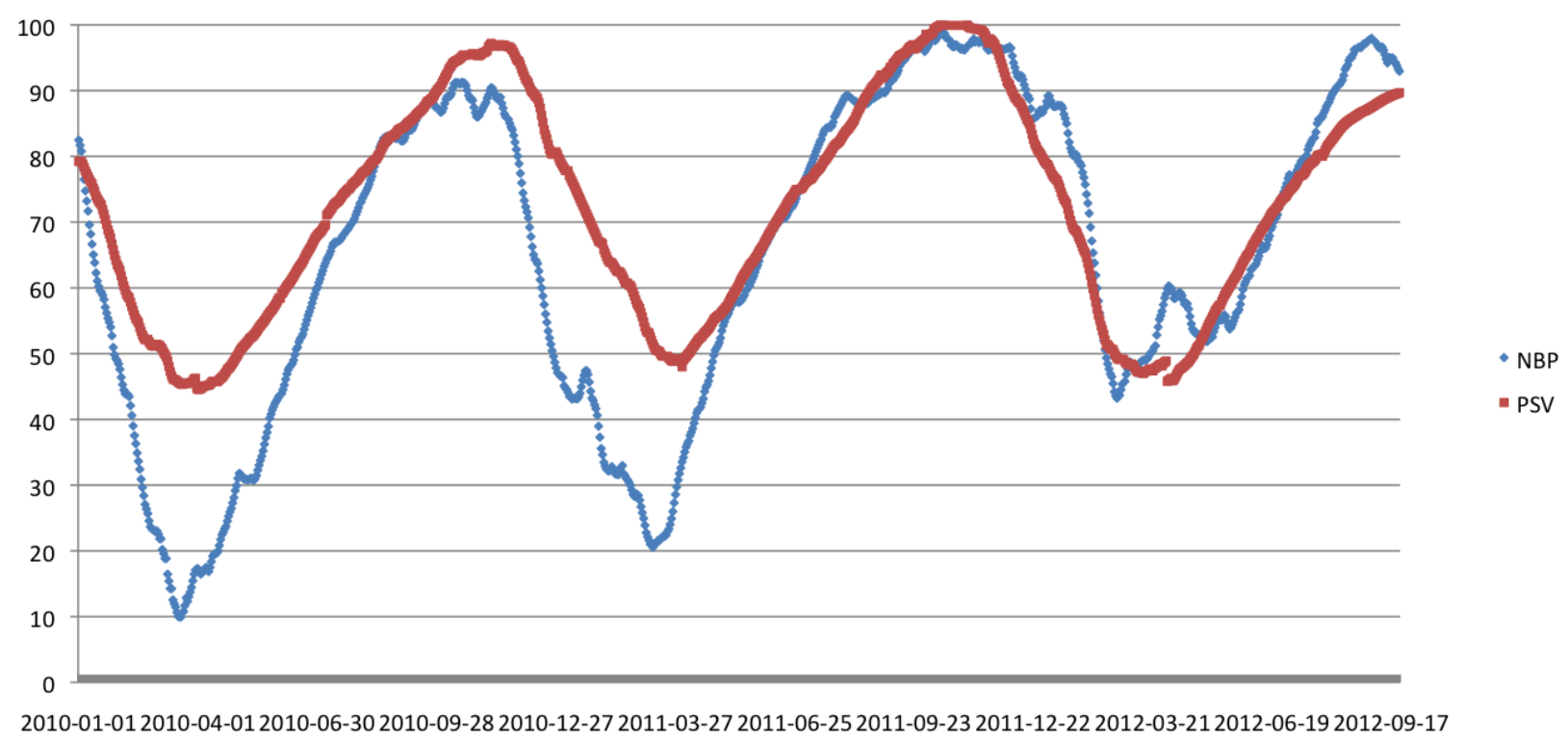

Source: GSE storage database

Figure 24 shows that the Italian storage profile is largely identical from one year to the next, even though, during this period, there were a number of changes to the supply/demand picture:

- demand fell by 6\% between 2011 and 2010 (BP, 2012);

- $\quad$ supply from Libya was stopped for 8 months during 2011; ${ }^{175}$

- the Transit gas pipeline in Switzerland, which brings gas from northern Europe to Italy, was closed for 5 months in 2010; ${ }^{176}$

- The country suffered "critical shortages" of Russian gas during the supply curtailments of February $2012^{177}$.

In GB on the other hand storage depletion was much greater during the cold winter of 2009/10 with clear periods of injection during winter periods. Note that this trend would be even more evident if only MRS storage withdrawals were shown.

How storage use is starting to change can be seen in Germany where the regulator BNetzA reports that from the end of 2010, there was a significant increase in the volume of bookable working gas capacity in storage. BNetzA suggest the main reason for this is that several customers of the storage facility operators have been allowed to return booked capacity and have taken advantage of this opportunity. ${ }^{178}$

Given that there would appear to be unused storage capacity in some European systems this raises two questions:

\footnotetext{
175 http://www.naturalgaseurope.com/italian-eni-restart-libyan-gas-supplies-3025

$176 \mathrm{http} / / / \mathrm{www}$.upstreamonline.com/live/article230581.ece?service=print

177 http://www.ft.com/cms/s/0/0f5b6d10-50e9-11e1-939d-00144feabdc0.html\#axzz2C2bfch6f

178 BNetzA 2011
} 
- Is there is overall spare capacity when comparing total deliverability (of both storage and other sources of supply) with peak demand?

- If such "surplus" deliverability exists is there theoretical capacity for this gas to transit to the GB gas market

Table 22: Maximum potential deliverability to GB gas market by source as at May 2012 $(\mathbf{m c m} / \mathbf{d})$

\begin{tabular}{|l|l|l|l|l|l|l|}
\hline Country & $\begin{array}{l}\text { Peak } \\
\text { demand } \\
\text { mcm/d } \text { 179 }^{-}\end{array}$ & $\begin{array}{l}\text { Import } \\
\text { supply } \\
\text { capacity }\end{array}$ & $\begin{array}{l}\text { Indigenous } \\
\text { supply } \\
\text { capacity }\end{array}$ & $\begin{array}{l}\text { Storage } \\
\text { withdrawal } \\
\text { capacity }\end{array}$ & $\begin{array}{l}\text { Capacity } \\
\text { "surplus” }\end{array}$ & $\begin{array}{l}\text { Export } \\
\text { capacity to: }\end{array}$ \\
\hline Germany & 529 & 568 & 97 & 445 & 581 & Bel: 34 \\
France & 401 & 300 & - & 217 & 116 & Neths: 43 \\
\hline Netherlands ${ }^{181}$ & 451 & Ger: 43 & 340 & 80 & 136 & GB: 46 \\
\hline Belgium & 151 & Nor: 84 & & Bel:102 \\
\hline
\end{tabular}

Source: ENTSOG Capacity Map, ENTSOG 2011b, GSE Storage database, GTS

Table 22 attempts to answer both these questions. It illustrates that in theory there is a potential surplus of capacity in key NW European markets and the scope for this surplus to reach GB. In practice there may be bottlenecks within or between particular systems that reduce the potential surplus and this is an area that may merit further investigation. Furthermore the apparent surplus in the Netherlands does not take account of export commitments from that country to Germany, France and Belgium. However, as Bradshaw (forthcoming) has noted European gas companies are increasingly trading and balancing their portfolios on a supra-national basis, so pressure for improved cross border capability is likely to grow.

\footnotetext{
${ }^{179}$ Forecast January peak for 2012 from ENTSOG 2011b.

${ }^{180}$ Based on nameplate withdrawal capacity.

${ }^{181}$ Production figure is highest recorded daily output from GTS

http://www.gastransportservices.nl/en/downloads/publications/reports. Storage withdrawal capacity does not include upstream storage facilities - this deliverability is within the indigenous supply number. Total upstream and downstream storage deliverability is stated by GTS to be $180 \mathrm{mcm} / \mathrm{d}$ growing to $237 \mathrm{mcm} / \mathrm{d}$ in 2014 when Bergermeer comes on stream.
} 
A further dimension to the capacity situation is the degree of new build that is being undertaken in Europe. As Rogers points out (2011) planned new build could account for an over $30 \%$ increase in working capacity. Table 23 updates the latest situation with regard to storage investments in the countries.

Table 23: Planned storage investments in selected European countries

\begin{tabular}{|l|l|l|l|}
\hline Country & $\begin{array}{l}\text { No of } \\
\text { storage } \\
\text { projects }\end{array}$ & $\begin{array}{l}\text { Total Working } \\
\text { capacity mcm }\end{array}$ \\
\cline { 3 - 4 } & & 2015 & 2020 \\
& & & \\
\hline Germany & 23 & 6,026 & 3,990 \\
\hline France & 8 & 1,045 & 1,080 \\
\hline Netherlands & 2 & 4,280 & - \\
\hline Belgium & 1 & 25 & - \\
\hline
\end{tabular}

Source: GSE Investment Database, http://www.gie.eu.com/index.php/maps-data/gse-investment-database

The number of new projects in Germany is particularly notable. Many of these are salt cavern developments at locations such as Epe and Etzel - both close to the Dutch border and some of these facilities already serve the Dutch market. The $4.1 \mathrm{bcm}$ working capacity Bergermeer depleted field storage in The Netherlands which will have a $57 \mathrm{mcm} / \mathrm{d}$ deliverability and is due on stream in 2014 is also a very significant addition to gas storage in NW Europe.

\section{Figure 25: Number of separate sources of gas supply for EU countries by year of FID}

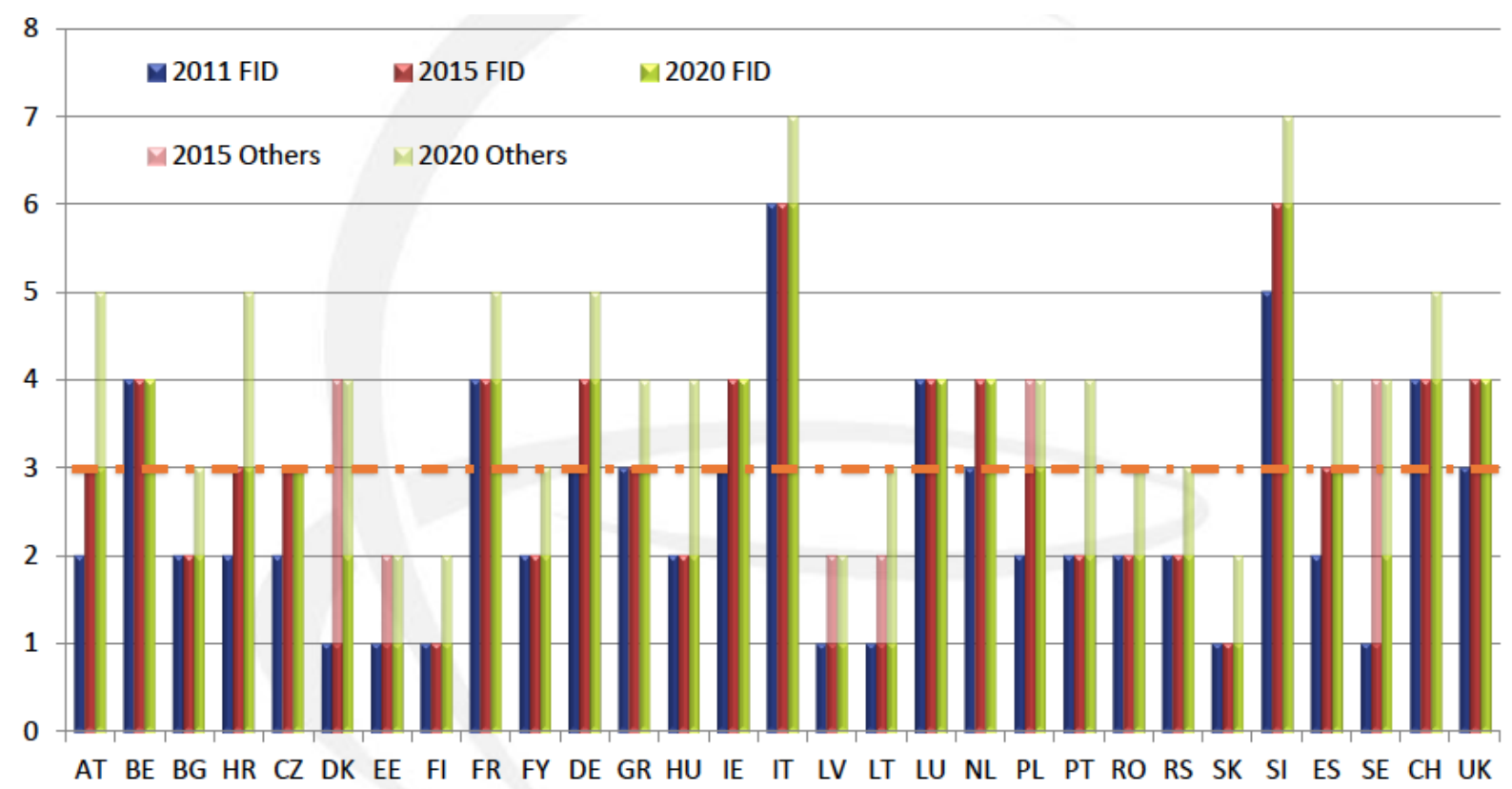

Source: ENTSOG 2011a, P61

In addition to new storage investments there are also a number of planned transit and interconnector pipelines. This is illustrated in Figure 25 which shows the comparative levels of source accessibility calculated by ENTSOG for all EU countries taking account of planned investments. The UK has three sources at present - Norway, LNG imports and indigenous 
production $^{182}$ - and this grows to four by 2015 as Russian supplies become available via Nord Stream and associated investments. It should also be noted that other countries in NW Europe all have at least four sources by 2015. In addition some new projects will have a direct influence on GB security - for example the EdF LNG terminal being built at Dunkirk which is due on stream in $2015^{183}$.

One concern over the availability of continental storage is the extent to which public service obligations (PSO) may restrict the release of gas from storage to serve markets other than the one in which the facility is located - particularly during the early part of the winter and/or times of exceptionally high demand. For example in The Netherlands the transporter, GTS is responsible for peak supply to residential consumers if temperatures fall below $-9{ }^{\circ} \mathrm{C}$ and shippers must have contracts in place to meet their demand down to this level (GTS, $2011^{184}$ ). GTS will reserve appropriate volumes and capacity to meet this requirement. In France shippers supplying domestic and some other categories of customers are required to book storage such that they are able to replace $85 \%$ of their main supply source for a 6-month period under normal weather conditions ${ }^{185}$. The extent to which national security of supply standards are coordinated and standardised in the future is likely to become an increasingly important issue in the security of supply debate.

\subsection{Summary and conclusions on the future requirements for storage in GB}

The need for storage in the future will be primarily driven by two key requirements:

- The need for growing flexibility as a result of increased variability of demand for gas-fired power generation caused by the intermittency of wind-powered renewable energy;

- To underpin supply security in the event of an outage in a major supply source.

The flexibility needs are essentially met by an increase in daily deliverability and, in the view of National Grid, the fast cycle storage facilities presently under development coupled with the swing available from other sources should be sufficient to meet this need. To meet the perceived security requirement would require a significant increase in aggregate storage working volume and projects providing this are unlikely to materialise under current market conditions - not least because of the likely availability of spare storage capacity in the Netherlands and Germany.

\section{Conclusions}

This study has sought to explain the reasons for the relatively low level of gas storage developments in GB despite declining indigenous production, potentially increasing flexibility requirements and growing concerns over security of supply.

It is clear that the prime commercial reason for lack of new storage projects is the relative collapse in summer-winter spreads in recent years. The present and future spreads are insufficient to provide a necessary return for new storage investments and a return to spreads

\footnotetext{
${ }^{182}$ Interconnections within the EU are excluded unless they are direct transit lines such as the EuRoPol line from Russia via Poland into Germany as are sources supplying less than 5\% of demand

${ }^{183}$ For more details see http://www.dunkerquelng.com/dunkerque-lng-201172.html

${ }^{184}$ Page 4

185 Poyry, 2010 p119
} 
in the region of 20p/therm or more would be required. Furthermore this recovery in spreads would need to be both sustained and credible to bring forward significant new investments.

Associated with the decline in spreads has been the fall in price volatility at the NBP trading hub. This has reduced the opportunity to capture extrinsic value from storage investments and so has reduced the upside associated with such investments. Gas storage facilities would appear to be operating ever more flexibly, with injection and withdrawal often taking place on the same day - this could further reduce within day price volatility.

Whilst the reduction in spreads can be seen as the reason for the lack of new storage projects it can equally be argued that these narrower spreads are a clear indication from the market that new storage is not required. The contribution to flexibility from existing and planned fast cycle storage, LNG imports and continental imports via IUK and BBL has been demonstrated in recent winters to be sufficiently responsive to deal with a range of supply and demand events.

It remains the case that with a growing dependence on imports, GB could become increasingly exposed to high impact/low probability events which, by definition, the market is unable to price. A sustained loss of key infrastructure such as the feeder from Milford Haven or the Rough storage facility occurring at a time of prolonged high demand would have a major impact, though this impact is most likely to be in the form of (perhaps sharply) increased prices rather than interruptions to firm supplies. Whilst the impact of price spikes should not be dismissed they could be seen as a necessary feature of a commodity market such as gas if the requirement for new supplies is to be met. Furthermore the variability of supply sources has increased over time (as measured by the HHI of import capacities) and this could mitigate the quantum of the price impact.

Looking forwards the case for more storage investments could be predicated not only on the continuing decline in indigenous production, but also the growing flexibility needs arising from intermittency of renewables being met by gas-fired power. Estimates by National Grid and others suggest that existing and planned storage - particularly given the trend to faster cycling - coupled with the swing available from import sources such as IUK, BBL and, in the future, Norway - should meet even the most extreme short term increases in demand.

Storage and import sources also have more than sufficient capacity to meet projected seasonal demands under a severe weather scenario though again a sustained loss of key infrastructure would have a major impact on prices with significant interruption (either mandatory or voluntary) for some larger users. NG indicates that the planned seasonal storage projects, which would more than double existing working capacities, should be adequate to meet these eventualities.

However, as already described, the market is unlikely to deliver this solution on its own. This raises the question of whether government should intervene in order to ensure "sufficient" storage is provided - and this remains under active consideration by DECC at the time of writing. There are a range of options available though perhaps the most important issue is the danger of unintended consequences from intervention in markets. Despite ever increasing intervention in the electricity sector the GB gas market has retained many of the features that made it the most liberalised market outside North America. Indeed the move away from oil indexation in continental gas contracts and the growth of European trading hubs are clear signs that the trend towards more open markets is spreading. 
This trend can only benefit the UK as gas flows become more responsive to price signals and infrastructure such as gas storage becomes more market orientated. Full market opening in countries such as Germany and France could lead to the conclusion that rather than the UK being exposed from too little storage these countries are exposed to too much. This is particularly possible in Germany where a large number of new storage projects are being built. The trend of European regulation with the emphasis on unrestricted flows between hubs in response to price signals is another argument for continued reliance on market based mechanisms.

There is a secondary issue of whether new large scale storage that has been facilitated by government intervention should be "strategic" - in other words only available for genuine emergencies - or allowed to operate within the market albeit under predetermined rules. One potential danger of the first option is illustrated by oil, where there is pressure on the IEA to use OECD strategic reserves to mitigate the price impact of the Iranian oil sanctions ${ }^{186}$. The temptation for political interference with strategic stocks remains an ever present risk. On the other hand a large subsidised storage facility with relatively unfettered market access would act as a major suppressant to price volatility and spreads and would damage the profitability of existing and planned commercial storage.

Whilst the relative cost of funding new seasonal/strategic storage for the UK would be minor compared to the overall level of future energy investments the damage caused by ill considered intervention could be much greater. In addition to the impact on commercial storage, intervention of this nature could make the GB market less attractive for other suppliers. LNG marketers may downgrade the UK as an option if the possibility for big returns during periods of tight supply no longer exists. Measures taken to improve security of supply could therefore have the opposite effect.

Whilst there may not be a case for intervention in the present circumstances it would be unwise to be complacent. Government and Ofgem should continue to monitor the long term situation regarding both markets and supply outlook. Developments such as

- A major increase in forecast gas demands

- A material change in the geo-politics of LNG supply,

- A reduction in the pace of liberalisation of the NW European gas market

- An appreciable widening of price spreads that did not stimulate new storage investments

would all merit the case for intervention to be re-appraised.

The present policy hiatus, now extended to at least spring 2013, is increasing uncertainty and, possibly, leading some storage investors to hold of from investment commitments in case they rule themselves out of some new incentive. It is the contention of this paper that Government intervention is presently not justified and a clear statement to this effect from Government would reduce market uncertainty.

\footnotetext{
${ }^{186}$ See the May 2012 G7 ministers’ communique http://www.g8.utoronto.ca/summit/2012campdavid/g8oil.html
} 
So to summarise:

This paper sought to answer two key questions.

- Why have so few storage projects been developed to date

- Is there a case for more storage and if so how can it be achieved?

The main answer to the first question is that the commercial fundamentals in terms of summer-winter spreads and volatility have shifted against new storage.

Regarding the second question there may be a case for new GB storage in the future but it faces strong competition from other sources - not least the large number of facilities in NW Europe - and, under present conditions, the market not government should be relied upon to meet this need. 


\section{References}

Alterman, S, Natural Gas Price Volatility in the UK and North America, OIES, 2012

BNetzA 2011, Monitoring Benchmark Report 2011, Bundesnetzagentur fur Elektrizität, Gas, Telekommunikation, Post und Eisenbahnen, http://www.energyregulators.eu/portal/page/portal/EER_HOME/EER_PUBLICATIONS/NATIONAL_REPOR TS/National\%20Reporting\%202011/NR_En/C11_NR_Germany-EN.pdf

BP, 2012, Statistical Review of World Energy, 13 June 2012

http://www.bp.com/assets/bp_internet/globalbp/globalbp_uk_english/reports_and_publicatio ns/statistical_energy_review_2011/STAGING/local_assets/spreadsheets/statistical_review_of _world_energy_full_report_2012.xlsx

Bradshaw M, Forthcoming, A Supply Chain Approach to Gas Security, University of Leicester

Cedigaz 2010; Underground Gas Storage in the World, 2010; CEDIGAZ, Paris

Chaudry M, Ekins P. et al, Building a Resilient UK Energy System, UKERC Working Paper, 31 March 2009: REF UKERC/WP/ES/2009/023

Clingendael 2006: The European Market for Seasonal Storage 4 , Clingendael International Energy Programme, Discussion Paper, February 2006.

http://www.clingendael.nl/publications/2005/20050800_ciep_misc_gas_storage.pdf

Clingendael International Energy Programme.,2011; Seasonal flexibility in the NWE Gas Market; April 2011

http://www.clingendael.nl/publications/2011/201104_ciep_energypaper_seasonal_flexibility_ gas.pdf

Competition Commission, 2003 Centrica plc and Dynegy Storage Ltd and Dynegy Onshore Processing UK Ltd: A report on the merger situation http://webarchive.nationalarchives.gov.uk/+/http://www.competitioncommission.org.uk/rep_pub/reports/2003/480centrica.htm

DECC 2008, Energy Markets Outlook, 2008

http://webarchive.nationalarchives.gov.uk/+/http://www.berr.gov.uk/files/file49406.pdf

DECC 2010: Gas Security of Supply: a policy statement from DECC, Department of Energy and Climate Change, HM Government, London, April 2010, http://www.decc.gov.uk/publications/AdvancedSearch.aspx?term=gas\%20security\%20of\%2 0supply\&tags $=21 \& u r n=\&$ fromDate $=\&$ toDate $=\&$ alpha $=$

DECC, 2011 Statutory Security of Supply Report: A report produced jointly by DECC and Ofgem November 2011 http://www.decc.gov.uk/assets/decc/11/meeting-energydemand/energy-security/3425-statutory-security-of-supply-report-2011.pdf 
DECC 2012a, Energy Bill (HC Bill 100), November 2012, http://www.publications.parliament.uk/pa/bills/cbill/2012-2013/0100/cbill_201220130100_en_1.htm

DECC, 2012b, Annual Energy Statement 2012, Cm 8456, November 2012

http://www.decc.gov.uk/en/content/cms/meeting_energy/aes/aes.aspx

DECC, 2012c, Gas Generation Strategy, Cm 8407, December 2012

http://www.decc.gov.uk/en/content/cms/meeting_energy/oil_gas/gasgenstrat/gasgenstrat.aspx

DTI, 2003, Energy White Paper - Our energy future - creating a low carbon economy, Presented to Parliament by the Secretary of State for Trade and Industry in February 2003 Cm 5761;

http://webarchive.nationalarchives.gov.uk/+/http://www.berr.gov.uk/files/file10719.pdf

DTI, 2004; “Implementation of EU Directive 2003/55 Concerning Common Rules for the Internal Market in Gas. Consultation”, DTI, February 2004.

DTI, 2006, The effectiveness of current gas security of supply arrangements: A consultation, Department of Trade and Industry HM Government, London, October 2006; www.dti.gov.uk/consultations/page34643.html

DTI, 2007a, Government response to the consultation on the effectiveness of current gas security of supply arrangements, Department of Trade and Industry HM Government, London, May 2007;

ECC, 2008; The outlook for Gas Storage in the UK, The Energy Contract Company October, 2008

ECLIPSE 2012, Security of Price, 2020-2026: A study for Centrica; Eclipse Energy Group 20 October 2012

http://www.eclipsewebsite.com/images/stories/PressRelease/Security\%20of\%20Price\%20\%20Eclipse\%20Energy\%20Group\%20report\%20-\%2029th\%20October\%202012.pdf

EFET, 2009; Gas Storage in Europe; Adding Security through Flexibility. Position paper, 6 July, 2009, http://www.efet.org/Position_Papers/Gas_Position_Papers_2005today_4945.aspx?urlID2r=62

EFET, 2011, Integration and Harmonisation: development of the Italian Gas Market, Presentation by Ilaria Conti to Conference on Challenges for a Comprehensive European Energy Security for Gas, Brussels, 2 March 2011

ENTSOG, 2011a, Ten-Year Network Development Plan 2011 - 2020, 17 February 2011 http://www.gie.eu/adminmod/show.asp?wat=TYNDP_Report_110217_MQ_.pdf 
ENTSOG, 2011b; Winter Supply Outlook 2011-2012 \& Seasonal Reviews Summer 2010, Winter 2010-2011 and Summer 2011 (preliminary) 14 December 2011

http://www.gie.eu/adminmod/show.asp?wat=ENTSOG_WO_2011-12_Reviews_201011_Final.pdf

ENTSOG, 2012a, ENTSOG Summer Supply Outlook 2012 and Seasonal Reviews SO0011224 May 2012,

http://www.gie.eu/adminmod/show.asp?wat=SO001_120524_REP_2012_Reviews_Final.pdf

ENTSOG, 2012b, Market Integration and Security of Supply, Presentation to Stakeholder Joint Working Session - 26 April 2012, ENTSOG;

http://www.gie.eu/adminmod/show.asp?wat=TYNDP_120426_SJWS-

06_SoS_MI_updated_proposal.ppt

ENTSOG, 2012c; Winter Supply Outlook 2012-2013 and Winter 2011/12 Review, ENTSOG, WO002-12 08 November 2012

http://www.gie.eu/adminmod/show.asp?wat=WO_121031_WinterOutlook_2012-

13_Review_Report.pdf

ERGEG, 2006, Final 2006 Report on Monitoring the Implementation of the Guidelines for Good TPA Practice for Storage System Operators (GGPSSO)

Ref: E06-GFG-20-03, 6 December 2006

ERGEG 2007, Report on Monitoring the Implementation of the Guidelines for Good Practice for Storage System Operators, Energy Sector Inquiry,

European Commission, 2003; Directive 2003/55/EC of the European Parliament and of the Council of 26 June 2003 concerning common rules for the internal market in natural gas and repealing Directive 98/30/EC http://eur-

lex.europa.eu/LexUriServ/LexUriServ.do?uri=CELEX:32003L0055:EN:NOT

ERGEG 2011, Guidelines for Good TPA Practice for Storage System Operators (GGPSSO) of 2 March 2005 as updated in July 2011, http://www.energy-

regulators.eu/portal/page/portal/EER_HOME/EER_PUBLICATIONS/CEER_PAPERS/Gas/ 2005/ERGEG_GGPSSO_Approved2005-03-02\%20updated\%202011_07_14\%20Clean.pdf

Escobar and Arteaga 2011: Underground Natural Gas Storage in the UK: Business Feasibility Case Study, SPE 143019, May 2011.

European Commission, 2003; Directive 2003/55/EC of the European Parliament and of the Council of 26 June 2003 concerning common rules for the internal market in natural gas and repealing Directive 98/30/EC; Brussels, 26 June 2003 http://eur-

lex.europa.eu/LexUriServ/LexUriServ.do?uri=CELEX:32003L0055:EN:NOT

European Commission, 2004; Council Directive 2004/67/EC concerning measures to safeguard security of gas supply;

http://europa.eu/legislation_summaries/other/l27047_en.htm 
European Commission, 2009; Directive 2009/73/EC of the European Parliament and of the Council of 13 July 2009 concerning common rules for the internal market in natural gas and repealing Directive 2003/55/EC; http://eur-

lex.europa.eu/JOHtml.do?uri=OJ:L:2009:211:SOM:EN:HTML

European Commission, 2010; Regulation 994/2010 concerning measures to safeguard security of gas supply and repealing Council Directive 2004/67/EC;

http://europa.eu/legislation_summaries/energy/external_dimension_enlargement/en0026_en.h tm

Felix B., Woll O, Weber C., 2010 Gas storage valuation under limited market liquidity, University of Duisberg-Essen, 2010, http://citeseerx.ist.psu.edu/viewdoc/download?doi=10.1.1.158.899\&rep=rep1\&type=pdf

Frontier 2012, External Review of Ofgem's Gas Security of Supply Further Interventions; A report prepared for Centrica October 2012 http://www.frontier-

economics.com/_library/publications/external\%20review\%20of\%20ofgems\%20gas\%20secur ity\%20of\%20supply\%20further\%20interventions.pdf

Gas Forum, 2011, Response to Ofgem's initial consultation on the Gas Security of Supply Significant Code Review, Letter dated 22 Feb 2011:

http://www.gasforum.co.uk/admin/documents/GF\%20Response\%20to\%20SoS\%20SCR.pdf

Gas Forum, 2012, Response to Ofgem's draft policy decision on the Gas Security of Supply Significant Code Review, Letter dated 31 Jan 2012:

http://www.gasforum.co.uk/admin/documents/GF\%20SCR\%20policy\%20decision\%2031\%2 0Jan\%202012\%20-\%20FINAL.pdf

Giulietti, Grossi \& Waterson, 2012; A Rough Analysis: Valuing Gas Storage, The Energy Journal, Volume 33, no. 4, International Association for Energy Economics, 2012

http://www.iaee.org/en/publications/ejarticle.aspx?id=2498

GTS, 2011, Report - The Security of Gas Supply 2011, Gas Transportation Services, Groningen, The Netherlands, 2011

http://www.gastransportservices.nl/en/corporate/publications/reports-4

Hawdon D and Stevens N, 2001, Regulatory Reform of the UK gas market: The case of Storage Auctions, Fiscal Studies (2001) vol. 22, no. 2, pp. 217-232, http://www.ifs.org.uk/fs/articles/0040a.pdf

Helm D, 2002 Energy Policy and the PIU Energy Review in Towards an energy policy. OXERA Publications, Oxford, pp. 5-16. ISBN 1-873482-41-8 http://www.dieterhelm.co.uk/sites/default/files/EnergyPolicyPIUEnergyReview.pdf

Henderson \& Heather, 2012, Lessons from the February 2012 European gas, Oxfrod Energy Comment, OIES, 16 April 2012, http://www.oxfordenergy.org/wpcms/wpcontent/uploads/2012/04/Lessons-from-the-February-2012-gas-crisis.pdf 
HSE, 2008, An appraisal of underground gas storage technologies and incidents, for the development of risk assessment methodology; Prepared by the British Geological Survey for the Health and Safety Executive 2008

IEA, 2002, Study on Flexibility in Natural Gas Supply and Demand, A note by the Secretariat, July 2002

Ilex, 2006a, Economic implications of a gas supply interruption to UK industry; www.berr.gov.uk/files/file28936.pdf

Ilex, 2006b, Strategic Storage and other options to ensure long term gas security, A report to DTI, April 2006, http://webarchive.nationalarchives.gov.uk/+/http://www.berr.gov.uk/files/file31788.pdf

Kaminski, V., Feng, Y. and Pang Z Value, Trading Strategies and Financial Investment of Natural Gas Storage Assets, Northern Finance Association Conference (Kananaskis, Canada) - 2008 at http://www.northernfinance.org/2008/papers/75.pdf

Knights, 2012, What is the Future for UK Storage, Presentation to the Energy Institute, 22 March 2012; Available on the Deloitte website; http:/www.deloitte.com/assets/DcomUnitedKingdom/Local\%20Assets/Documents/Industries/EIU/uk-eiu-andrew-knights-eilecture-March-2012.pdf

Kubler, M. Examining the Demand of Natural Gas Storage in Europe, Trends 2012-2030 Presentation to Energy Wise Conference, Manchester, June 72012.

http://europeangashub.newsweaver.com/fyg9cscawmlgnqcg3odtqz?email=true \&a=5\&p=283 $36265 \& \mathrm{t}=20084315$

National Grid: 2007: Gas Transportation Ten Year Statement 2007 , December 2006 http://www.nationalgrid.com/NR/rdonlyres/F085FC32-8C53-4999-AF8880388A29AE2C/22103/TYS2007.pdf

National Grid 2008: Winter Consultation report, 2008/9 A review of winter 2007/8 \& preliminary outlook for winter 2008/9 June 2008 http://www.ofgem.gov.uk/Markets/WhlMkts/CustandIndustry/winout2008/Documents1/Wint er\%20Outlook\%20Consultation\%20Report\%20(June).pdf

National Grid 2010a: Winter Consultation report, 2010/11; A review of winter 2009/10 \& preliminary outlook for winter 2010/11 June 2010 http://www.nationalgrid.com/uk/Gas/TYS/outlook/

National Grid 2010b, Safety Monitor and Firm Gas Monitor Requirements September 2010, http://www.nationalgrid.com/NR/rdonlyres/EE344897-2842-4D20-8078872727637C02/43347/StorageMonitorsSeptember2010.pdf

National Grid 2011a: Winter Consultation report, 2011/12; A review of winter 2010/11 \& preliminary outlook for winter 2011/12, 6 July 2011 
http://www.nationalgrid.com/NR/rdonlyres/C3A81245-D988-48A4-80F25082F601E06D/48771/WinterConsultation2011PUBLISHV2.pdf

National Grid: 2011: Gas Transportation Ten Year Statement 2011, December 2011 http://www.nationalgrid.com/NR/rdonlyres/E60C7955-5495-4A8A-8E808BB4002F602F/50703/GasTenYearStatement2011.pdf

National Grid 2012a: Winter Consultation report, 2011/12; A review of winter 2011/12 \& preliminary outlook for winter 2012/13, 9 July 2012

http://www.nationalgrid.com/NR/rdonlyres/9721EF19-2BA8-4DBD-880D90406603C176/54880/WinterConsultationReport201214.pdf

National Grid 2012b: Winter Outlook 2012/13, 10 October 2012 http://www.nationalgrid.com/NR/rdonlyres/623BA857-784F-4EFC-B16C97EF37CE530D/56932/WinterOutlookReport2012Final.pdf

National Grid 2012c: UK Future Energy Scenarios September, 2012 http://www.nationalgrid.com/NR/rdonlyres/2450AADD-FBA3-49C1-8D637160A081C1F2/56766/UKFutureEnergyScenarios2014.pdf

Noel P, 2012; Import Dependence and Supply Security; Presentation to Global Gas Challenge Seminar, London, 28 February 2012 Published by EPRG University of Cambridge http://www.eprg.group.cam.ac.uk/wpcontent/uploads/2012/03/PN_UKGasSecurityPolicy_120228_SEC.pdf

OECD Nuclear Energy Agency 2010, The Security of Energy Supply and the contribution of Nuclear Energy, OECD NEA, December, 2010 NEA\#06358, ISBN: 978-92-64-09634-9

Ofgas 1999, Review of the supply of gas storage and related services. The Director General's Initial Proposal, Ofgas June 1999.

Ofgem, 2001, Dynegy Inc’s proposed acquisition of BG Storage Ltd: A consultation document http://www.ofgem.gov.uk/About\%20us/enforcement/mergers/oft/Documents1/mergersandaq uisitions\%2062.pdf

Ofgem 2004a, The review of top up arrangements in gas: Conclusions document August 2004 http://www.ofgem.gov.uk/Networks/ad/Documents1/The\%20Review\%20of\%20Top\%20Up \%20Arrangements\%20in\%20Gas\%20-\%20Conclusions\%20Document.pdf

Ofgem 2004b, “The Second EU Gas Directive and storage regulation Great Britain”, Letter sent on 22 November 2004 , Ofgem 261/04 http://www.ofgem.gov.uk/Markets/WhlMkts/CompandEff/TPAccess/Documents1/9481_261 04.pdf

Ofgem, 2006, Winter 2005/6 Experience and issues for 2006/7, Sonia Brown, Ofgem, March 2006 
http://www.ofgem.gov.uk/Markets/WhlMkts/CustandIndustry/WinterOutlook/Archive/13407 -Sonia.pdf

Ofgem, 2007; Final Decision: Statoil UK Ltd's application for exemption from Section 19b of the Gas Act 1986

http://www.ofgem.gov.uk/Markets/WhlMkts/CompandEff/TPAccess/Documents1/STUK\%2 0revised\%20final\%20decision\%20signed.pdf

Ofgem, 2009; Project Discovery, Energy Market Scenarios; Ref: 122/09, 9 October, 2009 http://www.ofgem.gov.uk/Markets/WhlMkts/monitoring-energysecurity/Discovery/Documents1/Discovery_Scenarios_ConDoc_FINAL.pdf

Ofgem, 2010; Project Discovery, Energy Market Scenarios Update; Ref: 16a/10, 4 February, 2010 http://www.ofgem.gov.uk/Markets/WhlMkts/monitoring-energysecurity/Discovery/Documents1/DiscoveryEMSUpdateFINAL.pdf

Ofgem, 2011a, Gas Security of Supply Significant Code Review - Draft Policy Decision, Ref: 145/11 8 November 2011

http://www.ofgem.gov.uk/Markets/WhlMkts/CompandEff/GasSCR/Documents1/Draft\%20P olicy\%20Decision\%20Gas\%20Security\%20of\%20Supply\%20Significant\%20Code\%20Revie w.pdf

Ofgem, 2011b, Guidance on the regulatory regime for gas storage facilities in Great Britain, Ref: 168/11 December 2011

http://www.ofgem.gov.uk/Markets/WhlMkts/CompandEff/Documents1/Guidance\%20on\%20 the\%20regulatory\%20regime\%20for\%20gas\%20storage\%20facilities\%20in\%20GB.pdf

Ofgem 2012a, Gas Security of Supply Significant Code Review - Proposed Final Decision, Ref 111/12 31 July 2012

http://www.ofgem.gov.uk/Markets/WhlMkts/CompandEff/GasSCR/Documents1/120731_Ga sSCR_pfd.pdf

Ofgem, 2012b, Gas Security of Supply Report, November 2012 http://www.ofgem.gov.uk/Markets/WhlMkts/monitoring-energy-security/gas-security-ofsupply-report/Documents1/Gas\%20SoS\%20Report.pdf

Ofgem, 2012c, Gas Security of Supply Report, Further measures design appendix November 2012 http://www.ofgem.gov.uk/Markets/WhlMkts/monitoring-energysecurity/gas-security-of-supply-report/Documents1/Gas\%20SoS\%20Report\%20\%20Further\%20Measures\%20Appendix.pdf

Ofgem, 2012d, Gas Security of Supply Report, Risk and Resilience appendix November 2012 http://www.ofgem.gov.uk/Markets/WhlMkts/monitoring-energysecurity/gas-security-of-supply-report/Documents1/Gas\%20SoS\%20Report\%20\%20Risk\%20appendix.pdf

Oxera, May 2007, An assessment of the potential measures to improve gas security of supply www.berr.gov.uk/files/file38980.pdf 
Oxera 2010; Strong nerves needed? The economics of gas storage investments, Oxera, June 2010 , http://www.oxera.com/cmsDocuments/Agenda_June\%2010/The\%20economics\%20of\%20ga s\%20storage\%20investment.pdf.

Performance and Innovation Unit (PIU) 2002, The Energy Review, February 2002, http://webarchive.nationalarchives.gov.uk/+/http://www.cabinetoffice.gov.uk/media/cabineto ffice/strategy/assets/theenergyreview.pdf

Pirani, Stern and Yafimava, 2009; The Russo-Ukrainian gas dispute of January 2009: a comprehensive assessment; Oxford Institute for Energy Studies, February 2009 NG 27, http://www.oxfordenergy.org/wpcms/wp-content/uploads/2010/11/NG27TheRussoUkrainianGasDisputeofJanuary2009AComprehensiveAssessmentJonathanSternSimonPiraniKatjaYafimava-2009.pdf

Poyry, 2010, GB Gas Security of Supply and Future Market Arrangements, A report for the Gas Forum, July 2010: http://www.poyry.co.uk/sites/www.poyry.uk/files/528.pdf

Ramboll, 2008 Study on Natural Gas Storage in the EU, Ramboll Oil \& Gas, Virum, Denmark, October 2008

Rogers H, 2011, The Impact of Import Dependency and Wind Generation on UK Gas Demand and Security of Supply to 2025; Oxford Institute for Energy Studies, July, 2011, NG 54 http://www.oxfordenergy.org/2011/08/the-impact-of-import-dependency-and-windgeneration-on-uk-gas-demand-and-security-of-supply-to-2025-2/

Silve, Florent and Pierre Noël, (2010). "Cost Curves for Gas Supply Security: The Case of Bulgaria”, University of Cambridge, Electricity Policy Research Group, EPRG Working Paper 1031.

Stern 2002, Security of European Natural Gas Supplies: The impact of import dependence and liberalization, Royal Institute for International Affairs, June 2002 kms1.isn.ethz.ch/.../ISN/.../110-Security_Natural_Gas.pdf

Stern 2010 Gas Storage: A case of Market Failure in Rutledge I. and Wright P. (eds) UK Energy Policy and the End of Market Fundamentalism, OIES, 2010

Wicks M, 2009, Energy Security in Changing World, Published by Department of Energy \& Climate Change. 2009.

www.decc.gov.uk/en/content/cms/what_we_do/change_energy/int_energy/security/security.a spx

Winzer, c. 2011, Conceptualising Energy Security, EPRG Cambridge, 2011 http://www.eprg.group.cam.ac.uk/wp-content/uploads/2011/08/EPRG1123_complete.pdf 


\section{Glossary}

1 in 20 Peak Day: The level of daily demand that, in a long series of winters, would be exceeded in one out of 20 winters, with each winter counted only once.

ACER: Agency for the Cooperation of Energy Regulators, an EU Agency created by the Third Energy Package in March 2011 to further progress on the completion of the internal energy market in gas and electricity. It is based in Ljubljana, Slovenia with its own staff and resources.

Annual Contract Quantity (ACQ): The quantity that, under a gas contract, a buyer has the right to nominate and the seller the obligation to deliver.

Aquifer storage: Underground gas storage facility in a non hydrocarbon bearing aquifer

AUD: Australian dollars

Bacton-Zeebrugge Interconnector: see IUK

Bar: A measurement of pressure. A typical high pressure transmission system will operate at between 40 and 80 bar

Baumgarten: Austrian gas hub.

BBL: Balgzand (Holland) to Bacton (UK) pipeline, import capacity 53 mcm/d.

Bcm: one billion cubic metres.

Bcma: one billion cubic metres per annum.

BNetzA: German energy regulator (also covers telecommunications, post and rail)

Brine: Solution of water and salt produced by leaching salt caverns - disposal of brine usually requires special consent.

CATS: The UK offshore sub-sea Central Area Transmission System, a 223 mile pipeline from the Central North Sea to the CATS processing terminal in Teesside on the North East coast of England.

\section{CC: UK Competition Commission}

CCGT: Combined cycle gas turbine power station

CEER: The Council of European Energy Regulators association of Europe's national regulators of electricity and gas at EU and international level for cooperation and exchange best practice.

Centrica: The demerged part of British Gas plc that owns the GB supply business, the Morecambe Bay gas fields and the Rough storage facility 
Conventional Gas: Natural gas produced from an underground reservoir other than shale gas, tight gas or coal bed methane.

Convergence: that salt cavern capacities will normally reduce over time as a result of convergence - typical rates are below 1\% per annum

Crown Estates: Organisation established by Act of Parliament to manage property owned by the Crown which includes almost all of the seabed around the UK.

\section{CSL: Centrica Storage Ltd}

CSO (Customer Service Obligations): See PSO.

Cushion gas: (also referred to as Base Gas) the volume of gas required to be kept in a storage facility in order to maintain operating pressure but that is only produced when the facility is decommissioned

Cycle rate: Also called turnover. The number of times in a year that a storage facility could be filled and emptied. This is a theoretical measure used to demonstrate the relative flexibility of a storage facility. In this report cycle rates have been calculated as follows: (365-14)/(days to fill working volume + days to empty working volume) where 14 represents the number of days the facility is unavailable for routine maintenance. The cycle rates in the table are calculated on the assumption that injection rates are $70 \%$ of withdrawal with the exception of LNG which has a much slower injection rate

DECC: UK government Department of Energy and Climate Change

demand day to the lowest demand day in any given year

Depleted field storage: Underground gas storage facility located in a hydrocarbon bearing reservoir

DM: Daily metered gas consumer - normally very large users such as power stations

DSR: Demand Side response - fuel switching by consumers in response to higher gas prices or shipper/transporter initiated interruption

DTI: UK government Department of Trade and Industry - now superseded by DECC

EFET: The European Federation of Energy Traders

ENCC: Entry Capacity Concentration Index - a measure of supply diversity such that a country that is solely reliant on a single source of gas has the highest possible ENCC of 10,000 .

ENTSOG: The European Network of TSOs for gas

ENTSOG: The European Network of Transmission System Operators for Gas manages and coordinates TSO activities regarding the functioning of the internal market and cross-border trade for gas 
ERGEG: European Regulators Group for Electricity and Gas - now superseded by CEER and ACER

EU Emissions Trading System: A cap and trade system under which participating EU Member States allow qualifying CO2 emitting installations to trade CO2 permits. The number of $\mathrm{CO} 2$ permits are limited by agreed caps on $\mathrm{CO} 2$ emissions at the Member State level.

Extrinsic value: The price of an option minus its intrinsic value

Fast cycle storage: Storage that is able to switch from injection to withdrawal and vice versa quickly - typically salt cavern facilities

FID: Final Investment Decision: usually in the context of a gas project, this is the joint decision on the part of the investment companies and any state entities to proceed with the full development of a project through to commercial operation.

Forward curves: The predetermined delivery prices for gas to be paid at defined dates in the future.

Gas Forum: The body that represents the view of gas shippers and suppliers active in GB

Gas Holders: Low pressure above ground gas storage facilities (sometimes referred to as gasometers)

GBA: Gas balancing alert - issued by NG to provide a signal to the market that demand-side reduction and/or additional supplies may be required to avoid the risk of entering into a Network Gas Supply Emergency. The trigger level will be based on the NSS plus all storage sites with 2 or more days of deliverability

GDE Gas deficit emergency -a form of Gas Supply Emergency which occurs if there is insufficient gas available in the NTS to maintain a national supply / demand balance

GGPSO: Guidelines for Good Practice for Storage System Operators issued by ERGEG

GSE: Gas Storage Europe - the organisation representing the European SSOs

GSMR: Gas Safety Management Regulations

GSOG: SBGI Storage Operator’s Group

GT: Gas transporter

GTS: Gas Transportation Services - the Dutch gas TSO

GW: Gigawatt, i.e. 1 billion watts

GwH: Gigawatt hour; a unit of energy equivalent to a Gigawatt of power over the duration of one hour. In this report $1 \mathrm{mcm}=10.83 \mathrm{GwH}$ 
HHI: Herfindahl-Hirschman Index, normally used as an indicator of market concentration. It has also been used to assess the degree of supply security and diversity. It is calculated by squaring the share of each firm competing in a market or the share of each supply source feeding a market, and then summing the resulting numbers.

HSE: Health \& Safety Executive

IEA: International Energy Agency

IFA: Interconnexion France Angleterre, electricity interconnector between England and France

Infrastructure Planning Commission: See Planning Inspectorate

Intrinsic Value: - The actual value of a company or an asset based on an underlying perception of its true value including all aspects of the business, in terms of both tangible and intangible factors. In the case of storage usually based on the value gained from injecting (cheaper) gas in the summer and withdrawing (more expensive) gas in the winter - i.e. exploiting the seasonal

IRR: Internal Rate of Return

IUK: the shorthand name for the Bacton (UK) to Zeebrugge (Belgium) bi-directional gas pipeline. Import capacity 25.5 bcma, export capacity 20 bcma.

JESS: Joint Energy Security of Supply Working Group

Langeled: The 725 mile pipeline from the Nyhamna terminal in Norway via the Sleipner Riser platform in the North Sea to Easington Gas Terminal in England. Its capacity is 25.8 bcma.

Large Combustion Plant Directive: the LCPD aims to reduce acidification, ground level ozone and particles throughout Europe by controlling emissions of sulphur dioxide and nitrogen oxides and dust from large combustion plants. Member States can choose to meet the obligations by either complying with emission limits or limiting the remaining operating life of plant whose emissions exceed these limits.

LDC: Load duration curve, formed by ranking daily gas supply data from the highest Leaching: The process of salt cavern formation whereby water is pumped into salt deposits to dissolve the salt to form brine which, in turn, is replaced (dewatered) by gas under pressure.

LNG Terminal: Facility for importing ship borne LNG. Normally the LNG is stored at the terminal before regasification and injection into the transmission system.

LNG: Liquefied natural gas, natural gas liquefied by cooling to minus 162 degrees Centigrade

LNGs or LNG storage (also called LNG Peak Shaver): a gas storage facility which provides high output of natural gas albeit for a short duration. The facility extracts natural gas from the transmission grid, liquefies it and stores it in an insulated vessel. When gas is required to 
meet peak loads the LNG is regasified and injected into the transmission system. Note this definition does not include storage tanks at LNG regasification terminals

LRS: Long range storage - The Rough facility in GB

mcm; million cubic metres

mcm/day: Million cubic metres per day.

Mmbtu: Million British thermal units

Monte Carlo method: A simulation method for exploring the sensitivity of a complex system by varying parameters over a large number of iterations based on statistical variations of those parameters.

MRS: Mid range storage - All storage in GB apart from Rough and LNG storage

MWh: A unit of energy equivalent to a Megawatt of power over the duration of one hour.

NBP: the UK"s National Balancing Point: a virtual point (hub) in the National Transmission System where gas trades are deemed to occur. It is also used as shorthand for the UK spot gas price.

NDM: Non daily metered gas consumer - normally domestic and small industrial and commercial (I\&C)

NEC: Network Emergency Coordinator - NG holds this role.

Network Gas Supply Emergency: A ‘supply emergency’ as defined under the Gas Safety Management Regulations (GSMR Reg 2.1) means an emergency endangering persons and arising from a loss of pressure in a network or part thereof .

NG: National Grid plc

NPV: Net Present Value

NSS: Non Storage supply - i.e. gas supplies to GB market from UKCS, Norway, IUK, BBL and LNG imports

NTS: The National Transmission System - GB’s high pressure gas grid.

OCGT: Open Cycle Gas Turbine. The open cycle gas turbine is the most basic gas turbine unit. The working fluid does not circulate through the system, therefore it is not a true cycle. It consists of a compressor, a combustion chamber and a gas turbine. The compressor and the gas turbine are mounted on the same shaft.

Ofgas: GB gas regulator replaced by Ofgem

Ofgem: The Office of Gas and Electricity Markets, the GB gas and electricity regulator 
Oil Indexed Gas Prices: gas prices within long term contracts which are determined by formula containing rolling averages of crude oil or defined oil product prices.

Pigging: Pigging in the maintenance of pipelines refers to the practice of using pipeline inspection gauges or 'pigs' to perform various operations on a pipeline. These include cleaning and inspecting of the pipeline.

PIU: Performance and Innovation Unit, A 'unit' of the Cabinet Office 'providing the then Prime Minister (Tony Blair) and Government departments with a capacity to analyse major policy issues and design strategic solutions'.

Planning Inspectorate: UK body set up under the Planning Act 2008 responsible, inter alia, for national infrastructure planning, enforcement appeals and reporting on planning applications called in for decision. Replaced the Infrastructure Planning Commission

PSO (Public Service Obligations): Directive 2003/55/EC of the European Parliament and of the Council of 26 June 2003 concerning common rules for the internal market in natural gas provides for the possibility for Member States to impose public service obligations to guarantee security of supply, economic and social cohesion objectives, regularity, quality and price of the gas supply and protection of the environment.

RAV: regulated asset value

Safety monitors: These define levels of storage that must be maintained through the winter period. The focus of the safety monitors is public safety rather than security of supply (i.e. the safety consequences of having gas at inadequate pressures in the network) acting as a trigger mechanism for taking direct action to avoid a potential Network supply emergency.

Salt cavern storage: Underground gas storage facilities contained in salt caverns

SBGI: Society of British Gas Industries

SBU: storage bundled unit containing an appropriate mix of the three elements - injection, storage and withdrawal - typically designed to provide a single unit of delivery.

\section{SCR: Significant Code Review}

Seasonal Normal temperature (SNT): Temperature expected on average each day forecast by NG. It is updated every few years to include the most recent years' data and to include climate change.

Seasonal spread: The difference between the purchase price of gas in the summer and the sales price in the following winter at any one point in time.

Seasonal storage: Storage that is capable of delivering gas at maximum rates for extended periods - typically in excess of 90 days. These facilities will have high working volumes and will normally be in either depleted fields or aquifers. 
Shale Gas: natural gas formed in fine-grained shale rock (called gas shales) with low permeability in which gas has been adsorbed by clay particles or is held within minute pores and micro fractures.

SO: System operator - responsible for the day to day operation of the gas grid (NG in GB)

SRS: Short range storage - LNG Storage in GB

SSE: Scottish and Southern Energy

SSO: storage system operator

Storage Inventory: See Working Capacity

Strategic storage: Gas that is stored for use only in case of an emergency which would be a clearly defined set of circumstances

Ten Year Statement: Annual planning document issued by NG

Therm: Imperial unit of energy used in GB gas pricing - 1 therm is equal to $29.3071 \mathrm{kWh}$.

Tight Gas: natural gas formed in sandstone or carbonate (called tight gas sands) with low permeability which prevents the gas from flowing naturally.

Top Up: Additional storage booked by Transco/NG if necessary to maintain supply security. The top up regime was discontinued in 2004.

TPA: Third Party Access - in the context of storage there is regulated - rTPA - or negotiated third party access - nTPA .

Transco: The gas transportation arm of British Gas plc - subsequently unbundled into Lattice plc before merging with National Grid Plc (NG) in 2002.

TSO: Transmission System Operator

TTF: Title Transfer Facility - the Dutch trading hub

Turnover: See cycle rate

TWh: A unit of energy equivalent to a Terawatt of power over the duration of one hour. UIOLI: Use It or Lose It - usually refers to booked but unused (pipeline or storage) capacity that can be offered to the market in the short term

UKCS: The UK Continental Shelf

VoLL: Value of Lost Load - the amount in pence per kWh that gas consumers would pay to avoid supply interruptions 
Working Gas: the quantity of gas that is normally injected and withdrawn in any one year in a storage facility.

Working gas is distinct from "cushion gas" which is only withdrawn from storage when a storage site is decommissioned.

Working volume: Capacity of a storage facility to hold working gas 